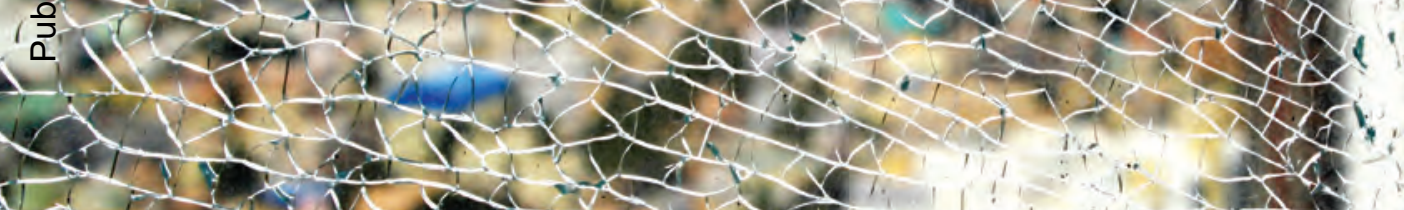
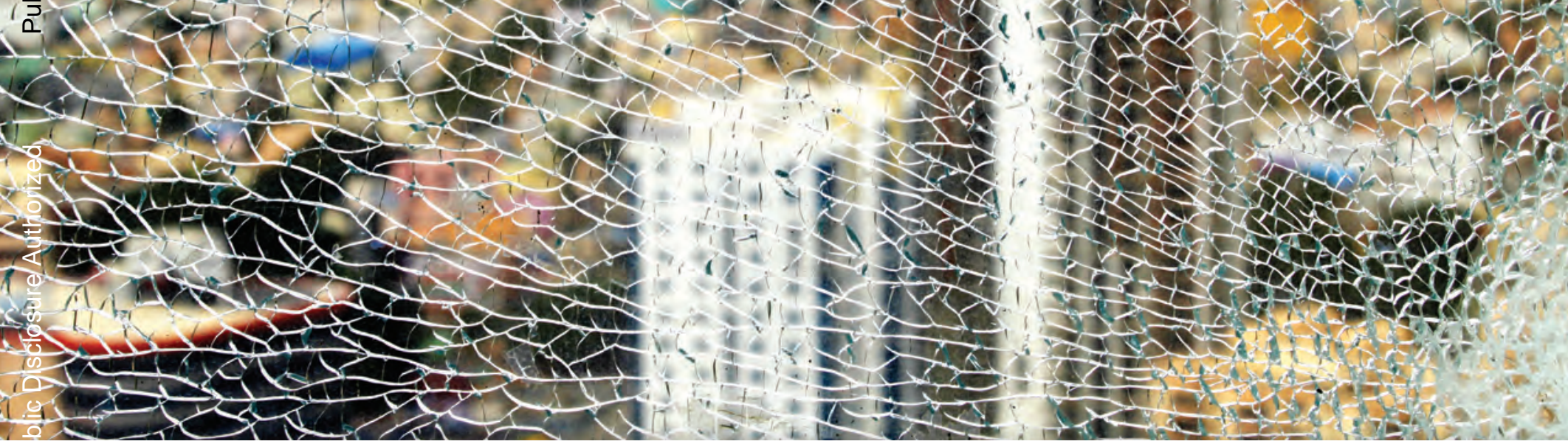
I $>-1-2515$ $x \rightarrow-125+26$

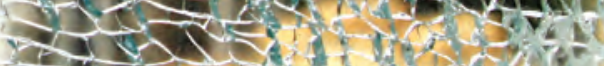

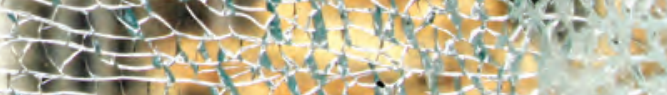
xis

\title{
World Bank Group Engagement in Situations of Fragility, Conflict, and Violence
}

(4) IEG WORLD BAMGgRoup

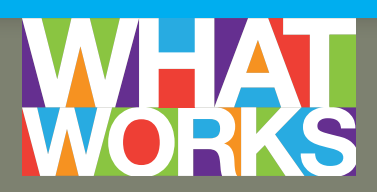




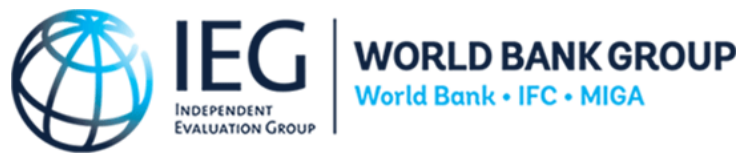

\title{
World Bank Group Engagement in Situations of Fragility, Conflict, and Violence
}

\author{
An Independent Evaluation
}


(C) 2016 International Bank for Reconstruction and Development / The World Bank

1818 H Street NW

Washington DC 20433

Telephone: 202-473-1000

Internet: www.worldbank.org

This work is a product of the staff of The World Bank with external contributions. The findings, interpretations, and conclusions expressed in this work do not necessarily reflect the views of The World Bank, its Board of Executive Directors, or the governments they represent.

The World Bank does not guarantee the accuracy of the data included in this work. The boundaries, colors, denominations, and other information shown on any map in this work do not imply any judgment on the part of The World Bank concerning the legal status of any territory or the endorsement or acceptance of such boundaries.

\section{Rights and Permissions}

The material in this work is subject to copyright. Because the World Bank encourages dissemination of its knowledge, this work may be reproduced, in whole or in part, for noncommercial purposes as long as full attribution to this work is given.

Any queries on rights and licenses, including subsidiary rights, should be addressed to World Bank Publications, The World Bank Group, 1818 H Street NW, Washington, DC 20433, USA; fax: 202-522-2625; email: pubrights@worldbank.org.

Suggested citation: World Bank. 2016. World Bank Group Engagement in Situations of Fragility, Conflict, and Violence. Washington, DC: World Bank. https://openknowledge.worldbank.org/handle/10986/24915 License: CC BY 3.0 IGO. 


\section{Contents}

ABBREVIATIONS

ACKNOWLEDGMENTS

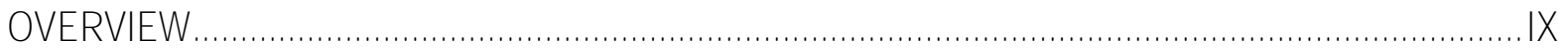

MANAGEMENT RESPONSE .............................................................................................. XIV

MANAGEMENT ACTION RECORD ............................................................................... XXII

CHAIRPERSON'S SUMMARY: COMMITTEE ON DEVELOPMENT EFFECTIVNESS..................XXXII

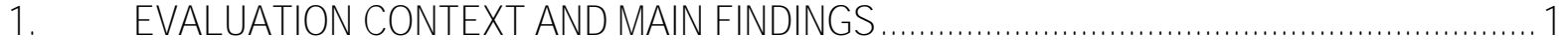

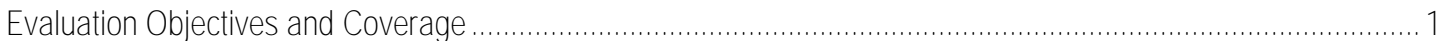

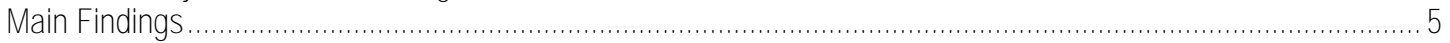

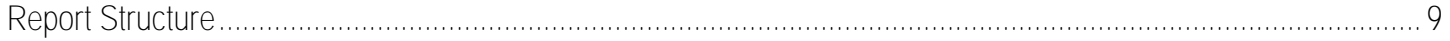

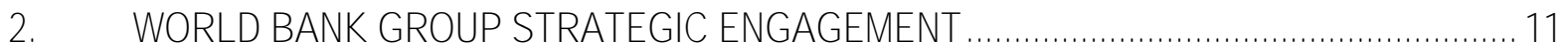

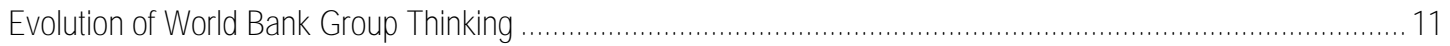

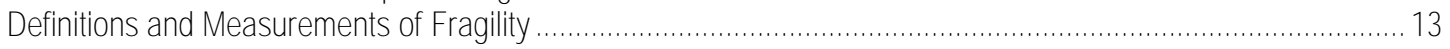

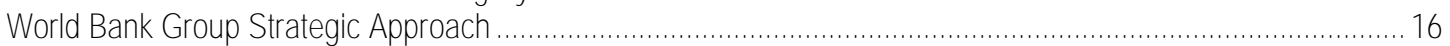

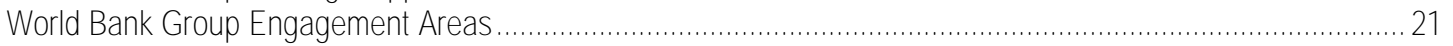

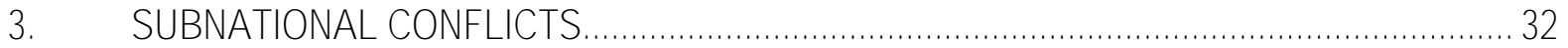

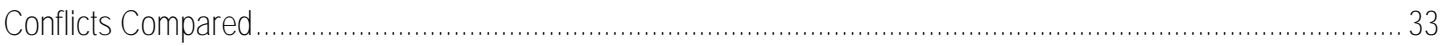

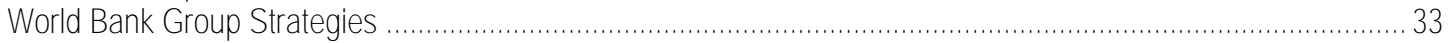

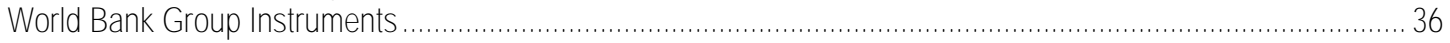

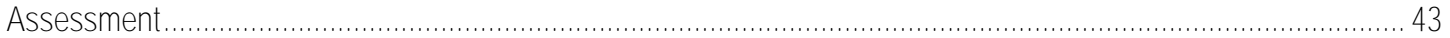

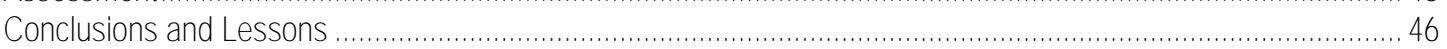

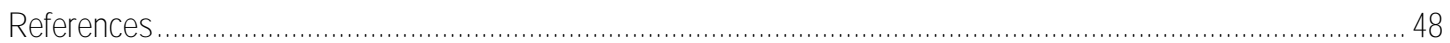

4. VIOLENCE RELATED TO CRIME AND DRUG TRADE ..................................................50

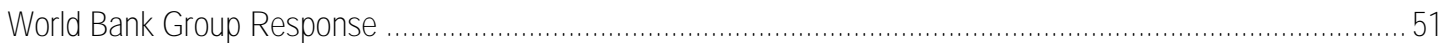

Assessment

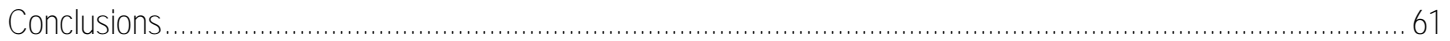

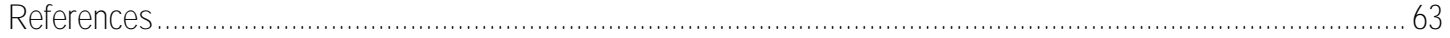

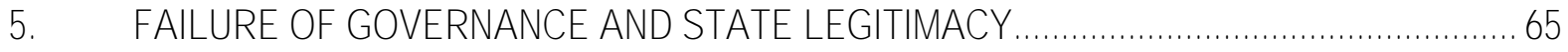

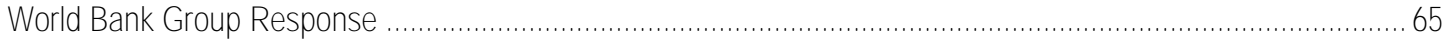

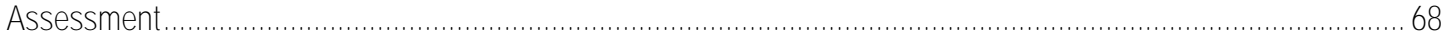

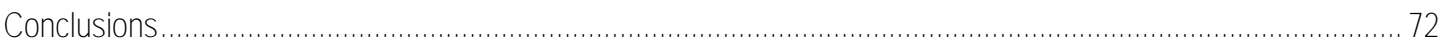

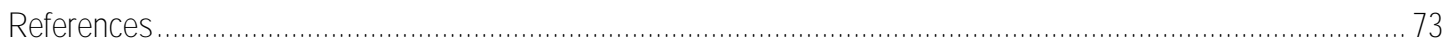

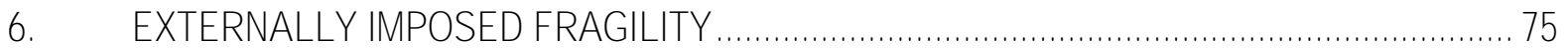

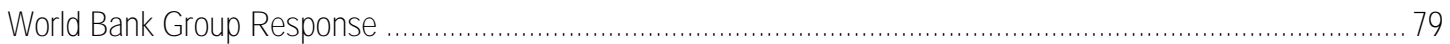

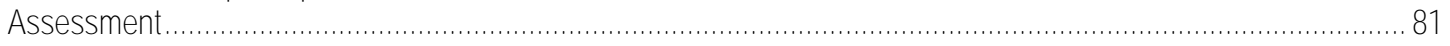

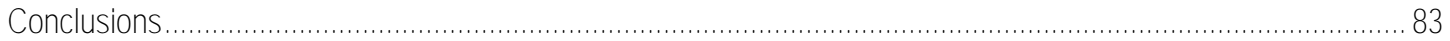

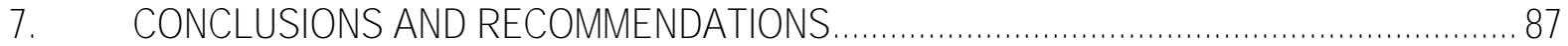

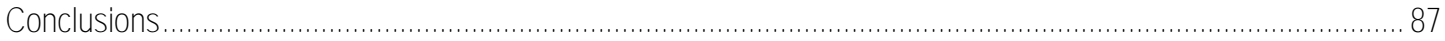

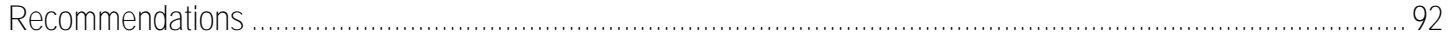




\section{Boxes}

Box 1.1. IEG Evaluation of World Bank Group Assistance to Low-Income Fragile and Conflict-Affected States (2014): Main Findings and Recommendations .................................................................. 3

Box 2.1. 2011 WDR: Institutions and Legitimacy Matter ..............................................................12

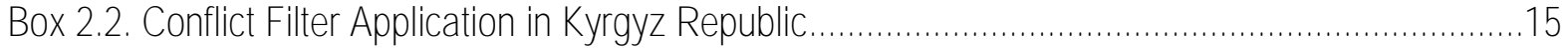

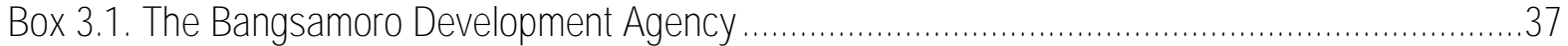

Box 3.2. IFC's Advisory Service and Client Engagement in Mindanao with Unifrutti ............................39

Box 4.1. Learning and Innovation Loans: The Magdalena Medio Series, 1998-2002 ..........................56

Box 6.1. Lebanon Economic and Social Impact Assessment Findings............................................79

\section{Table}

Table 3.1. World Bank Group Program Adjustment Post-Conflict.....................................................36

\section{Figure}

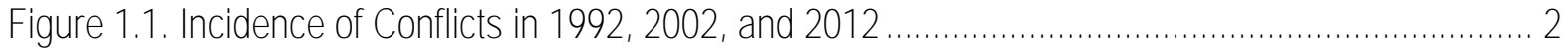

\section{Appendixes}

APPENDIX A. HISTORY OF CONFLICTS AND VIOLENCE.........................................................95

APPENDIX B. A SNAPSHOT OF FRAGILITY, CONFLICT, AND VIOLENCE BEYOND THE

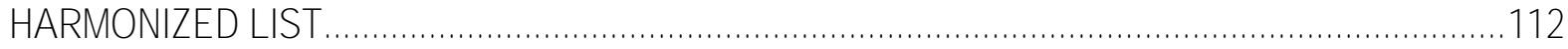

APPENDIX C. REFERENCE TABLES

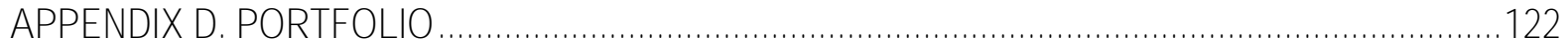

APPENDIX E.. PEOPLE MET ................................................................................................126 


\section{Abbreviations}

$\begin{array}{ll}\text { ADB } & \text { Asian Development Bank } \\ \text { ARMM } & \text { Autonomous Region of Muslim Mindanao } \\ \text { BDA } & \text { Bangsamoro Development Agency } \\ \text { BEE } & \text { Business Enabling Environment } \\ \text { CCSA } & \text { Cross-Cutting Solution Area } \\ \text { CDD } & \text { community-driven development } \\ \text { CMU } & \text { Country Management Unit } \\ \text { CoHA } & \text { Cessation of Hostilities Agreement } \\ \text { CPF } & \text { Country Partnership Framework } \\ \text { CPIA } & \text { Country Policy and Institutional Assessment } \\ \text { CPS } & \text { Country Partnership Strategy } \\ \text { DFID } & \text { Department for International Development } \\ \text { DPC } & \text { Development Policy Credit } \\ \text { ESIA } & \text { economic and social impact assessment } \\ \text { ESSRP } & \text { Emergency Services and Social Resilience project } \\ \text { FA } & \text { fragility assessment } \\ \text { FATA } & \text { Federally Administered Tribal Areas } \\ \text { FCS } & \text { fragile and conflict-affected situations } \\ \text { FCV } & \text { fragility, conflict, and violence } \\ \text { GP } & \text { Global Practice } \\ \text { IBRD } & \text { International Bank for Reconstruction and Development } \\ \text { ICR } & \text { Implementation Completion Report } \\ \text { IDA } & \text { International Development Association } \\ \text { IDB } & \text { Inter-American Development Bank } \\ \text { IDP } & \text { Internally displaced people } \\ \text { IEG } & \text { Independent Evaluation Group } \\ \text { IFC } & \text { International Finance Corporation } \\ \text { JRP } & \text { Jordan Response Plan } \\ \text { KDP } & \text { Kecamatan Development Program } \\ \text { KP } & \text { Khyber Pakhtunkhwa } \\ \text { LICUS } & \text { low-income countries under stress } \\ \text { LIL } & \text { Learning and Innovation Loan } \\ \text { LRA } & \text { Lord's Resistance Army } \\ \text { M\&E } & \text { monitoring and evaluation } \\ \text { MDB } & \text { multilateral development bank } \\ \text { MDF } & \text { Multi-Donor Facility } \\ \text { MDTF } & \text { Multi-donor trust fund } \\ \text { MEND } & \text { Movement for the Emancipation of the Niger Delta } \\ \text { MIC } & \text { middle-income country } \\ \text { MIGA } & \text { Multilateral Investment Guarantee Agency } \\ \text { MILF } & \text { Mindanao Islamic Liberation Front } \\ \text { MNLF } & \text { Moro National Liberation Front } \\ \text { NEIAP } & \text { North East Irrigated Agriculture Project } \\ \text { NHSFO } & \text { non-honoring of sovereign financial obligation } \\ \text { NUSAF } & \text { Northern Uganda Social Action Fund } \\ \text { NWFP } & \text { North-West Frontier Province } \\ & \text { Organisation for Economic Co-operation and Development } \\ \text { OECD } & \end{array}$


ABBREVIATIONS

PA Programmatic Approach

PCF Post-Conflict Fund

PCU Post-Conflict Unit

PEMFAR Public Expenditure Management and Financial Accountability Review

PEPAN Private Enterprise Partnership for Aceh and Nias

PER Public Expenditure Review

PFM public financial management

PPAF Pakistan Poverty Alleviation Fund

PRDP Peace, Recovery, and Development Plan

PRI political risk insurance

SDG Sustainable Development Goal

SEEFOR State Employment and Expenditure for Results

SPF State and Peace-Building Fund

UNDP United Nations Development Programme

UNHCR United Nations High Commission for Refugees

WCD war and civil disruption

WDR World Development Report

WFP World Food Programme 


\section{Acknowledgments}

This report was prepared by an Independent Evaluation Group (IEG) team led by Konstantin Atanesyan (Senior Evaluation Officer) and was conducted under the guidance and supervision of Marie Gaarder (Manager) and Nick York (Director), and the overall direction of Caroline Heider (Director-General, Evaluation). Jiro Tominaga (Senior Evaluation Officer) prepared the Approach Paper for the evaluation and led the task team until his departure from the World Bank Group in January 2015.

Other team members for this report were Anahit Aghumian, Diana Rangel Alfaro, Corky de Asis, Maria Baldauf, Lev Freinkman, Takatoshi Kamezawa, Lauren Keevill, Xue Li, Pradeep Mitra, Chris Nelson, Daniel Palazov, George Polenakis, Nigel Roberts, Marcelo Selowsky, Kate Steingraber, Inder Sud, Steven Webb, and Disha Zaidi. William Hurlbut provided editorial support and Yasmin Angeles provided administrative support. Nat Colletta (New College of Florida), John Wallis (University of Maryland), and Michael Woolcock (World Bank) were the peer reviewers for this report.

IEG is grateful to the numerous representatives of governments, private sector entities, international and bilateral development organizations, academia, and the civil society in Colombia, Honduras, Indonesia, Japan, Jordan, Kyrgyz Republic, Lebanon, Nigeria, Pakistan, the Philippines, Sri Lanka, and Uganda, as well as the staff of the World Bank Group, who provided valuable time, information, and feedback to the evaluation team. 



\section{Overview}

\section{Highlights}

* When middle-income countries experience situations of fragility, conflict, and violence, providing assistance can be a challenge for the World Bank Group. The government may have its own views on how and when to tackle the underlying issues, or may be reluctant to increase its borrowing to correct what may be seen as a localized or temporary problem.

* Through examining such cases, IEG concludes that the World Bank Group's comparative advantage is supporting countries in tackling longer-term development challenges, including early engagement and a sustained presence in conflict-affected areas, as well as continuous dialogue with the parties to violent conflicts, where possible.

* The World Bank has been adept at responding and at adjusting its strategies and analytical support to situations of violence and conflict, but its operational response has been constrained by its limited menu of instrument choices. Moreover, institutional and staff incentives to engage in conflict situations and to take risks seem to be lagging the spirit of its strategic approach, as expressed in various Bank documents, including the 2011 World Development Report on conflict, security, and development.

* The community-driven development model has often provided the World Bank Group with a point of entry in conflict-affected areas. Though it has not addressed the causes and consequences of violence, the approach has been useful as a form of establishing a presence and contextual learning to support more ambitious efforts once peace is restored.

* The World Bank Group can further enhance its impact in these situations by exploring opportunities beyond supporting livelihoods in conflict-affected communities, including support for private sector development, using its expertise in public financial management more effectively, and improving its monitoring and evaluation frameworks.

The prevalence of incidents of violent conflict in middle-income countries (MICs) today has meant that the development community's perception of conflict and violence is no longer primarily associated with low-income countries. In 2014 the Independent Evaluation Group (IEG) undertook an evaluation of World Bank Group activities in low-income countries classified as fragile and conflict-affected (FCS). It was agreed at the time that it would be followed by an evaluation of World Bank Group activities in countries not classified as FCS and experiencing localized or externally imposed situations of fragility, conflict, and violence (FCV).

This evaluation has three main objectives. First, it assesses and reports on the quality and results of selected World Bank Group programs and operations. Second, it provides a deductive analysis of the factors that lead to success or failure of World Bank Group engagements. Third, it aims to facilitate learning in this area, to help inform the design of future strategies and assistance programs. 
The current World Bank Group system of classifying countries as fragile and conflictaffected states relies on the Country Policy and Institutional Assessment (CPIA) index, which does not seek to capture subnational, cross-border, or supranational forms of stress and violence. In the absence of a defined list and accepted criteria for classifying nonfragile MICs facing localized or externally imposed fragility, this evaluation chose a group of countries using four broad parameters: prolonged and widely publicized episodes of conflict and violence; presence of significant World Bank Group programs; different levels of income and institutional capability; and representation from different global regions.

This evaluation classified the cases reviewed under four categories of stress factors that raise the risk of violence:

\section{Subnational conflicts with a regional or ethnic} identity marker. The experience, or perception, of injustice imposed by the state or by a dominant identity group is one of the most potent drivers of organized violence, especially when the ethnicity, geographical location, or religion of the affected group are easily defined. This essential driver applies to violence in the Philippines (Mindanao), Indonesia (Aceh), Uganda (the North), and Sri Lanka.

\section{Violence related to organized crime and drug} trafficking. In Colombia and Honduras, the expanding drug trade fed an exponential growth in violence and criminal gangs. The lawlessness fed on unresolved social issues (land ownership, income inequality) and a popular mistrust of the state's willingness to address them.

Systemic failures of governance and erosion of state legitimacy. Conflicts in some areas of Pakistan and Nigeria were a form of subnational organized violence, but they differ from the cases described earlier in that they reflect lack of loyalty with and popular legitimacy of national and local government-rather than primarily reflecting state hostility toward local minorities.

Overwhelming pressure from external political shocks. Lebanon and Jordan have been hosting millions of Syrian refugees at the expense of their already stressed national systems and public finances. Both countries argue that while providing a global public good by hosting the refugees, they have reached the limit of their capacity in hosting a large refugee population, and absent more adequate international support, they may not be able to survive this shock indefinitely.

\section{World Bank Group Strategy and Instruments}

The understanding of the nature and importance to development of organized violence has evolved over the years within the World Bank, and has come to embody a greater focus on the political economy of subnational violence and on analytical and operational instruments to address it. Structural reorganization of the World Bank Group in 2013 attempted to recognize the importance of organized violence as a key priority by establishing FCV as a crosscutting solution area (CCSA).

The theme of what the World Bank terms "conflict and violence"-and especially "localized conflict" — started appearing more prominently in World Bank Group strategies in non-FCS MICs relatively recently, in the past 5-7 years. Earlier World Bank Group strategies acknowledged the presence of the problem, but were either silent about any response or explicitly noted that the World Bank would be staying away.

The 2011 World Development Report (WDR) on conflict, security, and 
development was an important milestone in this regard, as it formulated the currently accepted analytical framework.

Subsequently, the theme of conflict and violence, including subnational conflicts, became more apparent in country strategies.

\section{Main Findings}

World Bank Group strategic presence. Sustained engagement of the World Bank Group in conflict areas ahead of peace settlements and during ongoing violence is critical, as experience, contacts, and credibility acquired in this process have important payoffs once there was peace. Maintaining a presence (even nominal) in former conflict zones is essential to help sustain peaceful development through a continuous process of identifying and tackling factors that can lead to violence.

World Bank Group assistance, while useful, is not likely to fundamentally alter the fragility profile of many countries, especially MICs, because of the mismatch between the challenges faced and the level of resources the World Bank can bring to bear.

The World Bank Group comparative advantage continues to be helping these countries to tackle longer-term developmental challenges through earlier engagement and sustained presence in the conflict-affected areas, and continuous dialogue with the parties to violent conflicts, where possible. The World Bank Group can add value by analyzing the nature of conflict, and then catalyzing appropriate responses.

In many instances, the problems have much deeper regional roots and the World Bank Group needs to develop a broader and more holistic view of the problems and their spill-over effects.
Success in FCV situations requires good knowledge of local conditions and deep understanding of the political economy. Hence, continuity in staffing policy is very important. It was, however, not common in cases observed. Moreover, the institutional and staff incentives for engagement in conflict situations and risk-taking seem to be lagging the spirit of its strategic approach to FCV, as reflected in various Bank documents, including the 2011 WDR. The World Bank Group is often reluctant to compromise lending volumes by an excessive focus on core drivers of violence: regional conflicts and governance.

World Bank Group operational response. In the countries reviewed, the World Bank Group was generally fast to respond and adjust its strategies and analytical support to emergency situations, but its operational response was often constrained by the limited choice of instruments at its disposal and depended to a large extent on donor financing and presence of large multi-donor trust funds.

World Bank Group definitions, measurement metrics, and policy application are not entirely consistent along the full spectrum of countries experiencing FCV. In this regard, the role of the new structural unit, the FCV CCS $A$ could be particularly important, especially in redefining and finetuning fragility diagnostic and measurement instruments. It will be useful for the CCSA to have more authority on policy matters, while also finding a way to maintain closer connection to operational work led by the Global Practices (GPs).

World Bank Group engagement in promoting private sector development as means of mitigating causes and dealing with consequences of violence was rather limited. International Finance Corporation (IFC) almost exclusively focused on post-conflict reconstruction, reflecting in part the high- 
risk perceptions, but also the limited choice of instruments, and lack of institutional incentives and corporate targets for nonFCS countries. In those cases where the World Bank Group could find a niche and identify private sector clients, its contribution was relevant and effective. There were some promising initiatives involving Bank-IFC cooperation, but those appear to be the exception rather than a norm.

The Multilateral Investment Guarantee Agency (MIGA) political risk insurance products are a useful tool that can help facilitate foreign direct investment when a country faces FCV situations, including at subnational level, and their use can be further expanded.

Projects with a community-driven development (CDD) design were a useful point of entry for the World Bank Group in conflictaffected areas, used also as a form of information-gathering and contextual learning. They were not, however, a forum for addressing the causes and consequences of violence. Success of CDD projects in conflict zones was highly context-specific.

FCV-specific diagnostic work (fragility assessments, conflict filters) was useful and relevant when it was invoked, but was not the norm within the reviewed group of countries. The utility of fragility assessments in non-FCS could be limited by the fact that their preparation, disclosure, and even discussion with the client are optional.

PFM diagnostics in the conflict-affected regions, and particularly policy advice on budgeting and governance arrangements in the security sector and fiscal decentralization, deserve more attention, especially since the World Bank does have proven technical expertise and positive experience with such analysis.
Weak monitoring and evaluation (M\&E) frameworks undermined the assessment of results in many of the cases observed, and diminished the learning potential from the projects even when they were designed as pilots. FCV factors were generally reflected in project design and during implementation, but rarely captured in results.

\section{Partnerships. World Bank Group-United} Nations partnership was particularly important in the FCV context, as the United Nations agencies have political and security-related skills and contacts that the World Bank needs to leverage, and the United Nations system is the prime actor on the humanitarian front. Such partnerships were not systematic and their frequency and effectiveness varied across the countries and themes. The existing system did not encourage building partnerships because of perceived high transaction costs, lack of strong staff incentives, incompatibility of the fiduciary and legal frameworks, and competition for influence and limited donor resources. A more nuanced strategic and technical dialogue is needed to delineate respective roles and comparative advantages.

Multi-donor trust funds are vital strategic tools in conflict regions, but their effectiveness can be enhanced by stronger links to the rest of the World Bank portfolio. Global thematic trust funds (State and PeaceBuilding Fund, Global Program of Forced Displacement, others) were helpful in supporting synergies in the FCV context. However, their impact (particularly in MICs) was diminished by their fragmentation.

\section{Recommendations}

Based on the findings of this evaluation, the following recommendations are made: 


\section{On World Bank Group Strategic Approach}

- Review the institutional setup and interaction of various World Bank Group units dealing with FCV matters to ensure that the FCV CCSA drives substantive thinking on strategy and policy in this area across the World Bank Group. This would also entail closer operational engagement of CCSA staff with and across members (including IFC and MIGA), and Regional and thematic departments.

- Develop a new multidimensional publicly disclosed system of markers and flags for monitoring and measuring fragility, including in nonFCS countries. Linked to this, integrate fragility assessments as part of the SCD/CPF process to be applied systematically in countries where conflict and violence or externally imposed fragility constitute a significant impediment to attaining the strategic objectives of the World Bank Group.

- Scale up regional presence and outlook, including through regional projects and joint analytic and advisory work across relevant countries, and ensure World Bank Group sustained presence in FCVaffected areas, monitoring the fragility profile of the countries/regions.

\section{ON World Bank Group Operational RESPONSE}

- Develop new financial mechanisms or fast-response facilities to be used when outbreaks of violence or external threats jeopardize resilience in MICs. Improve strategic alignment and use of global FCV thematic trust funds, while boosting their agility. Options to consider include using these funds for cofinancing small pilot programs in FCV-affected areas with potential of scaling-up.

- Within the new SCD/CPF model, develop a broader strategic approach to interventions in FCVaffected areas, expanding sector interventions beyond the CDD model, and improving coordination and information sharing within the World Bank Group, with particular attention to private sector development activities (through a more customized approach to risk assessment, project mix, policies and procedures), public financial management (including fiscal decentralization and broader use of diagnostic tools), education, and gender (including integration of conflict-specific gender issues in project design and implementation). Strengthen M\&E frameworks by including FCV-related outcome indicators.

\section{ON PARTNERSHIPS}

- Develop institutional incentives for collaboration and strategic thematic guidance on partnering-particularly with the United Nations but also with other partners. Introduce systematic communication and staff exchange programs to increase the level of collaboration. 


\section{Management Response}

The Management of the World Bank Group institutions welcomes the evaluation of the Independent Evaluation Group (IEG) entitled World Bank Group Engagement in Situations of Fragility, Conflict, and Violence. Overall the evaluation is useful for identifying lessons from experience and understanding the World Bank Group's contributions in providing solutions to cope with situations of fragility, conflict, and violence (FCV) in mostly middle-income countries (MICs).

The evaluation rightly asserts that, given the current global context, conflict and violence are no longer primarily a low-income country problem. The evaluation recognizes the progress the World Bank Group has made in addressing issues of conflict and violence, more systematically discussing the political economy around these issues, and developing analytical and operational instruments to provide support. As the report acknowledges, the theme of conflict and violence, including in cases of subnational conflict, has become "more apparent in country strategies."

Management broadly agrees with all recommendations of the IEG evaluation. Management's views are summarized below, and the detailed responses to the IEG recommendations are presented in the Management Action Record.

\section{World Bank Management Comments}

\section{Strategic Presence}

The report rightly points out that the World Bank's sustained physical presence in conflict-affected areas is crucial. As the World Development Report 2011 noted, breaking cycles of violence requires a long-term process of creating legitimate institutions. Ensuring sustained engagement, presence, and continuity is indeed a critical element for successful work in conflict-affected areas, as the World Bank's recent experience shows. ${ }^{1}$ An important operational point to consider is how the World Bank's presence can continue even during periods of political crises. In this context, it is important to forge close links with a wide range of actors on the ground, from nongovernmental organizations and academics to labor unions and media. There are several examples of continued and sustained technical assistance

\footnotetext{
${ }^{1}$ Sustained engagements in regions of protracted FCV include Afghanistan, Bosnia and Herzegovina, and West Bank and Gaza.
} 
engagements, including some in extremely difficult circumstances, in which the World Bank is playing a leading role in strengthening local capacity.

Management agrees that the regional dimensions of FCV situations are increasingly important. Contemporary fragility is characterized less by interstate wars than by civil conflicts, violence, and transnational crimes, with regional spillovers and global implications. Because localized conflicts can trigger regionwide conflicts and destabilize neighboring countries, it is necessary to take regionwide approaches to conflict resolution and management. Therefore, the World Bank Group's approach incorporates the multidimensional nature of FCV, internal risk factors and stresses, and regional/external risks from spillovers. ${ }^{2}$ For the World Bank, the task is to strengthen its ability to engage on fragility issues at the regional level, in terms of both analysis (e.g., through regional fragility assessments) and appropriate financing, and to build the necessary partnerships to be able to effectively contribute to a broader, multidimensional international engagement.

\section{Operational Response}

Management has taken steps to strengthen the overall organizational structure to effectively deliver on the World Bank's FCV agenda. The FCV Cross-Cutting Solutions Areas (CCSA) has a substantive role in coordinating the institutional approach of the World Bank in FCV issues. It also has a major role in providing inputs to policies related to FCV strategy and operations. The FCV CCSA was created in FY15 to support the World Bank Group's strategic engagement in FCV situations; provide knowledge management, cross-country support, and experiencesharing in addressing drivers of fragility; strengthen partnerships; and improve the World Bank Group's response to the forced displacement crisis. Recently the FCV CCSA has strengthened a global operations support team in Nairobi, and it has assigned dedicated specialists to FCV countries to augment country engagement and coordination with development partners.

Management plans to fine-tune the fragility measurement instrument. Regarding the call for redefining and fine-tuning the fragility measurement instruments, in 2015 the FCV CCSA initiated analytical work to improve the metric for identifying fragility. The starting point of the exercise was the need to capture fragility beyond the fragile states list and permit a view beyond static situations that only depict outcomes. The expanded metric framework will capture fragility across multiple

\footnotetext{
${ }^{2}$ For example, the Middle East and North Africa strategy recognizes that a reduction in conflict in any one country will benefit the Region as well as other countries. Peace and stability in the Region are hence global public goods, and a global coalition is required to pool resources and expertise to bring them about.
} 
dimensions by using a combination of key indicators on adverse outcomes and risk flags based on the Country Policy and Institutional Assessment (CPIA); the gross national income per capita cutoff is not applied. The data on adverse outcomes will be made public, and will allow the World Bank to answer with greater precision such questions as how many people live in FCV situations. The risk factors scan through the CPIA flags described above is meant to be an internal tool, since CPIA ratings are not disclosed for MICs. Also, any risk scan can only be indicative. It will not be able to provide a detailed and nuanced understanding of the nature of the fragility in FCV countries. To identify fragility risks, the World Bank will draw its information from several sub indicators of the CPIA, complemented by other robust indicators of fragility and qualitative assessments produced by internationally recognized and specialized organizations. Such information will constitute the basis on which the World Bank Group will engage clients in discussions on potential risk management and prevention.

Management welcomes IEG's finding that the FCV diagnostic was useful and relevant, when it was used. The evaluation suggests that such diagnostic work should be more systematically built into FCV operations, and Management agrees that this would be useful. During the 18th Replenishment of the International Development Association (IDA) and beyond, the World Bank Group will continue to address fragility in countries on the Harmonized List of Fragile and Conflictaffected Situations. It will also adopt an expanded approach to identify and address the fragility dynamic than can persist in countries not on the list. To gain more indepth understanding of the issues at play in such countries, the World Bank Group will undertake detailed fragility assessments or similar diagnostics (also increasingly referred to as Assessment of Risks and Resilience) as part of the Systematic Country Diagnostic (SCD) and Country Partnership Framework (CPF) process to be applied systematically in countries where fragility is a threat to the achievement of the strategic objectives of reducing poverty and sharing prosperity.

The value of the community-driven development (CDD) approach goes well beyond establishing a presence and contextual learning. CDD operations in FCV settings have provided a local platform for inclusive dialogue about development; opened space for line agencies (which often cannot enter the areas for security reasons) to connect with local communities through subproject support; helped establish positive relationships with rebel groups; and enhanced the World Bank's credibility, trust, and acceptance by state and nonstate actors through building partnerships. Management agrees with the report's finding that creating opportunities for generating employment and local entrepreneurial success are important. Support to the education sector can address psychosocial issues among children and provide safe spaces for integration and community cohesion to develop. Policy advice on 
budgeting and fiscal decentralization also deserves more attention, especially since the World Bank has proven technical expertise and experience with such analysis.

Management agrees that FCV-sensitive operational responses require a core program that effectively translates diagnostics into programming. However, there is no one-size-fits-all approach to preventing, managing, and mitigating FCV. What constitutes FCV-sensitive programming can be determined only at the country level. Program approaches may include mainstreaming sensitivity to FCV across the portfolio, incorporating activities that address the direct outcomes of FCV, or directly tackling the drivers of FCV. Further effort is needed to develop innovative operations that address key drivers of FCV, either to avoid an occurrence of FCV in the first place or to prevent its recurrence. This effort should include, among other things, consideration of various sectoral efforts or approaches (e.g., CDD, fiscal decentralization, private sector development, education, provision of justice) to address the economic drivers of conflict (e.g., corruption, access to land, political participation, exclusion or discrimination). The FCV-CCSA is preparing a note on operationalizing fragility that will outline a shared understanding of how the World Bank Group can assess a country's vulnerability to FCV and prepare programs that sets out feasible pathways for inclusive peace and development. However, it will not attempt to prescribe a standard or comprehensive response to FCV situations.

Management agrees with the need to strengthen monitoring and evaluation (M\&E) frameworks and to record positive experiences for better assessment of results and learning from projects. However, M\&E in FCV countries faces several challenges, including dearth of baseline data, potential political sensitivity in data collection, and the difficulty of defining appropriate measures of near-term progress for institutional reforms. Despite these challenges, there are hopeful signs that new tools and technologies will help overcome some of these challenges to better monitor and evaluate results - for example, the explosion of new information communication technologies; unprecedented increases in phone and Internet connectivity; availability of low-cost, web-based tools and information; use of the services of third-party monitoring agents; and modern monitoring techniques using remote sensing and satellite imagery analysis. Management has also produced a Pilot Toolkit, accompanied by a searchable FCV indicator database, designed to assist teams in measuring peace-building and state-building progress. The toolkit is an interactive resource to help inform strategic and operational results frameworks and enhance practical data collection efforts.

Management is committed to further strengthening the partnership with development partners in FCV issues. Management welcomes the report's reference to the commitments made in 2011 at the Fourth High Level Forum on Aid 
Effectiveness in Busan. The main thrust of the "New Deal for Engagement with Fragile States," endorsed by development partners at that meeting, was that achieving any substantial progress is unlikely without country ownership and leadership, and inclusive political dialogue. ${ }^{3}$ The New Deal also called on donors to work more transparently and make real progress in coordinating their efforts under country leadership, while also using aid to strengthen and use country systems as much as possible with a view toward building countries' capacity. The report also refers to the World Bank's partnership with the United Nations, which remains our primary international partner for fragile and conflict-affected situations (FCS). This partnership has evolved, moving gradually from a focus on post-conflict recovery and reconstruction (and assumptions of clearly phased linear progress) to an approach that addresses challenges of fragility, peace-building, and institutional strengthening. A key area of focus will be the increasingly important humanitarian/development nexus, an area where both institutions are engaging at the highest levels.

Management agrees that there is a need to develop innovative financing mechanisms and to leverage the use of the existing instruments or fast-response facilities. There are also challenges related to speed and flexibility in responding to crises or conflict situations and mobilizing sufficient resources for post-conflict reconstruction. In light of the World Bank Group's work on redefining fragility, there is interest in exploring innovative ways to mobilize and delivering financing for FCV in MICs; for example, the Middle East and North Africa Region is establishing a Concessional Financing Facility to provide refugee host countries with access to finance on more concessional terms than International Bank for Reconstruction and Development financing. ${ }^{4}$ The report makes a case for the need to set aside specific financing to be mobilized rapidly as needed for FCV interventions in nonfragile countries. Such interventions have often been supported by the State-

\footnotetext{
${ }^{3} \mathrm{http}: / /$ www.pbsbdialogue.org/media/filer_public/07/69/07692de0-3557-494e-918e18df00e9ef73/the_new_deal.pdf.

${ }^{4}$ The New Financing Initiative to Support the Middle East and North Africa was established in October 2015 during the World Bank Group-IMF Annual Meetings in Lima, Peru. The working group formed then, co-chaired by the United Nations, the World Bank Group, and the Islamic Development Bank Group, is now developing a roadmap for implementation. The approach proposes blending contributions from supporting countries with lending from implementation support agencies (a broad range of partners, including multilateral development banks) to improve the concessionality of development financing. It integrates blending arrangements with a financing facility that can provide coordination and oversight. The World Bank Group would act as the trustee for a financial intermediary fund, receiving contributions from supporting countries, holding and investing these funds, and transferring funds to implementation support agencies (including United Nations agencies).
} 
and Peace-Building Fund (SPF), as the fund's eligibility criteria allow for support to all borrowing countries regardless of country classification. We also agree on using global FCV thematic trust funds while boosting their agility, as well as on the merits of starting with small pilots. Management will explore appropriate modalities for high-risk investments in FCV situations, particularly in MICs.

Management agrees with the finding that multi-donor trust funds (MDTFs) are "vital strategic tools in conflict regions, but their effectiveness can be enhanced by stronger links to the rest of the World Bank portfolio." The overall impact of IDA resources in fragile and conflict-affected situations has been greatly enhanced by mobilizing complementary resources through trust fund support, at both the country level through MDTFs and at a global level through funds such as the SPF. The availability of additional trust fund resources has allowed the financing of (i) seed interventions in non-IDA-eligible countries and countries in arrears (e.g., Somalia); (ii) innovative high-risk schemes that lay the groundwork for impactful follow-up IDA investments; (iii) regional and global initiatives to build the evidence base and share knowledge on emerging themes; and (iv) partnership initiatives (e.g., with the United Nations or under the New Deal). Trust funds have also helped nonfragile countries cope with negative spillovers from fragile neighbors. In some countries, such as Afghanistan, IDA has helped to leverage additional trust fund resources.

\section{IFC Management Comments}

Management of the International Finance Corporation (IFC) welcomes the IEG evaluation World Bank Group Engagement in Situations of Fragility, Conflict, and Violence, highlighting the World Bank Group's efforts in countries that were not classified as FCS and experienced localized or externally imposed situations of FCV at the time of the evaluation. IFC staff appreciates the engagement with IEG throughout the preparation of the report and believes that this report will provide a useful platform for further discussions with a view to improving the effectiveness of operations in fragile situations. More outreach to IFC teams during the field visits would have provided the IEG team better opportunities to learn first-hand about IFC's efforts on the ground.

IFC Management broadly agrees with the report's recommendations. Regarding the institutional approach to FCV situations, it is important to note that IFC adopted some enhancements as of January 2017 in line with IFC 3.0 strategy. A new Vice Presidency for Blended Finance and Partnerships includes a new FCS/IDA Unit (building on the former IFC FCS Coordination Unit), which now provides cohesive 
oversight to IFC's support for private sector development in fragile situations, including several FCV countries. The FCS/IDA Coordination Unit remains in routine communications and close engagement with FCV CCSA and an FCS Network of more than 400 IFC and other World Bank Group staff focused on private sector development in FCS. It also continues to support and coordinate IFC's business in fragile situations through focal points in all IFC operational departments and key support units. As IFC aims to ramp up support for fragile situations and other challenging markets, including through the deployment of the IDA18 Private Sector Window, IFC Management believes that this institutional set-up will enable efficient information flows between IFC's central team and operational departments and creates strong links between strategy and operations.

To the extent that the evaluation stresses a strong distinction between FCS and FCV countries, IFC's focus at the corporate level has been on FCS, which is among IFC's current strategic priorities. Over the five years through FY16, IFC's new investment commitments in FCS countries have increased to average at over $\$ 800$ million per year, including mobilization, and IFC's annual advisory expenditure has averaged over $\$ 40$ million. IFC has been an integral part of the international effort to move fragile states away from the margins, enabling them to entrench stability and growth. In partnership with the World Bank, the Multilateral Investment Guarantee Agency (MIGA), and other development partners and clients, IFC has been striving to stimulate private investment and growth in fragile situations. IFC believes that economic growth and employment can make a significant contribution to reducing fragility. The private sector plays a key role, providing 90 percent of jobs in developing countries. Private companies often deliver essential goods and services in fragile situations, and create tax revenues for governments. That said, however, many fragile situations also suffer from extremely challenging business environments. Firms in those situations cite access to power, access to finance and political instability as the top three barriers to growth. For this reason, alleviating the barriers to business growth underpins IFC's strategy in fragile situations.

As the report highlights, IFC has been also providing diverse types of relevant support for fragile situations in countries not classified as FCS. In IFC, such support has been developed and provided at a regional and country level, given the unique challenges and more localized and often rapidly evolving nature of those situations. This evaluation provides an opportunity for IFC to consider enhanced approaches, including more corporate efforts and cross-fertilization among its teams engaging with the private sector and other stakeholders in FCV situations.

Management agrees that fragility assessments are useful tools that the World Bank Group has used in certain country strategy processes when it was determined 
appropriate. IFC is also piloting some additional analytical work, complementary to Risk and Resilience Assessments and aimed at adapting the fragility assessments to private sector needs. The IFC team will continue collaborating with the World Bank and MIGA in developing SCDs and CPFs in countries characterized by FCV. With respect to developing a new multidimensional system of markers and flags for monitoring and measuring fragility, including in non-FCS countries, IFC is monitoring with strong interest the fragility markers that FCV CCSA is developing.

As the evaluation found, IFC does generally maintain more engagement in FCV areas post-conflict. However, as the report recognizes, when fragility, conflict, or violence is not completely over, this can pose challenges as it limits IFC's presence on the ground, which is key to local market intelligence and IFC's understanding of the situation. Without a minimum level of security and stability, investment is impossible, or inadvisable.

Management also agrees that a holistic and sequenced approach to private sector development in FCV situations is critical. In this regard, IFC will seek to increase collaboration with the World Bank, MIGA, and other key institutions, in particular, to strengthen government and private sector capacity and develop new tools to "derisk" projects and crowd-in private capital.

Regarding IFC's operational response, first, Management agrees that specially designed products would facilitate support for the private sector in fragile and conflict environments. The IFC FCS Risk Envelope is an example of a program that is specifically designed to help stimulate more investments in FCS and increase IFC's development impact in these most difficult operating environments by allowing teams to take additional, defined risks. IFC will also further explore ways to deploy donor funds and blended finance in FCV situations in a speedy manner, as appropriate, building on its successful access, including at the Ebola outbreak.

Second, IFC will continue to engage with the World Bank and MIGA in the $\mathrm{SCD} / \mathrm{CPF}$ process for enhancing private sector development in $\mathrm{FCV}$-affected areas (through a more customized approach to risk assessment, project mix, policies, and procedures). Management agrees that it would be helpful to improve coordination and information-sharing within the World Bank Group, with attention to the areas mentioned. In this regard, IFC looks forward to the findings of the upcoming IEG evaluation of SCD/CPF processes. Management is committed to advancing and improving the M\&E framework in FCV situations and believes that greater flexibility, with room for adjustment during project/ program implementation, would allow adapting to evolving conditions. IFC has started to test this with its FCS M\&E framework. Finally, regarding partnerships, Management is pleased to 
note that IFC teams have been developing various partnerships and exchange and collaboration mechanisms with bilateral and multilateral organizations that would help IFC's support for FCV situations.

\section{MIGA Management Comments}

MIGA Management welcomes the IEG evaluation report World Bank Group Engagement in Situations of Fragility, Conflict, and Violence. In the absence of accepted criteria for classifying nonfragile MICs facing situations of fragility, conflict, and violence, the evaluation has proposed choosing a group of countries using four parameters: (i) prolonged and widely publicized episodes of conflict and violence; (ii) presence of significant World Bank Group programs; (iii) different levels of income and institutional capability; and (iv) representation from different global regions. MIGA notes that this classification system could be useful in identifying other FCV situations.

The report concludes that MIGA's political risk insurance products are a useful tool that can help facilitate foreign direct investment when a country faces FCV situations, including at the subnational level, and the use of these products can be further expanded. While agreeing with this assessment in principle, MIGA notes the need to be cognizant of its demand-driven business model. Even so, the jointness envisaged under the World Bank Group's New Country Engagement Approach provides the potential for proactive MIGA engagement in FCV situations. MIGA also notes its ongoing interactions with the FCV CCSA for operational work. Regarding the report's suggestion of MIGA's non-honoring of sovereign financial obligations (NHSFO) coverage as relevant to FCV situations, MIGA notes that the stringent requirements for NHSFO guarantee projects are likely to be challenging in FCV situations with diminished state capacity and effectiveness. 


\section{Management Action Record}

\begin{tabular}{|c|c|c|c|}
\hline IEG Findings and Conclusions & IEG Recommendations & $\begin{array}{l}\text { Acceptance by } \\
\text { Management }\end{array}$ & Management Response \\
\hline $\begin{array}{l}\text { Cooperation between different } \\
\text { parts and units of the World } \\
\text { Bank Group, good knowledge of } \\
\text { local conditions and } \\
\text { understanding of the political } \\
\text { economy are the key for } \\
\text { successful interventions in } \\
\text { fragile, conflict, and violence } \\
\text { (FCV) situations. }\end{array}$ & $\begin{array}{l}\text { Review the institutional setup } \\
\text { and interaction of various World } \\
\text { Bank Group units dealing with } \\
\text { FCV matters to ensure that the } \\
\text { FCV Cross-Cutting Solutions } \\
\text { Area (CCSA) drives substantive } \\
\text { thinking on strategy and policy } \\
\text { in this area across the World } \\
\text { Bank Group. This would also } \\
\text { entail closer operational } \\
\text { engagement of CCSA staff with } \\
\text { and across the World Bank } \\
\text { Group members (including the } \\
\text { International Finance } \\
\text { Corporation [IFC] and the } \\
\text { Multilateral Investment } \\
\text { Guarantee Agency [MIGA]), and } \\
\text { Regional and thematic } \\
\text { departments. }\end{array}$ & $\begin{array}{l}\text { World Bank, } \\
\text { IFC, MIGA: } \\
\text { Agree }\end{array}$ & $\begin{array}{l}\text { Management has taken steps to strengthen } \\
\text { the overall organizational structure to } \\
\text { effectively deliver on the World Bank } \\
\text { Group's FCV agenda. Recently the FCV } \\
\text { CCSA has strengthened a global } \\
\text { operations support team in Nairobi, and it } \\
\text { has assigned dedicated specialists to FCS } \\
\text { countries to augment country engagement } \\
\text { and coordination with development } \\
\text { partners. } \\
\text { The FCV CCSA plays a key role in } \\
\text { coordinating the World Bank Group's } \\
\text { engagement and plays a substantive role } \\
\text { in developing the strategic directions for } \\
\text { the World Bank Group on this theme. This } \\
\text { role includes providing inputs to } \\
\text { strengthen operational policies affecting } \\
\text { FCV countries, which are institutionally } \\
\text { coordinated by Operations Policy and } \\
\text { Country Services. } \\
\text { Regarding the institutional approach to } \\
\text { FCVs, situations, it is important to note } \\
\text { that IFC adopted some enhancements as of } \\
\text { January } 2017 \text { in line with IFC } 3.0 \text { strategy. } \\
\text { A new Vice Presidency for Blended } \\
\text { Finance and Partnerships includes a new }\end{array}$ \\
\hline
\end{tabular}




\begin{tabular}{|c|c|c|c|}
\hline IEG Findings and Conclusions & IEG Recommendations & $\begin{array}{l}\text { Acceptance by } \\
\text { Management }\end{array}$ & Management Response \\
\hline & & & $\begin{array}{l}\text { FCS/International Development } \\
\text { Association (IDA) Unit (building on the } \\
\text { former IFC FCS Coordination Unit), which } \\
\text { now provides cohesive oversight to IFC's } \\
\text { support for private sector development in } \\
\text { fragile situations, including several FCV } \\
\text { countries. The FCS/IDA Coordination } \\
\text { Unit remains in routine communications } \\
\text { and close engagement with FCV CCSA } \\
\text { and an FCS Network of more than } 400 \text { IFC } \\
\text { and other World Bank Group staff focused } \\
\text { on private sector development in FCS. It } \\
\text { also continues to support and coordinate } \\
\text { IFC's business in fragile situations through } \\
\text { focal points in all IFC operational } \\
\text { departments and key support units. As } \\
\text { IFC aims to ramp up support for fragile } \\
\text { situations and other challenging markets, } \\
\text { including through the deployment of the } \\
\text { 18th Replenishment of IDA Private Sector } \\
\text { Window, IFC Management believes that } \\
\text { this institutional set-up will enable } \\
\text { efficient information flows between IFC's } \\
\text { central team and operational departments } \\
\text { and creates strong links between strategy } \\
\text { and operations. } \\
\text { FCV CCSA will share lessons learned on } \\
\text { FCV-related issues within and outside the } \\
\text { World Bank with operational teams, } \\
\text { increasing World Bank-wide knowledge }\end{array}$ \\
\hline
\end{tabular}




\begin{tabular}{|c|c|c|c|}
\hline IEG Findings and Conclusions & IEG Recommendations & $\begin{array}{l}\text { Acceptance by } \\
\text { Management }\end{array}$ & Management Response \\
\hline & & & $\begin{array}{l}\text { for in-country policy and program } \\
\text { development. FCV CCSA staff is } \\
\text { strategically involved in operations where } \\
\text { appropriate. }\end{array}$ \\
\hline $\begin{array}{l}\text { World Bank Group definitions, } \\
\text { measurement metrics, and } \\
\text { policy application are not } \\
\text { entirely consistent along the full } \\
\text { spectrum of countries } \\
\text { experiencing FCV. In this } \\
\text { regard, the role of the new } \\
\text { structural unit, the FCV CCSA } \\
\text { could be particularly important, } \\
\text { especially in redefining and fine- } \\
\text { tuning fragility diagnostic and } \\
\text { measurement instruments. FCV- } \\
\text { specific diagnostic work } \\
\text { (fragility assessments, conflict } \\
\text { filters) was useful and relevant } \\
\text { when it was invoked, but was } \\
\text { not the norm within the } \\
\text { reviewed group of countries. } \\
\text { The utility of fragility } \\
\text { assessments in non-FCS could } \\
\text { be limited by the fact that their } \\
\text { preparation, disclosure, and } \\
\text { even discussion with the client } \\
\text { are optional. }\end{array}$ & $\begin{array}{l}\text { Develop a new multidimensional } \\
\text { publicly disclosed system of } \\
\text { markers and flags for monitoring } \\
\text { and measuring fragility, } \\
\text { including in non-FCS countries. } \\
\text { Linked to this, integrate fragility } \\
\text { assessments as part of the } \\
\text { Systematic Country Diagnostic } \\
\text { (SCD) and Country Partnership } \\
\text { Framework (CPF) process to be } \\
\text { applied systematically in } \\
\text { countries where conflict and } \\
\text { violence or externally imposed } \\
\text { fragility constitute a significant } \\
\text { impediment to attaining the } \\
\text { strategic objectives of the World } \\
\text { Bank Group. }\end{array}$ & $\begin{array}{l}\text { World Bank, } \\
\text { IFC, MIGA: } \\
\text { Agree }\end{array}$ & $\begin{array}{l}\text { Acting on the IEG's recommendations in } \\
2015 \text { and its mandate to enhance World } \\
\text { Bank Group effectiveness in FCS, the FCV } \\
\text { CCSA initiated analytical work to improve } \\
\text { the metric for identifying fragility beyond } \\
\text { the FCS list. The CCSA will adopt an } \\
\text { expanded approach to identify and } \\
\text { address the fragility dynamic that can } \\
\text { persist in countries not on the list. It will } \\
\text { develop an expanded metric framework } \\
\text { by using a combination of key indicators } \\
\text { on adverse outcomes and Country Policy } \\
\text { and Institutional Assessment (CPIA)- } \\
\text { based risk flags; the gross national income } \\
\text { per capita cutoff will not be applied. The } \\
\text { data on adverse outcomes will be made } \\
\text { public. The risk factors scan through the } \\
\text { CPIA flags is meant to be an internal tool, } \\
\text { since CPIA ratings for middle-income } \\
\text { countries (MICs) are not disclosed. During } \\
\text { IDA18 and beyond, the World Bank will } \\
\text { continue to address fragility in countries } \\
\text { on the Harmonized List of FCS. } \\
\text { To identify fragility risks, the World Bank } \\
\text { will draw its information from several sub }\end{array}$ \\
\hline
\end{tabular}




\begin{tabular}{|c|c|c|c|}
\hline IEG Findings and Conclusions & IEG Recommendations & $\begin{array}{l}\text { Acceptance by } \\
\text { Management }\end{array}$ & Management Response \\
\hline & & & $\begin{array}{l}\text { indicators of the CPIA, complemented by } \\
\text { other fragility indicators and qualitative } \\
\text { assessments produced by internationally } \\
\text { recognized and specialized organizations. } \\
\text { Such information will constitute the basis } \\
\text { on which the World Bank Group will } \\
\text { engage clients in discussions on potential } \\
\text { risk management and prevention. } \\
\text { The World Bank will also undertake } \\
\text { detailed fragility assessments or similar } \\
\text { diagnostics (e.g., Assessment of Risks and } \\
\text { Resilience) as part of the SCD/CPF } \\
\text { process in countries where fragility is a } \\
\text { threat to the achievement of the strategic } \\
\text { objectives of reducing poverty and sharing } \\
\text { prosperity. } \\
\text { IFC is also piloting some additional } \\
\text { analytical work, complementary to Risk } \\
\text { and Resilience Assessments and aimed at } \\
\text { adapting the fragility assessments to } \\
\text { private sector needs. The IFC team will } \\
\text { continue collaborating with the World } \\
\text { Bank and MIGA on the SCD/CPF } \\
\text { programs of FCV countries. }\end{array}$ \\
\hline $\begin{array}{l}\text { The World Bank Group } \\
\text { comparative advantage } \\
\text { continues to be in helping } \\
\text { countries to tackle longer-term } \\
\text { developmental challenges }\end{array}$ & $\begin{array}{l}\text { Scale up regional presence and } \\
\text { outlook, including through } \\
\text { regional projects and joint } \\
\text { analytic and advisory work } \\
\text { across relevant countries, and }\end{array}$ & $\begin{array}{l}\text { World Bank, } \\
\text { IFC, MIGA: } \\
\text { Agree }\end{array}$ & $\begin{array}{l}\text { There are numerous ways to scale up the } \\
\text { World Bank's Regional presence-through } \\
\text { analysis, appropriate financing, and } \\
\text { partnerships to effectively contribute to a } \\
\text { broader, multidimensional international }\end{array}$ \\
\hline
\end{tabular}




\begin{tabular}{|c|c|c|c|}
\hline IEG Findings and Conclusions & IEG Recommendations & $\begin{array}{l}\text { Acceptance by } \\
\text { Management }\end{array}$ & Management Response \\
\hline $\begin{array}{l}\text { through earlier engagement and } \\
\text { sustained presence in the } \\
\text { conflict-affected areas, and } \\
\text { continuous dialogue with the } \\
\text { parties to violent conflicts, } \\
\text { where possible. In many } \\
\text { instances, the problems have } \\
\text { much deeper regional roots and } \\
\text { the World Bank Group needs to } \\
\text { develop a broader and more } \\
\text { holistic view of the problems } \\
\text { and their spill-over effects. }\end{array}$ & $\begin{array}{l}\text { ensure World Bank Group } \\
\text { sustained presence in FCV- } \\
\text { affected areas, monitoring the } \\
\text { fragility profile of the } \\
\text { countries/regions. }\end{array}$ & & $\begin{array}{l}\text { engagement. First, there is scope for the } \\
\text { SCD/CPF process to make more } \\
\text { systematic assessments of spillover risks } \\
\text { from neighboring states and consider the } \\
\text { actions that can minimize the impact of } \\
\text { such spillovers. Second, Regional } \\
\text { programming for mitigating the impact of } \\
\text { issues like forced displacement could also } \\
\text { help address such spillover effects. } \\
\text { During IDA18, Management is also } \\
\text { developing financing and risk } \\
\text { management modalities for } \\
\text { comprehensive response to FCV risks in } \\
\text { both lower- and middle-income countries. } \\
\text { Management expects to roll out various } \\
\text { financial products to countries that are } \\
\text { refugee hosts or are affected by regional } \\
\text { FCV risks. }\end{array}$ \\
\hline $\begin{array}{l}\text { World Bank Group operational } \\
\text { response to FCV, and } \\
\text { emergencies, in particular, is } \\
\text { often constrained by the limited } \\
\text { choice of instruments at its } \\
\text { disposal and depends to a large } \\
\text { extent on donor financing and } \\
\text { presence of large multi-donor } \\
\text { trust funds. Global thematic } \\
\text { trust funds were helpful in } \\
\text { supporting synergies in FCV }\end{array}$ & $\begin{array}{l}\text { Develop new financial } \\
\text { mechanisms or fast-response } \\
\text { facilities to be used when } \\
\text { outbreaks of violence or external } \\
\text { threats jeopardize resilience in } \\
\text { MICs. Improve strategic } \\
\text { alignment and use of global FCV } \\
\text { thematic trust funds, while } \\
\text { boosting their agility. Options to } \\
\text { consider include using these } \\
\text { funds for co-financing small pilot }\end{array}$ & $\begin{array}{l}\text { World Bank, } \\
\text { IFC, MIGA: } \\
\text { Agree }\end{array}$ & $\begin{array}{l}\text { Management agrees that there is a need to } \\
\text { develop innovative financing mechanisms } \\
\text { and to leverage the use of the existing } \\
\text { instruments or fast-response facilities. The } \\
\text { report also makes a case to set aside } \\
\text { specific financing to be mobilized rapidly } \\
\text { as needed for FCV interventions in non- } \\
\text { fragile countries. Such financing has often } \\
\text { been supported in the past by the State- } \\
\text { and Peace-Building Fund. }\end{array}$ \\
\hline
\end{tabular}




\begin{tabular}{|c|c|c|c|}
\hline IEG Findings and Conclusions & IEG Recommendations & $\begin{array}{l}\text { Acceptance by } \\
\text { Management }\end{array}$ & Management Response \\
\hline $\begin{array}{l}\text { context. However, their impact } \\
\text { (particularly in the MIC context) } \\
\text { was diminished by their } \\
\text { fragmentation. }\end{array}$ & $\begin{array}{l}\text { programs in FCV-affected areas } \\
\text { with potential of scaling-up. }\end{array}$ & & $\begin{array}{l}\text { Management agrees with the suggested } \\
\text { recommendation to improve the strategic } \\
\text { alignment and use of global FCV thematic } \\
\text { trust funds while boosting their agility, as } \\
\text { well as to increase the use of pilot } \\
\text { programs. } \\
\text { The IFC FCS Risk Envelope is an example } \\
\text { of a program specifically designed to help } \\
\text { stimulate more investments in FCS and } \\
\text { increase IFC's development impact in } \\
\text { these most difficult operating } \\
\text { environments by allowing teams to take } \\
\text { additional, defined risks. IFC will also } \\
\text { further explore ways to deploy donor } \\
\text { funds and blended finance in FCV } \\
\text { situations in a speedy manner, as } \\
\text { appropriate. }\end{array}$ \\
\hline $\begin{array}{l}\text { Projects with a CDD design } \\
\text { were a useful point of entry for } \\
\text { the World Bank Group in } \\
\text { conflict-affected areas, used also } \\
\text { as a form of information- } \\
\text { gathering and contextual } \\
\text { learning. They were not, } \\
\text { however, a forum for addressing } \\
\text { the causes and consequences of } \\
\text { violence. Creating opportunities } \\
\text { for private sector development, } \\
\text { generating employment and }\end{array}$ & $\begin{array}{l}\text { Within the new SCD/CPF model, } \\
\text { develop a broader strategic } \\
\text { approach to interventions in } \\
\text { FCV-affected areas, expanding } \\
\text { sector interventions beyond the } \\
\text { CDD model, and improving } \\
\text { coordination and information } \\
\text { sharing within the World Bank } \\
\text { Group, with particular attention } \\
\text { to private sector development } \\
\text { activities (through a more } \\
\text { customized approach to risk }\end{array}$ & $\begin{array}{l}\text { World Bank, } \\
\text { IFC, MIGA: } \\
\text { Agree }\end{array}$ & $\begin{array}{l}\text { Management agrees that FCV-sensitive } \\
\text { operational responses require a core } \\
\text { program that effectively translates } \\
\text { diagnostics into programming. However, } \\
\text { there is no one-size-fits-all approach to } \\
\text { preventing, managing, and mitigating } \\
\text { FCV. What constitutes FCV-sensitive } \\
\text { programming can be determined only at } \\
\text { the country level. } \\
\text { Program approaches may include } \\
\text { mainstreaming sensitivity to FCV across } \\
\text { the portfolio; incorporating activities that }\end{array}$ \\
\hline
\end{tabular}




\begin{tabular}{|c|c|c|c|}
\hline IEG Findings and Conclusions & IEG Recommendations & $\begin{array}{l}\text { Acceptance by } \\
\text { Management }\end{array}$ & Management Response \\
\hline $\begin{array}{l}\text { local entrepreneurial success are } \\
\text { important to making a peace } \\
\text { settlement last. In this area, } \\
\text { however, opportunities were } \\
\text { sometimes missed due to the } \\
\text { lack of coordination and } \\
\text { communication between } \\
\text { different parts of the World } \\
\text { Bank Group, including IFC and } \\
\text { MIGA, as well as lack of } \\
\text { flexibility of World Bank Group } \\
\text { instruments and inadequate } \\
\text { staff incentives. Support to the } \\
\text { education sector can be } \\
\text { important in dealing with issues } \\
\text { of fragility, particularly as they } \\
\text { pertain to psycho-social issues } \\
\text { among children and providing } \\
\text { safe spaces for integration and } \\
\text { community cohesion to develop, } \\
\text { and dealing with the problem of } \\
\text { "lost generations" in more } \\
\text { protracted conflicts. PFM } \\
\text { diagnostics in the conflict- } \\
\text { affected regions, and } \\
\text { particularly policy advice on } \\
\text { budgeting and governance } \\
\text { arrangements in the security } \\
\text { sector and fiscal } \\
\text { decentralization, deserve more }\end{array}$ & $\begin{array}{l}\text { assessment, project mix, policies } \\
\text { and procedures), public financial } \\
\text { management (including fiscal } \\
\text { decentralization and broader use } \\
\text { of diagnostic tools), education, } \\
\text { and gender (including } \\
\text { integration of conflict-specific } \\
\text { gender issues in project design } \\
\text { and implementation). Strengthen } \\
\text { M\&E frameworks by including } \\
\text { FCV-related outcome indicators. }\end{array}$ & & $\begin{array}{l}\text { address the direct outcomes of FCV; or } \\
\text { directly tackling the drivers of FCV. } \\
\text { Further effort is needed to develop } \\
\text { innovative operations that address key } \\
\text { drivers of FCV, either to avoid the } \\
\text { occurrence of FCV in the first place or to } \\
\text { prevent its recurrence. This will include, } \\
\text { among other things, considering a mix of } \\
\text { various sectoral efforts or approaches. } \\
\text { The FCV-CCSA is preparing a note on } \\
\text { operationalizing fragility. The purpose of } \\
\text { this paper is not to prescribe a standard or } \\
\text { comprehensive response to FCV } \\
\text { situations, but to outline a logical structure } \\
\text { for World Bank Group engagement-from } \\
\text { diagnostics to programming through } \\
\text { monitoring. } \\
\text { Management has also produced a Pilot } \\
\text { Toolkit, accompanied by a searchable FCV } \\
\text { indicator database, to assist teams in } \\
\text { measuring peace-building and state- } \\
\text { building progress. The toolkit is an } \\
\text { interactive resource to help inform } \\
\text { strategic and operational results } \\
\text { frameworks and enhance practical data } \\
\text { collection efforts. } \\
\text { IFC Management is committed to } \\
\text { advancing and improving the framework } \\
\text { in FCV situations and believes that greater }\end{array}$ \\
\hline
\end{tabular}




\begin{tabular}{|c|c|c|c|}
\hline IEG Findings and Conclusions & IEG Recommendations & $\begin{array}{l}\text { Acceptance by } \\
\text { Management }\end{array}$ & Management Response \\
\hline $\begin{array}{l}\text { attention, especially since the } \\
\text { World Bank does have proven } \\
\text { technical expertise and positive } \\
\text { experience with such analysis. } \\
\text { The World Bank Group's focus } \\
\text { was limited on gender issues in } \\
\text { conflict-affected areas reviewed } \\
\text { by this evaluation: few } \\
\text { programs were designed or } \\
\text { implemented taking into } \\
\text { consideration gender disparities, } \\
\text { and the little analytical work } \\
\text { done was not translated into } \\
\text { operations. Weak monitoring } \\
\text { and evaluation (M\&E) } \\
\text { frameworks undermined the } \\
\text { assessment of results in many of } \\
\text { the cases observed, and } \\
\text { diminished the learning } \\
\text { potential from the projects even } \\
\text { when they were designed as } \\
\text { pilots. FCV factors were } \\
\text { generally reflected in project } \\
\text { design and during } \\
\text { implementation, but rarely } \\
\text { captured in results. }\end{array}$ & & & $\begin{array}{l}\text { flexibility, with room for adjustment } \\
\text { during project/program implementation, } \\
\text { would allow adapting to evolving } \\
\text { conditions. IFC has started to test this with } \\
\text { its FCS M\&E framework. }\end{array}$ \\
\hline $\begin{array}{l}\text { World Bank Group-United } \\
\text { Nations partnership was } \\
\text { particularly important in the } \\
\text { FCV context, as the United }\end{array}$ & $\begin{array}{l}\text { Develop institutional incentives } \\
\text { for collaboration and strategic } \\
\text { thematic guidance on } \\
\text { partnering - particularly with the }\end{array}$ & $\begin{array}{l}\text { World Bank, } \\
\text { IFC, MIGA: } \\
\text { Agree }\end{array}$ & $\begin{array}{l}\text { The World Bank Group will work with the } \\
\text { United Nations to further strengthen the } \\
\text { partnership in the following ways: } \\
\text { systematizing staff exchanges to increase }\end{array}$ \\
\hline
\end{tabular}




\begin{tabular}{|c|c|c|c|}
\hline IEG Findings and Conclusions & IEG Recommendations & $\begin{array}{l}\text { Acceptance by } \\
\text { Management }\end{array}$ & Management Response \\
\hline $\begin{array}{l}\text { Nations agencies have political } \\
\text { and security-related skills and } \\
\text { contacts that the World Bank } \\
\text { needs to leverage, and the } \\
\text { United Nations system is the } \\
\text { prime actor on the humanitarian } \\
\text { front. World Bank Group- } \\
\text { United Nations institutional } \\
\text { partnership was not systematic } \\
\text { and its frequency and } \\
\text { effectiveness varied across the } \\
\text { countries and themes. The } \\
\text { existing system did not } \\
\text { encourage building partnerships } \\
\text { because of perceived high } \\
\text { transaction costs, lack of strong } \\
\text { staff incentives, incompatibility } \\
\text { of the fiduciary and legal } \\
\text { frameworks, and competition } \\
\text { for influence and limited donor } \\
\text { resources. A more nuanced } \\
\text { strategic and technical dialogue } \\
\text { is needed to delineate respective } \\
\text { roles and comparative } \\
\text { advantages. }\end{array}$ & $\begin{array}{l}\text { United Nations but also with } \\
\text { other partners. Introduce } \\
\text { systematic communication and } \\
\text { staff exchange programs to } \\
\text { increase the level of } \\
\text { collaboration. }\end{array}$ & & $\begin{array}{l}\text { the complementarity of skill sets (such as a } \\
\text { recent collaboration with the United } \\
\text { Nations High Commission for Refugees in } \\
\text { situations of forced displacement); joint } \\
\text { analysis in conflict situations with the } \\
\text { United Nations and the European Union, } \\
\text { using a common methodology and } \\
\text { platform (Post-Conflict Needs } \\
\text { Assessments, for example); and regular, } \\
\text { institutionalized communication with the } \\
\text { United Nations through regular United } \\
\text { Nations-World Bank Steering Committee } \\
\text { and biannual Assistant Secretary General- } \\
\text { level meetings, and regular meetings with } \\
\text { the United Nations and European Union } \\
\text { in a High Level Advisory group, } \\
\text { established in February 2016. } \\
\text { IFC teams have been developing various } \\
\text { partnerships and exchange and } \\
\text { collaboration mechanisms with bilateral } \\
\text { and multilateral organizations that would } \\
\text { help IFC's support for FCV situations. }\end{array}$ \\
\hline
\end{tabular}




\section{Chairperson's Summary: Committee on Development Effectiveness}

The Committee on Development Effectiveness discussed the report of the Independent Evaluation Group (IEG) entitled World Bank Group Engagement in Situations of Fragility, Conflict, and Violence: An Independent Evaluation and the draft response by Management of the World Bank Group institutions.

The committee welcomed the evaluation and was pleased that Management broadly concurred with the report's findings and recommendations. Members noted the timeliness of the discussion in the context of the Forward Look, the 18th Replenishment of the International Development Association (IDA18), and the general reassessment of the World Bank Group's engagement model in fragile and conflict situations. The committee commended the engagement to date of Management of the World Bank Group institutions, acknowledging the implicit challenges to long-term development success in settings of fragility, conflict, and violence (FCV). Members highlighted the World Bank Group's response to the call of the IDA deputies for the World Bank to "innovate and do everything it can to be a critical implementation agent for achieving the 2030 Agenda." They welcomed the World Bank Group's progress in tackling FCV in middle-income countries more strategically, in consolidating the FCV cross-cutting solutions areas, and mainstreaming FCV strategy and knowledge into Global Practices and World Bank Group projects.

Members noted that success in FCV situations requires sound knowledge of local conditions and a deep understanding of the political context as well as of the drivers of violence and conflict; being responsive and agile to detect fragile situations at country and regional levels; and shifting resources and instruments into new priorities. They indicated that a better understanding of potential weaknesses and the challenges of remaining engaged would allow the World Bank Group to be more selective in its approach, despite potential operational, fiduciary, and reputational risks. The Committee supported mainstreaming a strategic, long-term approach that would include a new agile engagement model in these countries. Members acknowledged Management's effort to update its existing tools, such as the "Risk and Resilience Assessment" to assess impediments to country stability and sustainability. This new model would take into account political economy issues and include a multidimensional system for monitoring and diagnosing fragility and creating cross-cutting solutions for fragile and conflict-affected situations (FCS) and FCV, where possible. Members expressed concerns regarding the mismatch of 
available resources to address fragility challenges and inquired about the World Bank Group's prevention work.

Members urged Management to address the regional drivers of fragility, particularly with respect to disabling effects of cross-border spillover. They encouraged Management to address M\&E system weaknesses. They underscored the importance of integrating the new multidimensional publicly disclosed system for monitoring and measuring fragility into Systematic Country Diagnostics and Country Partnership Frameworks. Members stressed the importance of enhancing local institutional capacity and considering the potentialities offered by South-South knowledge exchange. They acknowledged the World Bank Group's strategic advantages and capacity to assist affected countries in the long-term development challenges, including in creating and consolidating legitimate institutions and strengthening governance.

Members underscored the need to develop innovative financing mechanisms and to leverage the use of existing instruments or fast-response facilities. They encouraged the International Finance Corporation (IFC) to move beyond the definition of FCS and incorporate FCV challenges into its strategy. They urged IFC and the Multilateral Investment Guarantee Agency to play more significant roles to attract and maintain private sector investment. The committee also highlighted the importance of building strong partnerships not only with the United Nations but with multilateral development banks (MDBs) and local institutions and underscored the importance of donor division of labor based on respective comparative advantages. Management informed the committee of ongoing progress including a joint study with other MDBs on migrations issues, and with the United Nations and think tanks on building sustainable peace and development. 



\section{Evaluation Context and Main Findings}

\section{Evaluation Objectives and Coverage}

Context. Fragility, conflict, and violence (FCV) are known to have significant adverse impacts on economic development and poverty levels. According to the 2011 World Development Report (WDR) on conflict, security, and development (World Bank 2011), countries that experienced major violence over the period 1981 to 2005 had poverty rates 21 percentage points higher than those that did not experience significant violence. The Institute for Economics and Peace estimated the cost to the world economy of containing violence at $\$ 14.3$ trillion in 2014, or almost 13.4 percent of global gross domestic product (GDP). ${ }^{1}$

The United Nations Sustainable Development Goals (SDGs) recognize the importance to human development of peace and effective governance, and SDG 16 proposes to "promote peaceful and inclusive societies for sustainable development, provide access to justice for all and build effective, accountable and inclusive institutions at all levels." This expansive goal implies that fragility is no longer seen as restricted to fragile states; in fact, fragility and violence affect nearly all states, and if all types of violence are included, in particular, organized criminal violence, FCV can be seen as primarily a middle-income country (MIC) problem.

The development community has often linked fragility and violence with a country's lack of development progress. However, instances of organized violence in MICs have recently exceeded those in low-income countries, suggesting that it is no longer primarily a LIC problem (Figure 1.1). Today, violence or the imminent threat of violence affect development outcomes for almost 2 billion people, 37 percent of whom live in higher-MICs and 37 percent in lower-MICs, with the remaining 25 percent in LICs. ${ }^{2}$

The commitments made at the Fourth High Level Forum on Aid Effectiveness (Busan 2011) included the "New Deal for Engagement with Fragile States". Although the document refers specifically to FCS, some of the New Deal principles are equally applicable to MICs. In particular, the document noted that achieving any substantial progress is unlikely without country ownership, leadership and inclusive political dialogue. It also called on development partners to work more transparently and make real progress in pooling their efforts in support of country leadership, while also using aid to strengthen and use country systems as much as possible with a view of building state capacities. 
The 2011 WDR was the first major piece of World Bank Group analysis to highlight the potential for severe fragility and violence in parts of countries that are not classified as, or considered to be, fragile. Although the WDR focuses on the development problems posed by lowincome "fragile states," much of its analysis and prescriptive advice is nonetheless applicable to MICs.

The impacts of severe and widespread violence with
Figure 1.1. Incidence of Conflicts in 1992, 2002, and 2012

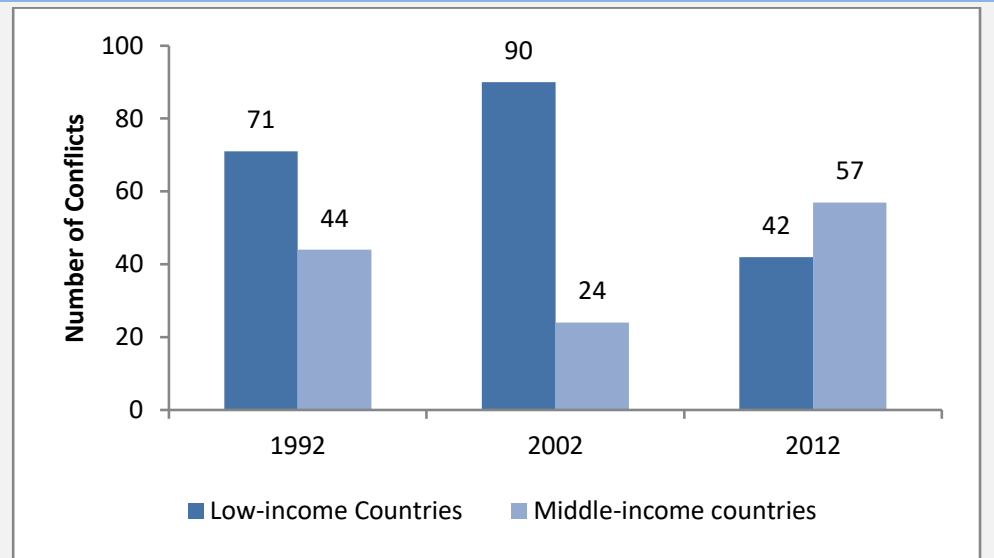

Source: The UCDP/PRIO Armed Conflict Dataset Version 4-2013; UCDP Non-State Conflict Dataset Version 2.5-2013; UCDP One-sided Violence Dataset Version 1.4-Decemer 2-013.

Note: The income group classifications applicable in 1992 and 2002 are used for data in corresponding years. The most recent classification (FY14) is used for 2012 data. Three types of incidences are included in the counting, including state-based conflicts, nonstate conflicts, and one-sided violence. If the location of a conflict is across two/three countries, the incidence is recorded for all the countries involved. destabilizing effects on a country are usually obvious and long-lasting. But violence that creates localized pockets of insecurity can also pose considerable local and national challenges. These situations may not always present an immediate threat to the overall stability of the country, but they do have far-reaching development consequences, harming the economy and resulting in loss of life, disability, and displacement.

Hence, helping country clients to address the challenges of organized violence is an important component of the World Bank Group Strategy (World Bank 2013) and will be essential to achieving its twin goals: to end poverty and promote shared prosperity. ${ }^{3}$ However, MICs are typically reluctant to engage in dialogue on subregional conflicts, and the World Bank Group, by virtue of its limited lending to these countries, has little leverage to push such engagement. Moreover, exiting from fragility and violence is complex and difficult to achieve and sustain. The 2011 WDR suggests that the high road to peace and prosperity is best approached through a consensual form of politics featuring inclusive political coalitions, credible signals of intent, and the development of accountable institutions. Desirable as this may be, it is the road less travelled in the early stabilization and recovery trajectories of lowincome fragile states, where the historical record show that post-colonial stabilization in low-income countries was frequently achieved through judicious admixtures of authoritarian governance and economic patronage. It can indeed be argued that the 2011 WDR's exit narrative has greater applicability in MICs, with 
generally more advanced institutions and higher capacity supported by emerging middle classes. However, MIC governments tend to consider such internal political challenges as outside the remit of the World Bank.

In 2014 the Independent Evaluation Group (IEG) undertook an evaluation of World Bank Group activities in LICs that were classified as fragile and conflict-affected (FCS). ${ }^{4}$ World Bank Group management has developed an implementation plan for the recommendations of that evaluation and implementation of the plan is underway. At the concept stage of that evaluation IEG agreed with management and the Board that it would be complemented by an evaluation of World Bank Group activities in countries not classified as FCS. This evaluation fulfills that request.

\section{Box 1.1. IEG Evaluation of World Bank Group Assistance to Low-Income Fragile and Conflict-} Affected States (2014): Main Findings and Recommendations

The evaluation examined the relevance and effectiveness of World Bank Group country assistance strategies and assistance programs to 'fragile and conflict-affected states' (FCS) over the period 2001-2012. Operations in FCS are more resource intensive and require customized operational approaches. Reforms in the World Bank's policies since 1997 led to enhanced financial and staff resources and greater managerial attention in FCS. As a result, portfolio performance in low-income FCS at the end of the review period was better than in low-income countries that were not FCS.

The evaluation found that the World Bank has been most responsive to FCS in the immediate aftermath of violent conflict. However, classification of FCS is not based on political economy and violent conflict risks, and country assistance strategies often lack realism and tailoring to those risks. Gender issues are increasingly integrated in sector programs, but Bank assistance has paid insufficient attention to conflict-related violence against women and economic empowerment of women in FCS. CDD has been a useful vehicle for short-term assistance in FCS but needs institutions to ensure program sustainability. The World Bank Group lacks a realistic framework for inclusive growth and jobs that is based on economic opportunities and constraints in FCS and effective coordination and synergies across World Bank Group institutions.

To enhance the relevance and effectiveness of its assistance to FCS, the evaluation recommends that the World Bank Group adjust its strategy, approach, and product mix by: developing a more suitable and accurate mechanism to classify FCS; tailoring country strategies to fragility and conflict contexts; providing support for state capacity building at national and subnational levels; enhancing the institutional sustainability of community development programs; addressing the effects of violence against women; developing a more realistic framework for inclusive growth and jobs; and adapting the business models, incentives, and systems of the International Finance Corporation (IFC) and the Multilateral Investment Guarantee Agency (MIGA) to the needs of FCS.

Source: IEG 2014. 
Objectives. The main task of this evaluation is to identify lessons from experiences in coping with FCV situations in countries not on the FCS list and to better understand how the World Bank Group can be effective in these situations. The cases of violence examined in this study have occurred in relatively affluent and stable countries with functioning systems of government. Thus, they ask questions of the widely accepted assumption still prevailing in non-FCS, that violent conflict is associated with a lack of development progress, and of the prioritization of economic interventions that flow from such an assumption. The World Bank Group and the development community as a whole are aware of this emerging challenge, as evident in their commitment to the SDGs, but a focused analysis of a wide set of cases of violent conflicts in otherwise nonfragile countries could help increase the robustness of the World Bank Group strategies and approaches.

This report does not aim to define the nature, drivers, and political economy of violent conflict, but draws on existing research and experience. Breaking recurrent cycles of violent conflict requires time, patience, and the contributions of multiple actors. Particularly in the MICs, the World Bank Group is often not the major player in these efforts, but it can nonetheless play an important role. This evaluation therefore focuses on the contributions that World Bank Group activities have made to creating positive solutions through the relevance and effectiveness of its activities.

Coverage and typology. There is no defined and widely accepted list of "non-FCS countries experiencing or threatened by major forms of FCV situations." This evaluation therefore aimed to select a representative group of MICs, by using the following criteria: (i) prolonged and widely publicized episodes of organized violence, with significant levels of fatalities and costs to development progress; (ii) presence of significant World Bank Group programs, including work related to FCV; (iii) different levels of income and institutional capability (IBRD, blend, and IDA); and (iv) a reasonable cross-section of different global Regions.

For the purposes of this evaluation, four dominant drivers of organized violence were selected. We do not intend to suggest that these were/are the only drivers present, nor that only one driver was present in each situation--in fact most sustained outbreaks of organized violence are driven by multiple factors. The intermingling of factors can be seen in the typology presented below. The categorization we have used is principally to allow for a more nuanced appreciation of the appropriateness, and effectiveness, of the remedial measures attempted by the World Bank Group. The four drivers selected are:

- Subnational (local) violence with a regional or ethnic identity marker, often involving prejudicial disputes over land and natural resources. A core issue 
animating rebellion in such instances is the reality of, or a perception of bias and injustice imposed by the State or by a more dominant identity group. The emotions stirred by such conflicts are often amplified when the ethnicity, geographical location, or religion of the affected group are easily defined or visible. This driver is a critical factor in violence in four cases in this report: the Philippines (Mindanao), Indonesia (Aceh), Uganda (the North), and Sri Lanka.

- Organized crime/drug trade-related violence. This is a dominant factor in Central and South America (represented by Colombia and Honduras in this report), where the expanding drug trade has fed an exponential growth in organized criminal gangs. The lawless violence thus created has been nurtured by perceptions of the illegitimacy of the state and its inability/unwillingness to address socioeconomic issues such as skewed land ownership and gross income inequality.

- Systemic failures of governance and an overall erosion of state legitimacy: Sustained failures of national and local governance, including widespread and visible corruption, have alienated broad swaths of the population from the "state project" and have encouraged forms of violence driven both by perceptions of unfairness as well as by opportunism in the face of ineffective state constraining mechanisms. This kind of violence is witnessed in cases that highlight problems in parts of Pakistan (Balochistan, Federally Administered Tribal Areas, and Khyber Pakhtunkhwa provinces), Nigeria (Delta) and Kyrgyz Republic (Fergana Valley).

- Overwhelming pressure from external political shocks. Some smaller middleincome countries can become inadvertent victims of a violent and unstable neighborhood that draws in forces beyond anything that individual governments can repel. Two such cases are reviewed: Lebanon and Jordan. Both are impacted by civil war in Syria and Iraq and the consequent influx of refugees, causing immense pressure on state systems and resources. The issue in these cases is not internal fragility per se, but rather the compounding effects of external pressure, and the impossibility of addressing the 'hosting' problem without significant external support.

\section{Main Findings}

This section summarizes the main findings of this report in a few broad crosscutting areas: World Bank Group strategic presence, instruments, sector engagement, and partnership modalities. 


\section{Evaluation Context ANd Main Findings}

World Bank Group strategic engagement and presence. The high incidence of violent conflicts in MICs with established institutions suggests that FCV is not primarily a low-income country problem and that impoverishment per se is only one driver of organized violence. Localized violence in relatively stable and economically successful countries poses particular challenges to World Bank Group engagement. MICs have in general been less receptive than many LICs to Bank involvement, given their ability to 'contain' subnational violence, and to manage the fiscal consequences of such violence. This places a greater premium on World Bank Group diplomatic skills, creativity, and appreciation of the local political economy in finding entry points that do not enervate political sensitivities.

Involvement in attempting to mitigate violent conflict has required the World Bank Group to trade away the benefits of demonstrating quick wins for the uncertain and sometimes costly process of addressing root cause issues, often from an oblique angle. It is often more attractive for the World Bank Group to engage where it believes it can achieve visible impact (emergency response) than in situations where the problems are more intractable. At the same time, World Bank Group emergency assistance, while important of itself, is unlikely to fundamentally alter the fragility profile of many, especially middle-income, countries, and its strategic comparative advantage remains in helping countries to tackle essential longer-term developmental challenges.

The World Bank Group's sustained strategic presence in all types of FCV situations, reflected in project financing, analytical work, and direct dialogue with wide array of stakeholders in conflict-affected areas (including ahead of the peace settlement, during ongoing violence, and after settlement) has been shown to be of critical importance. This presence can help to develop contacts and build credibility among the parties to the conflicts, and can have important payoffs once there is a peace settlement. Strong partnerships with local communities are important to ensure that the entire community and region are vested in the success.

Maintaining a presence (even nominal) in former conflict zones may be necessary to help sustain peaceful development, while abrupt exit following the cessation of hostilities could be detrimental to sustained peace and post-conflict reconstruction, given the often-weak institutional capacity in post-conflict situations and the high risk of resuming the conflict and violence.

Success in FCV situations requires excellent knowledge of local conditions as well as determination, commitment, and often plain courage on the part of Bank staff and local counterparts. In this context, continuity in staffing policy is very important, albeit not common in the cases observed. However, when it happened, the payoff was clear. For example, the transfer of many Bank staff who worked on conflict and 
violence issues in Aceh, Indonesia, to the World Bank's Philippines country office resulted in the effective transfer of knowledge and expertise that benefited the program in Mindanao.

Most of the time, the main drivers of violent conflict go beyond the boundaries of single countries, and require much broader, regional approaches, including regional projects or joint analytic and advisory work across the relevant countries.

World Bank Group instruments: An FCV environment can limit the choice of instruments available to the World Bank Group. In such situations, flexibility of project design and ability of management at various levels (project and country) to take quick decisions is particularly important.

Often relatively small and experimental operations can be highly relevant, particularly during the periods of extreme violence. Such operations can generate significant amount of new knowledge, as well as allow to gradually scale up at more peaceful times, and replicate the positive experience elsewhere. At the same time, such operations are often reputationally (as well as operationally) risky, time-consuming, and costly to implement. Specialized grant programs to top-up operational budgets for small pilot programs in FCV situations could be a way of dealing with it.

In some situations, finding alternative financing instruments has been a challenge for the World Bank Group. Helping Lebanon and Jordan to cope with the Syrian refugee crisis is a recent vivid example. The most easily available option of IBRD loans was quickly exhausted (and not particularly embraced by the governments), while the alternative sources and mechanisms (IBRD surplus, trust funds) were a far cry from the needs. An important lesson from this experience is that the World Bank Group needs to develop financial mechanisms or fast-response facilities to be used in similar situations, as well as use its global convening power more effectively.

Analytical and advisory work was relevant and generally of high quality, and often contributed to awareness and understanding of the issues and main challenges. Most of it was part of larger studies (often in partnership with donors), such as needs assessments, political economy analyses, and core economic diagnostics. These assessments helped to set the stage for subsequent reconstruction and development efforts and were widely used by the governments and the international community.

FCV-specific diagnostic work (fragility assessments, conflict filters) was generally useful and relevant, but not particularly common in non-FCS group of countries. Fragility assessments, in particular, are a useful tool, but there is no obligation for Bank staff to conduct them in non-FCS environments. Even when conducted, 
sharing them with client governments, or making them part of the broad country dialogue remains at the discretion of Bank management.

Public financial management (PFM) diagnostics - a clear area of World Bank Group comparative advantage - appeared to have been deployed in an ad hoc manner to look into issues of fragility and violent conflict in the reviewed sample, whereas their potential is much higher. The World Bank has both the mandate and the capacity to carry out reviews of fiscal decentralization and security sector budgeting and governance, and these core tools should be exploited more often than they have been.

One of the operational weaknesses observed across the board in many Bank projects in fragile and violent environments is the inadequate attention paid to the monitoring and evaluation (M\&E) frameworks - a deficit which has undermined the assessment of results and diminished the learning potential. Despite efforts to account for FCV factors in project design and implementation, they were rarely captured in results. Only a third of observed programs recorded fragility-specific outcomes, and only a quarter of them had M\&E systems specifically designed to track FCV issues.

World Bank Group definitions, measurement metrics, and policy application along the full spectrum of countries experiencing fragility and violence remain somewhat inconsistent (more pronounced in the non-FCS group). The CPIA index, despite its usefulness as a gross measure of fragility has many deficiencies if used as the main tool for assessing specific kinds of fragility or forecasting the risk of violent conflict. Moreover, the low-income country cut-off excludes MICs, where much of today's violent conflict is occurring.

Sector engagement: Within the reviewed sample, community-driven development (CDD) was by far the most popular type of intervention employed by the World Bank Group. While it did prove to be a useful entry point for the World Bank Group into the conflict-affected areas and a convenient tool for facilitating participation of local stakeholders, its impact on improving social cohesion and reducing the risk of violent conflict should not be overestimated, given that these projects were not designed as fora for addressing the causes and consequences of violence. The broader lesson is that the success of CDD projects in conflict resolution or mitigation is highly context-specific, and that these projects give the World Bank a placeholder - an opportunity to acquire the local knowledge necessary for more ambitious efforts at a later stage.

Creating opportunities for private sector development, generating employment and local entrepreneurial success can be important to making a peace settlement last. In this area, opportunities were sometimes missed due to the lack of coordination and 
communication between different parts of the World Bank Group, including IFC and MIGA, as well as lack of flexibility of World Bank Group instruments and inadequate staff incentives.

Support to the education sector can be important in dealing with issues of fragility, particularly as they pertain to psycho-social issues among children and providing safe spaces for integration and community cohesion to develop, countering radicalization, and dealing with the problem of "lost generations" in more protracted conflicts. The experience in Pakistan showed that even with small regional commitments and relatively high cost, implementation of nationwide education programs in fragile and violent environments, adjusted to local realities, can deliver important developmental outcomes and contribute to progress on conflict mitigation.

Partnerships. One of the comparative advantages of the World Bank Group in FCV situations is its ability to play convening role and generate and disseminate knowledge. World Bank Group engagement was most successful in situations of fragility and violence when it had catalytic impact - triggering scaling up and replication by the governments and other partners.

Partnership between the World Bank Group and United Nations agencies was of particular importance in the FCV contexts. Yet, the evaluation found that it was not systematic and its frequency and effectiveness varied across the countries and themes. The main factors negatively affecting such partnerships are perceived high transaction costs, lack of strong staff incentives, incompatibility of the fiduciary and legal frameworks, and competition for influence and limited donor resources at the country level.

Multi-donor trust funds (MDTFs) are a vital strategic tool in conflict regions, and they require a diverse and specific skill set. This includes the ability to liaise and interact effectively with donors, effectively link MDTF projects to other projects in the World Bank portfolio, establish, build, and maintain relations with regional governments in difficult circumstances, as well as the foresight to see how different project priorities can be made to serve with longer-term strategic planning.

\section{Report Structure}

This report consists of seven chapters. Chapter 1 lays out the context and structure of the report, and summarizes its main findings. Chapter 2 includes an overview of the World Bank Group strategic approach and instruments. Chapters 3-6 assess World Bank Group programs in response to four main drivers of FCV: 
subnational/ethnic violence, violence driven by crime and the drug trade, failure of governance and state legitimacy, and externally imposed fragility. Chapter 7 summarizes the main conclusions and recommendations.

The key outputs and building blocks of the evaluation are the case studies of World Bank Group activities in selected countries, complemented by cross-cutting thematic reviews. These studies were based on IEG's own research as well as interviews with the main stakeholders and participants in the field and at World Bank Group headquarters in Washington, DC. The evaluation covered 11 country cases (7 of which included field visits): Colombia, Honduras, Indonesia, Jordan, Kyrgyz Republic, Lebanon, Nigeria, Pakistan, Philippines, Sri Lanka, and Uganda. One of the main limitations was restricted access to some of the project sites and beneficiaries due to security concerns. In these cases, the team relied on secondary data and analyses. Another limitation was that due to time and budget constraints the study could only cover a relatively small sample of countries and situations, so the report is cautious to avoid over-attribution and hasty generalizations.

${ }^{1}$ Global Peace Index (Institute for Economics and Peace 2015)

2 Source: FCV CCSA. Also see appendix C.

3 While the 2013 Strategy acknowledges the effects of FCV on the development goals of LICs, it is silent on FCV in MICs.

4 "World Bank Group Assistance to Low-Income Fragile and Conflict-Affected States: An Independent Evaluation" (IEG 2014). 


\section{World Bank Group Strategic Engagement}

\section{Evolution of World Bank Group Thinking}

The understanding and discourse on violence in the World Bank Group has evolved over the years, reflecting the way that the World Bank is gradually becoming more comfortable focusing on the political economy of subnational violence and developing analytical and operations instruments to address it.

The evolution of the World Bank's involvement with organized violence dates from the 1990s when a Post-Conflict Unit (PCU) managed operational interventions using a Post-Conflict Fund (PCF). The concept of low-income countries under stress (LICUS) was also pioneered at that time, with a LICUS unit established within the Operations Policy and Country Services (OPCS) vice presidency, adding to the World Bank's analytical lexicon the notion that various stress factors could precipitate violent conflict. This risk was most strongly associated with LICs with weak institutions, and the World Bank found that sustained periods of policy and institutional weakness, as measured by the Country Policy and Institutional Assessment (CPIA) index, served as a useful predictor of violent conflict. The prevailing interest in the World Bank, the Organisation for Economic Co-operation and Development (OECD), and many bilateral agencies in the "conflict trap" afflicting several poor LICs led the World Bank to merge the PCU and the LICUS into a Fragile and Conflicted Affected Countries Department in 2007. At the same time, a separate stream of work had developed in the Social Development Department, especially in Latin America, focusing on interpersonal and criminal violence in MICs. These two streams of work proceeded relatively independently from one another. The PCF and LICUS Trust Fund were combined into the State and Peace-Building Fund (SPF) in 2008.

The 2011 WDR formulated an analytical framework for operations to address FCV, discussed further in the next section. The creation of a Global Center for Conflict, Security and Development (CCSD) in Nairobi was a specific outgrowth of the 2011 WDR. In retrospect, while placing operational staff near a quorum of the World Bank's "fragile states" clients made sense to ease operational support to task teams, it removed management of the Center from the Washington-based policy orbit. It also reinforced the notion that fragility was an African, LIC issue, which global developments in 2014-2015 have clearly refuted. ${ }^{1}$

Structural reorganization undertaken in 2013 attempted to elevate the place and role of FCV among the priorities of the World Bank Group. The establishment of FCV as 


\section{CHAPTER 2}

\section{BANK GROUP StRATEgIC ENGAGEMENT}

a cross-cutting solution area (CCSA) within the new organizational structure was supposed to reflect the high priority attached to this theme. The FCV CCSA was tasked with enhancing a systematic and coordinated approach to dealing with FCV across the World Bank Group and is responsible for providing advice to the World Bank's global practice (GP) units and support to country management teams. The Social, Urban, and Rural Global Practice (SURR) undertakes country social analysis as well as many operations that address conflict and violence. The FCV CCSA management was later relocated back to Washington with the rationale that proximity to decision-making processes would help in influencing the development of World Bank Group policy on fragility and violence. The most important issues that the FCV CCSA faces today are the degree of authority it should seek over operational policy, and how far it should involve itself in operational work.

\section{Box 2.1. 2011 WDR: Institutions and Legitimacy Matter}

The 2011 WDR developed an analytical framework that has been adopted by the World Bank Group in its work on FCV. The WDR reviewed about 40 countries' experiences in tackling deep-seated violent conflict over the past 60 years. It winds many complex and often opposing strands of political and economic research into a simple causative model - one in which the risk of organized violence is great when combinations of security, justice, and economic stresses encounter weak institutions. This model has relatively straightforward remedial implications: the restoration of sufficient stakeholder confidence to provide space and time to develop national institutions that are considered legitimate ("the causal relationship between weak institutional legitimacy and violence may be compared to the relationship between a human body's immune system and disease").

The 2011 WDR also stresses just how long it takes to create such institutions. The process is measured in decades, not project cycles, and it calls for new institutional behaviors and incentives. The report also shows how and why the temptation to pull the plug too early on difficult institutional support exercises needs to be resisted.

Many cases, including those covered in this report, show that the key to institutional legitimacy and staying-power is not technical excellence per se and its portability across contexts: it is the extent to which an institution is able to inspire trust. Although good performance is a vital aspect of legitimacy and can be influenced by example, much of what makes an institution responsive to local needs cannot be generalized. From this perspective, the 2011 WDR's support for "best fit" solutions over the pursuit of illusory "best practice," with context taken as the starting point, is fully consistent with this evaluation's findings. This underlines the importance of local knowledge and contextual understanding.

The 2011 WDR distinguishes between 'internal' and 'external' stress factors - internal stresses being those that emanate primarily from the dynamics within a particular society, and external stresses referring to pressures that arise from regional or global interests and developments. This distinction counteracts a common under-emphasis in academic and 
policy literature on the extent to which powerful external forces can determine the fate of smaller and more vulnerable countries. This is important when looking at violence in MICs -- though 2011 WDR country cases show that countries with capable national institutions have often managed external security stresses better than countries where elites and factions depend excessively on competing external actors for support and validation. A key residual question, though, is how organizations with multifaceted mandates and constrained budgets, like the World Bank Group, can achieve an acceptable balance between granular local adaptation and insights with 'global' applicability.

Source: World Bank, IEG

\section{Definitions and Measurements of Fragility}

Moving on from the CPIA. The FCV concept in the World Bank Group has hitherto been associated with LICs. The current system of classifying countries as fragile and conflict-affected states relies heavily on the CPIA index, and excludes IBRD-only countries (for which CPIA scores are not disclosed).

The World Bank currently identifies FCS as those countries or territories that present a very weak policy and institutional framework, signified by a CPIA score below 3.2, or countries with the presence of the United Nations or regional peace-keeping or peace-building mission during the past three years. The 2011 WDR comments favorably on the way in which the CPIA is a good predictor of FCV: it does a good job of capturing the efficiency and equity of economic policy, the delivery of public services and the quality and transparency of government -- but is one-dimensional on security (the state's ability to protect citizens and property from crime and crimerelated violence are assessed) and even more deficient on social inclusion (gender equality alone is assessed) and justice (restricted to the equity of public resource use). It is also a static measure and has no real predictive capacity. The LIC cut-off excludes MICs, where many of today's FCV situations are occurring. The aggregation of the indicators into one composite score can obscure serious or potential violence if there is strong performance along other performance axes; using the country as the unit of account may not capture subnational, cross-border, or supranational forms of stress and violence; and the destructive potential of specific kinds of short-term shocks is not brought out by the incremental scoring method used in the CPIA.

The 2014 IEG evaluation observed that relying on CPIA ratings to determine FCS status results in considerable errors of exclusion and inclusion in FCS classification. It recommended that the World Bank Group develop a more accurate mechanism to define FCS status, one that integrates indicators of conflict, violence, and political 


\section{CHAPTER 2}

\section{BANK GROUP StRATEgIC ENGAGEMENT}

risks within the current system. The 2015 OECD fragile states report, moreover, highlights the need for a more suitable descriptive and predictive framework than the Harmonized List's single measure of fragility, proposing the use of an index consisting of five measures of vulnerability (vulnerability to violence, injustice, illegitimate institutions, weak economic foundations and poor social resilience). Considering the 2014 IEG recommendation, World Bank Group management has committed to reviewing the criteria for FCS classification.

At the time this report was being finalized, the FCV CCSA was finalizing a system that assesses policy and institutional risks using clusters of revised CPIA measures (CPIA flags) applied to all countries irrespective of income level, and quantifies undesirable economic and social outcomes. A multidimensional marker system of this kind would deliver much more nuanced results and would permit a degree of prediction that the current CPIA does not. At the same time, the new "flag and outcome" system will have a much-diminished impact if it cannot be published and tracked openly.

The case for tracking fragility and the risk of violence more systematically in MICs is compelling: the impact of severe and widespread episodes of violence on 'non-FCS' significantly impacts their ability to reduce extreme poverty and increase shared prosperity, and this fact argues for the adaptation of analytical and operational tools that have been used successfully in FCS. At times, violence creates localized pockets of insecurity that pose considerable local and national challenges. These incidences may not always present an immediate threat to the overall stability of the country, but they do have far-reaching development consequences, harming the economy and resulting in loss of life, disability, and displacement.

Fragility Assessments. As part of the IDA 17 process, World Bank Group management committed to ensure that all Country Partnership Frameworks (CPFs) prepared in IDA FCS during the IDA 17 period will be informed by analysis of drivers of fragility and violence. This was reinforced by the 2014 IEG evaluation. For non-FCS (including IBRD) it has been at the discretion of the World Bank country management whether an FCV lens is used to help to address some of the key impediments to poverty reduction and shared prosperity, such as institutional fragility, urban crime and violence, terrorism, or subnational conflict. In the countries reviewed by this evaluation, most of which are IBRD borrowers, fragility assessments were prepared in three cases: Colombia, Kyrgyz Republic, and Nigeria. This section of the report briefly discusses the utility of such assessments, and particularly in the non-FCS and MIC context. 
According to a guidance note ${ }^{2}$ for preparing fragility assessments, the purpose of the assessment is to identify the underlying causes ("drivers") of fragility and violence, understand the capacity of institutions to manage them, and recommend how the World Bank can address the identified drivers. The note allows for a flexible format and content - the objectives, scope, timeframe, and resources required for a fragility assessment are to be defined by the Country Management Unit (CMU). Most commonly the assessments have been undertaken in tandem with the preparation of a Country Program Strategy. Under the new Country Partnership Framework (CPF) model, the fragility assessment is supposed to supplement the Strategic Country Diagnostic (SCD) and thereby contribute to the CPF.

The guidance makes a notable observation which clarifies that fragility and violence are not just a LIC/'fragile states' issue: "SDG 16 proposes to 'promote peaceful and inclusive societies for sustainable development, provide access to justice for all and build effective, accountable and inclusive institutions at all levels.' Such an encompassing goal implies that fragility is no longer seen as pertaining only to fragile states; in fact, FCV affects nearly all states; (different types of violence are included, many middle-income countries now top the list of countries affected)". The Note also stresses that political context matters and encourages an explicit discussion of elite motivations and understanding of political settlements. It broadens the 2011 WDR's emphasis on stress factors by insisting on the need to focus on resilience and institutional capabilities. It also introduces the possibility of subnational or supranational ("regional") fragility assessments. The flexibility of the assessment format is another commendable suggested feature: if the context does not support it, there is no need for a formal report.

At the same time, the utility of such assessments in non-FCS environments is somewhat undermined by two factors: (i) that it is at the discretion of the CMU in non-FCS environments as to whether such a diagnosis should be undertaken or not and (ii) that the World Bank is not obliged to share the results of the fragility assessment with client governments. It is not surprising, that the list of countries in which fragility assessments have been carried out over the past three and a half years includes only a handful of non-FCS. It is also noteworthy that the majority of these assessments (FCS and non-FCS) have not been discussed with the governments, and have not been made public.

\section{Box 2.2. Conflict Filter Application in Kyrgyz Republic}

In 2010 a violent overthrow of the ruling regime in Kyrgyz Republic caused a collapse of the government and led to an outbreak of inter-ethnic violence that caused hundreds of deaths, widespread damage, and displacement of an estimated 400,000 people. Most 


\section{CHAPTER 2}

\section{BANK GROUP StRATEgIC ENGAGEMENT}

refugees and internally displaced people returned home within the same year as violence subsided.

The World Bank co-led a multi-donor Joint Economic Assessment: Reconciliation, Recovery and Reconstruction (JEA) that indicated that the key drivers of conflict were not just interpersonal ethnic animosities but also national government policies. Earlier Bank projects in the conflict area did not mention ethnic tensions and potential for violence. Later, in acknowledgment of the changed circumstances, the World Bank approved additional financing and restructuring of an urban infrastructure project. The implementation and supervision plans included use of the conflict filter matrix to ensure adequate attention to social and conflict risks

The conflict filter was a screening tool that aimed to make sure that any Bank activity distributed benefits among ethnic and social groups in a way that seemed fair and would not exacerbate conflict situations. It aimed to provide information and guidance to improve the design of projects to mitigate the risk of violence and strengthen social cohesion. The objectives of the conflict filter were to make task teams more cognizant of the context in which they operate and assist the teams in identifying and managing the conflict and fragility risks. The conflict filter sought to identify and then avoid doing activities - lending and nonlending - in ways that might do harm by stirring up ethnic animosities.

A study by International Alerta reviewed Asian Development Bank (ADB) and World Bank urban projects in the city of Osh, where both organizations financed housing projects for post-conflict areas - the World Bank using the conflict filter and ADB without looking systematically at the ethnic distribution of benefits. While the ADB project experienced some vandalism, delays, and higher cost, these did not happen with the World Bank-financed project, the extension of which was implemented using the conflict filter. The International Alert evaluation gave credit for the better outcomes to the use of the conflict filter.

The Kyrgyz case shows that the World Bank can, at reasonable cost, gather information about the fault lines of potential conflict and design activities to bridge those fault lines rather than exacerbate them. This fairly simple and inexpensive tool seems to be most useful in the aftermath of relatively short and recent conflicts. Its application in other contexts, such as Sri Lanka, where the conflict was much more protracted and stayed unresolved for a very long time, was found to be less useful by the country teams.

Source: World Bank, IEG.

a. Fragile Reforms: World Bank and Asian Development Bank financing in fragile and conflict-affected situations." International Alert, 2014.

\section{World Bank Group Strategic Approach}

This evaluation reviewed World Bank Group programs in mainly IBRD borrower countries, where the nature and modality of engagement are generally different from those used in FCS. MICs are normally less aid-dependent, and are less likely to engage in dialogue on the sensitive political issues associated with subnational 
conflicts. World Bank Group strategies in these countries reflected this the more limited role that the World Bank Group is therefore able to play in tackling organized violence, and the World Bank objectives in the conflict zones depended heavily on what the governments were willing to allow.

The theme of conflict and violence - and especially "localized conflict" - started appearing in Bank strategies as a separate pillar (or subpillar) relatively recently, in the past 5-7 years. Earlier Bank strategies acknowledged the presence of the problem, but were either silent about any response or explicitly noted that the World Bank will be staying away. For example, the Indonesia 2001-03 CAS does refer to Aceh as one of four provinces with serious violent conflict, but it notes that the World Bank does not foresee taking a leadership role there. Colombia was a notable exception, where the 1997-2002 CAS introduced a specific pillar to address violence, acknowledging that this was a new and much riskier area of involvement, but the World Bank could no longer stay on the sidelines.

The 2011 WDR was a game changer in this respect. The theme of violent conflict, including subnational conflicts, becomes increasingly prominent in many country strategies, some of them quoting the 2011 WDR as the guiding analytical document for engagement in FCV situations. At the same time, the institutional and staff incentives for such engagement and the risk-taking associated with it continue to lag the spirit of the World Bank's strategic approach.

World Bank Group strategies generally pursued two broad objectives in relation to serious organized violence: addressing, or mitigating the impact of drivers of violent conflict. Mitigation activities at the local level (supporting communities and local institutions) were often the starting point. Concerns about security during the active conflict phase often limited the World Bank presence in the field to essential personnel, but Bank staff were often able to develop rapport and trust at the local level and effectively supervise projects, especially the CDD. The World Bank continued CDD projects in areas of ongoing conflict in Aceh, Mindanao, Sri Lanka, and nNorthern Uganda. In the end, such early engagement was relevant and useful for laying the foundation for post-conflict engagement.

World Bank Group strategies were generally supported by comprehensive analytical work, most commonly represented by diagnostic studies that identified the main drivers of conflict and violence for ongoing conflicts, or comprehensive post-conflict needs assessments.

One of the objectives of the new country engagement model (SCD/CPF) is to improve Bank-IFC cooperation, including through joint identification of needs, 


\section{CHAPTER 2}

\section{BANK GROUP StRATEgIC ENGAGEMENT}

shared assessments, and collaboration on projects. Among the cases reviewed were some promising initiatives in this direction, but they appear to be the exception rather than a norm. Engaging in FCV situations in non-FCS and MICs presented a distinct set of challenges and opportunities for IFC. Overall, IFC engagement on FCV in the reviewed cases was limited, almost exclusively focusing on post-conflict reconstruction.

\section{Gender in Bank Programs}

Conflict-affected areas posed both common and area-specific challenges on gender issues. Common themes included displacement, restricted mobility, an increase in the number of war widows and female-headed households, and psycho-social impacts of witnessing violence. Country-specific gender-based challenges were also common, such as targeted destruction of schools and health facilities in northwest Pakistan; human trafficking of young women and children in displaced communities in the ARMM region in the Philippines; forced marriages ("war wives") in Northern Uganda; war widows without access to adequate resources, housing, or vocational skills in the northeast of Sri Lanka; and high rates of rape and domestic violence in displaced populations in Colombia.

With few exceptions, World Bank Group country strategies did not focus on genderbased challenges in a conflict context until the latter half of the evaluation period (2010 onwards), and some crucial gender issues (such as forced marriages by the Lord's Resistance Army (LRA) in Uganda, acts of violent extremism targeted on keeping women away from schools and the workforce in Pakistan) were not mentioned in the strategies throughout the evaluation period.

The majority of Bank-supported nationwide projects were not gender-responsive in design or implementation in regions of subnational conflict. For example, even though Pakistan Poverty Alleviation Fund (PPAF) I, II, and III have operated in conflict regions like Balochistan, Federally Administered Tribal Areas (FATA), and Khyber Pakhtunkhwa (KP), the PPAF work has been retrofitted into the conflict situation rather than conflict-related issues (on security, mobility, women-headed households, etc.) being addressed specifically in the project design and implementation phase. The Pakistan Social Safety Net Program (which also includes the Benazir Income Support program) has a women's empowerment emphasis since it disburses cash only to female representatives of eligible families, but does not address the gender-based challenges in pockets of fragility and conflict.

CDD approaches have dominated work on gender issues in conflict-affected areas, where women's role in decision-making remains limited. Other sectors such as 
health, education, employment, agriculture, and social protection have not focused on gender issues.

Analytical work (AAA) on gender and conflict was sparse. In cases where it existed, it was not always translated into operations. The Philippines is one of the few countries that included gender and conflict-related AAA work during the evaluation period. The Philippines ARMM Human Development Sector Study suggested that more boys drop out of school in their early teens than girls, and observes that early dropout rates of boys may itself feed the supply of boys who take up arms. ${ }^{3}$ However, there were no follow-up programs that work with youth who are dropouts and had taken up arms or were ex-combatants.

Overall, the World Bank Group's focus on gender issues in conflict-affected areas reviewed by this evaluation was limited. In particular, few programs were designed or implemented taking into consideration gender disparities in conflict-affected areas, and the little analytical work on these issues was not translated into operations.

\section{Collaboration and Partnership With THE United Nations}

In recent years, demand for collaboration between the World Bank Group and United Nations agencies has grown. Such partnerships are particularly important in the FCV context, as the United Nations agencies have political and security-related skills and contacts that the World Bank needs to leverage, and the United Nations system, as the prime global actor on the security and humanitarian fronts, is almost always present where there is a serious conflict. As a growing number of MICs now face violence and crises, both the World Bank Group and the United Nations face challenges in responding to them. Neither of them is ready to tackle those challenges alone, as most of the intervention tools are not effective on their own.

Within the World Bank Group, the FCV CCSA is the lead focal point on global FCV partnerships, including the relationship with the United Nations. In the United Nations system, the responsibilities for FCV are shared widely. Citizen security, rule of law, and justice are largely the domain of the United Nations Development Programme (UNDP). The recent surge of violence and forced displacements increased the demand for stronger collaboration by the World Bank Group with United Nations agencies with humanitarian mandates, such as the United Nations High Commission for Refugees (UNHCR) and World Food Programme (WFP).

Mechanisms of collaboration. Country-level cooperation in observed cases was context-specific and ranged from information sharing in donor coordination forums to joint programmatic, operational, and analytic work. Operational partnership was 
CHAPTER 2

Bank GROUP StRategic EngagemEnT

often not easy to initiate because of the difficulty of cross-funding. The value added of this type of partnership in MIC countries was often small and had limited impact.

Analytical work often included joint economic and social impact assessments (ESIAs). In several countries, these assessments informed strategies and plans and paved the way for operational partnership, joint analytical work, and better alignment of programming efforts. Joint thematic analytical work was particularly valued as an area where the division of labor between the World Bank Group and partnering United Nations agency was clear, contributing to the success and uptake of those studies (Philippines Mindanao, ${ }^{4}$ Jordan, and Lebanon ${ }^{5}$ ).

Operational cooperation often meant the World Bank contracted a United Nations agency to implement activities in which the latter had clear comparative advantage. Collaboration between the WFP, UNHCR, and World Bank in Lebanon, within the framework of the National Poverty Targeting Program, was an example of introducing good practice solutions from humanitarian partners. The e-card program established a reliable channel to support vulnerable Lebanese and refugees and it is hoped that the government can scale it up for conditional transfers in education and health.

Examples of successful programmatic collaboration were limited. One of them was in Lebanon, where the World Bank and the United Nations Children's Fund provided a concerted response to the emergency and development needs in the education sector. ${ }^{6}$ A promising collaboration in Kyrgyzstan - the Joint Country Support Strategy (JCSS 2005) - never realized its full potential. The partners prepared a joint background analysis and results framework but had their own programs and implementation plans. It was a transaction-heavy undertaking that was challenging to implement.

Country-level MDTFs were effective tools for coordinated and timely international response and helped share the risks associated with operating in post-crisis environment. The Mindanao MDTF supported community-driven reconstruction and has successfully evolved into a facility supporting capacity building of the partner institutions. The United Nations-World Bank FASTRAC Facility in Mindanao is another smart transitional solution to support capacity building based on the different mandates and comparative advantages of the World Bank and the United Nations (see chapter 3).

Overall, cooperation between the World Bank and the United Nations followed the key principles of partnership, such as flexibility to respond to different country needs, appropriate division of labor, and recognition of the role of other regional 
and international partners. However, the existing system did not encourage building such partnerships, and the incentives to collaborate across institutions were not strong. While the benefits of effective partnership are clear, going an "extra mile" in partnership is not rewarded. Missed partnership opportunities may be visible only at the country level and are rarely noticed.

The cases reviewed by this report also offer some good examples of collaboration. These success stories can be attributed to the changing nature of challenges that required more multidisciplinary approaches, as well as the entrepreneurial skills and efforts of the World Bank and United Nations field staff that saw mutual benefits in collaboration and were willing to take the risks.

\section{World Bank Group Engagement Areas}

This section provides a brief overview of selected approaches and themes covered by the World Bank Group in FCV situations reviewed by this evaluation. It includes the World Bank Group's private sector development agenda (engagement in the public sector, which comprised the bulk of World Bank Group support, is covered in detail in chapters 3-6); PFM, and in particular, various diagnostic tools, as applied in FCV context; and CDD approach - the most common operational model applied by the World Bank Group in FCV situations.

\section{Private Sector Development}

The vulnerabilities caused by underdevelopment and unemployment are commonly recognized as a major driver of conflict (2011 WDR). There is also increasing recognition of potential contribution that private sector development (PSD) could make to the peace-building effort by strengthening economic foundations needed for sustainable growth. ${ }^{7}$ In the FCV context, jobs not only can provide people with livelihoods but also reconstruct the fabric of society. The private sector can reduce fragility by creating jobs, enabling economic opportunities, and supporting livelihoods but it needs nurturing, support, and engagement from the outset. ${ }^{8} \mathrm{~A}$ legacy of violence and conflict includes particular severe challenges for both private investments and private firms' operations, as it led to deterioration in trust and linkages between firms as well as in the infrastructure needed to access markets.

The 2014 IEG evaluation found that the World Bank Group had difficulty developing and implementing a PSD strategy that would be effective in the challenging environment of FCV situations. Specifically, the 2014 evaluation concluded that the World Bank Group "lacks a realistic framework for inclusive growth and jobs that is based on economic opportunities and constraints in FCS and 


\section{CHAPTER 2}

\section{BANK GROUP StRATEgIC ENGAGEMENT}

effective coordination and synergies across [World Bank Group] institutions... The World Bank Group did not adequately address major constraints and did not have a holistic approach to private sector development in FCS." This evaluation concurs with that conclusion. The World Bank Group still lacks a holistic and sequenced approach to private sector development in FCV situations in non-FCS, and its interventions that addressed the PSD agenda have been limited, with very few successful examples of cooperation across the World Bank Group.

The main support for the PSD agenda was delivered through CDD-type projects. Projects in Colombia and Indonesia (Aceh) aimed at boosting activities of small farmers in the conflict-affected areas. Other CDD projects supported small infrastructure (rural roads, etc.) that have broader benefits for PSD. In the Niger Delta, a Bank-supported project (SEEFOR) provided financing for a youth employment scheme (see chapter 5).

However, these projects did not include investments in small businesses. In other words, the primary focus of the World Bank efforts was on direct support to livelihood and short-term employment schemes, with rather questionable prospects for longer-term sustainability. This finding is similar to the conclusion of the 2014 IEG evaluation. At the same time, the scale of the problem ("inadequacy of efforts to support PSD") seems to be even more pronounced in cases covered by this evaluation, where the country risk heterogeneity is higher than in the countries on the FCS list. Many countries reviewed (in particular the larger ones, such as Indonesia and the Philippines) include, along with the high-risk conflict-affected areas, large territories with much lower investment risks and better investment climate (compare Mindanao and Manila), which attract most of World Bank Group PSD-related activities.

IFC engagement in the reviewed cases almost exclusively focused on post-conflict support during reconstruction, reflecting the difficulty and perception of high risk when operating in FCV situations, but also revealing lack of institutional staff incentives and corporate targets in the FCV context outside of FCS. It is worth noting that engaging in FCV situations presents a distinct set of challenges and opportunities for IFC. Specifically, IFC has taken very seriously the issues associated with compliance by potential local clients with the institutional integrity requirements, based on carrying out a detailed Integrity Due Diligence (IDD). More often than not, IFC decided not to proceed with its project financing due to concerns over IDD issues or other FCV-specific factors. ${ }^{9}$

In several cases IFC engagement has had a significant positive impact. The most prominent of them is IFC's post-tsunami support in Aceh, Indonesia, where IFC 
carried out an investment climate diagnostic. Based on this diagnostic, IFC and Agency for the Rehabilitation and Reconstruction of Aceh and Nias (BRR) jointly developed an investment climate and promotion strategy for the region, including drafting a new investment policy, establishment of the investor service center, and provision of training programs. IFC supported implementation of these efforts with its advisory services. Even in Aceh, however, scaling-up IFC support remains a challenge as witnessed by a large number of memoranda of understanding (MOUs) with private investors that have not been transformed into actual IFC investments.

In Sri Lanka, IFC was able to encourage its partner financial institution to expand business in the conflict-affected region of the country by offering both investment and advisory services to the client bank. ${ }^{10}$ In the Philippines, the Mindanao advisory project with Unifrutti, launched in 2008, is a good example of IFC-Bank collaboration, where the World Bank funded related infrastructure projects, such as farm-to-market roads and bridges (see chapter 3). IFC's engagement with Unifrutti also underscores an importance of long-term client engagement in FCV situations.

In most country cases reviewed, IFC has deployed its standard instruments with little adaptation to FCV circumstances or innovation. It is questionable, however, whether the standard investment strategy and operational model of IFC are appropriate in FCV situations. In contrast, IFC has adjusted its standard approach for its work in the countries on the FCS list and succeeded in increasing its business volumes in this group of countries for both investment and advisory services. In October 2015, IFC updated its investment policy in FCS by eliminating the restriction on processing smaller long-term investments (less than $\$ 10$ million) that fall outside of IFC's standard risk criteria. Regardless of the investment size, IFC can now consider investments with higher risks in FCS by assuming more risks that it normally does. In addition, IFC has set up a specific allocation of its economic capital dedicated exclusively to investments in FCS, and increased its capital allocation to $\$ 200$ million from $\$ 70$ million. Similarly, based on the Aceh experience, there was a discussion within IFC team about making specific adjustments to the IFC strategy and operation rules in the post-conflict environment, including considering making smaller investments, de-linking advisory from investment, reassessing the product mix, and adjusting general investment standards. It is not clear, however, if any of these options were pursued and turned into a policy change or a revised instrument in FCV situations.

MIGA's political risk insurance (PRI) products can help facilitate foreign direct investment when a country, or a part of it, faces FCV situations. In recent years, MIGA has been able to increase its role in addressing various risks for investing in FCS countries. ${ }^{11}$ Similar MIGA's activities could be useful in non-FCS countries 
facing FCV situations by offering one or a combination of its four insurance coverages under PRI (currency incompatibility and transfer restriction, expropriation, breach of contract, and war and civil disruption). Among these products, war and civil disturbance (WCD) coverage and the recently introduced non-honoring of sovereign financial obligations (NHSFO) coverage are perhaps the most relevant to the FCV circumstances. In recent years, MIGA has strengthened its due diligence process by incorporating conflict dimension into its standard risk analysis. This improvement, however, so far has applied mainly to FCS countries through the MIGA's Conflict-Affected and Fragile Economies Facility, whereas they could also be fully applicable to FCV situations in non-FCS countries. The MIGA staff should be encouraged to broaden the use of this innovation.

\section{Public Financial Management}

Bank teams have often used PFM diagnostics to provide inputs to development strategies in FCV context. These included expenditure, institutional, and regulatory analyses that assessed the efficiency and level of expenditure allocations, quality of underlying PFM institutions, robustness of intergovernmental fiscal arrangements, and related subjects.

Expenditure analysis for post-conflict reconstruction strategy. The Aceh Public Expenditure Analysis (2007) presented a picture of major fiscal gains from increased autonomy, granted to the region earlier, while showing that these additional allocations did not lead to improvements in service delivery and poverty reduction. Stakeholders interviewed by IEG gave the report considerable credit for guiding the recovery and reconstruction effort. The Public Expenditure Review for Northern Uganda (NUPER, 2007) provided a comprehensive picture of overall public financial flows, both off- and on-budget, being disbursed to the North. This was considered a critical input to finalizing the government's post-conflict strategy-Peace, Recovery, and Development Plan (PRDP). Similarly, in Pakistan the World Bank's KP provincial Public Expenditure Review (PER 2013) was one of the important outcomes of regional Post-Crisis Needs Assessment.

Analysis of horizontal fiscal inequality. One of the common drivers for regional conflicts relates to the perceived unfairness in distribution of national resources, especially of public expenditures, across the regions. In Uganda, the 2007 NUPER found that per capita fiscal flows are the same to the North as they are to other regions. This finding was politically important as it suggested that there was no evidence of discrimination against the North. Similarly, in Indonesia the PER (2007) did not find any evidence that the central government treated Aceh fiscally unfavorably. According to the report, Aceh's poverty reduction has been lagging not 
because of insufficient funding, but largely due to institutional bottlenecks, including inadequate capabilities and incentives of local governments. In contrast, in the Philippines the PER (2011) showed that public spending per capita is lower in the ARMM region than elsewhere, particularly for human development. The PER concluded that after two decades of decentralization, regional inequality in revenues and expenditures, living standards, and access to public services remains stark and in critical aspects has been growing.

Analysis of public expenditures in the security sector. The World Bank has traditionally abstained from the analysis of national security arrangements. In the country programs that were the focus of this evaluation no such analysis has been undertaken so far. However, by now the World Bank has accumulated important and innovative experiences of policy analysis in this sector. Most of the World Bank's expenditure analysis in the security sector so far has been concentrated in low-income FCS. The PER for Guatemala (2012) represents a relatively rare example of in-depth review of security arrangements in MICs that have been facing elevated security risks. The PER provided an assessment of both the level and quality of public expenditures related to the security sector, complemented by institutional analysis of the sector's governance arrangements. The report concluded that the existing level of expenditures was low for the size of the problem and provided a set of recommendations aimed at improving efficiency of spending within the existing budget envelope. This type of Bank analysis would have been applicable and useful in many countries reviewed by this evaluation.

Strengthening intergovernmental fiscal arrangements. Issues of regional autonomy and subnational control over resources have been among the core drivers of conflict in many countries, including a few covered by this evaluation. The World Bank has recognized that redesigning intergovernmental fiscal relations in FCV situations could be an important element of post-conflict risk mitigation strategy. Resource allocation that is seen as fair and politically sensitive can alleviate the conflict. ${ }^{12}$ However, the programs reviewed for this report contained only a few examples of policy advice on decentralization arrangements in the conflict-affected areas. There has been no common approach to the decentralization agenda across the country programs within the sample reviewed. The analysis usually did not represent the core of the respective programs and was done on a case-by-case basis with no sustained follow-up over the medium term. Thus, NUPER (2007) carried out a detailed examination of the central government's system of fiscal transfers to local governments in Northern Uganda and provided recommendations to address the system's weaknesses. But the World Bank did not follow up on this work through another study to analyze the latest developments and it therefore remains unclear how many of the recommendations were implemented by the government. 


\section{CHAPTER 2}

\section{BANK GROUP StRATEgIC ENGAGEMENT}

The most prominent example of World Bank Group advisory support on decentralization in FCV situations in the sample comes from Mindanao, where the World Bank helped to design decentralization arrangements for the newly established Bangsamoro Autonomous Region. Under the Facility for Advisory Support for Transition Capacities (FASTRAC), the World Bank supported the policy dialogue related to the implementation of the Peace Agreement, including allocation of responsibilities across various governments in particular sectors. However, decentralization of advisory support in Mindanao still was quite modest compared to other better-funded and higher-profile decentralization programs run by the World Bank (for example, the Decentralization and State-Building Program in Yemen, 2012-14).

At the same time, in several countries covered by this evaluation, the World Bank conducted the traditional, high-profile and generally high-quality analysis of the existing system of intergovernmental fiscal arrangements. These include PERs for Philippines (2011) and Uganda (2013). However, these reports were prepared outside of Bank's FCV strategies as their diagnostics and recommendations were not intended to address political issues of regional tensions and longer-term conflict. This is somewhat unexpected, given the wealth of expertise accumulated by the World Bank in this area, and the importance of regional autonomy and fiscal decentralization for addressing actual or potential violence.

PFM diagnostics as an entry point for engagement: The Nigeria program is a good example of the use of PFM diagnostics as an entry point for engagement. In the Delta, a general failure to provide adequate governance has been one of the core drivers of conflict. The 2005 Country Partnership Strategy (CPS) for Nigeria linked the possibility of direct state-level lending to demonstrated commitment to the reform through Bank-led PFM diagnostics and state governments' decisions to address identified weaknesses. For the Delta states the CPS emphasized actions to strengthen the demand side of governance reforms - supporting public-private dialogue and growth of coalitions around management of oil resources within the framework of the Extractive Industries Transparency Initiative. The World Bank's Public Expenditure Management and Financial Accountability Reviews (PEMFARs), based on which the states prepared reform action plans, created enabling conditions for direct Bank lending to Delta states.

The above strategy has been consistently followed over the last decade, but the implementation has been quite slow and so far did not bring conclusive results, in part due to slower than expected build-up of state commitment. The CAS Progress Report (2011) admitted that progress in governance at the state level had been slow. The State Employment and Expenditure for Results (SEEFOR) project was approved 
in 2012 to assist, under its PFM component, four states in the Delta to advance their governance reforms and capacity building in public finance. The recent (2014) CPS Completion Report acknowledged some progress on state-level PFM under the SEEFOR, especially in public procurement. In several aspects, the World Bank program in Nigeria Delta could be seen as an example of governance-centered conflict-responsive lending, illustrating major associated risks and costs.

Institutional strengthening of local governments. One of the lessons learned by the World Bank in the post-conflict context suggests that community participation and related efforts aimed at bottom-up state-building tend to be quite beneficial for risk mitigation in the long term. Therefore, various World Bank Group project interventions in the conflict-affected regions contain (usually quite small and complementary) technical assistance components aimed at strengthening accountability and transparency of local governments. This type of project interventions is considered important because it is expected to strengthen the legitimacy and credibility of local governments and thus contribute to the sustainability of conditions for peace over time. As local institutional capabilities in post-conflict situations are often rudimentary, the project interventions in question are quite basic, do not promise to deliver much, and tend to plan for sustained longterm engagement. This seems appropriate, as it would be naïve to expect that strong PFM capacity could be built in such adverse circumstances over the lifetime of a single World Bank Group operation. Instead, the World Bank projects tend to deliver some basic training, introduce straightforward processes for budgeting and reporting, and, especially, help to strengthen local demand for government accountability by reaching out to local nongovernmental players.

Overall, the combination of Bank investments in CDD projects with small volumes of technical assistance to improve local governance looks sustainable from the development perspective and is attractive to the World Bank's clients. Such projects also tend to leverage considerable amount of bilateral technical assistance for local capacity building. Examples include Northern Uganda Social Action Fund 2 (NUSAF 2), the Peace and Development Project in Colombia, and North East Local Services Improvement Project in Sri Lanka. The latter project aimed at comprehensive strengthening of local government capacity in the conflict-affected areas. While its main focus was on rehabilitation of local infrastructure, the project also had two governance components - to strengthen accountability and build capacities at the local level. 
CHAPTER 2

BANK GROUP StRategic Engagement

\section{Community-Driven DeVelopment ApProach}

Projects with a CDD design were an important tool in many reviewed countries and were a useful point of entry for the World Bank Group in areas affected by actual or potential violence. While the details are context-specific, CDD projects in such contexts are typically justified because they help to deliver a blend of the following objectives: rebuilding trust and social cohesion, shifting the locus of decision-making to the communities, incremental funding for public goods, and rapid disbursement that offers a peace dividend. The evidence from the case studies does not always bear out these presumptions.

Public versus private goods. The World Bank used Learning and Innovation Loans (LILs, 1998-2002) with CDD-like characteristics to support communities under stress in rural Colombia, where local government institutions were virtually absent. Contrary to any presumption of fostering collective action in pursuit of the provision of public goods, however, an overwhelming number (60 out of 67) of LIL 1 subprojects identified by the communities were individual farmers' projects. LIL 2 had two sets of projects: "social projects" and productive projects that helped small farmers diversify output and improve food security. In the end, most subprojects were productive projects and social interventions did not contain subprojects to sustain education and health services. This may have reflected either the overriding importance of farm output for food security at a time of loss of livelihoods, or the complexity and time-consuming nature of collective decision-making for public goods.

Northern Uganda Social Action Fund (NUSAF 1, 2002) was designed as a CDD project and sought to empower communities confined to camps for internally displaced people (IDPs). Project funds could be spent on community infrastructure, livelihood support, or reconciliation and conflict management. However, not all members of a camp were necessarily drawn from the same village, making it difficult to determine the location for infrastructure. This resulted in project funds being allocated more to support income-generating activities, including provision of livestock, with the cost of this component becoming 2.5 times as high as estimated at project appraisal. This illustrates the difficulty of using a CDD design to decentralize decision-making for public goods in an environment where the notion of community is hard to define. In contrast, the successor project NUSAF2, implemented in conditions of peace, which allowed people in the camps to return to their villages, has disbursed nearly two-thirds of its funds for community infrastructure. 
Typically, three-quarters of project funding under a large nationwide Kecamatan Development Program (KDP) in Indonesia was used for community infrastructure, with one-quarter allocated as individual grants for productive investment. In contrast, 95 percent of project funds in conflict-affected Aceh went for community infrastructure, with only a small amount for individual grants. This was due to the risk of extortion by both parties to the conflict. After the 2004 tsunami and the 2005 peace agreement, some KDP money was used for aid to victims of the conflict. A similar government program, the Community-Based Reintegration Assistance for Conflict Victims Program (BRA-KDP), had the same open menu as the KDP, and channeled national government funds allocated to support reintegration. However, in a pattern similar to that in Colombia LIL1, the communities allotted 90 percent of funds for livelihoods proposals, such as livestock, agriculture, and small trading by individuals, leaving the remaining 10 percent for community infrastructure. This was because the program was seen by villagers as providing them with compensation for damage and loss from the conflict. This is in contrast with the KDP in the rest of Indonesia, where community infrastructure projects were dominant.

Context-specificity is important and three examples of the balance between public goods and private livelihood support from Colombia, Uganda, and Indonesia do not lend themselves to generalization. However, they demonstrate that any presumption that communities will mostly choose subprojects with the characteristics of public goods may not hold under conditions of insecurity.

Development impact. Impact assessments examine how effectively CDD projects achieve their objectives of providing services and benefits to communities and restoring trust and social cohesion through a process of collective decision-making. An instructive example is provided by an impact assessment of the Autonomous Region of Muslim Mindanao Social Fund project (ARMM, 2003) in the Philippines. The following results were found.

The impact of the project on people's perception of quality of life was not significant. On community cohesion and social capital, the impact evaluation showed minor increases in membership of community groups. The impact on reduction in violence and conflict and safety was mixed, the results depending on the nature of the conflict. There was no improvement in community perceptions of local governments' ability to deliver on poverty and public service outcomes.

The minimal impact of the ARMM project on governance and social cohesion is notable. This might be because more time is needed for such an impact to be seen. But it might also point to the need for more concerted action beyond CDD projects to strengthen institutions of local government that have been degraded by conflict. 
An impact evaluation of the NUSAF 1 project in Uganda found that it had a significant impact on access to water and sanitation, quality of school buildings, and the quality of students and teachers, but not much impact on social capital improvement in NUSAF communities compared to non-NUSAF communities. The NUSAF project was dogged by allegations of corruption and elite capture, captured in audits. This is an example of the speed of disbursement outrunning the capacity of local institutions to enforce fiduciary standards, highlighting the risk of financial irregularity in the pursuit of a potential post-conflict peace dividend.

Learning and scaling up. Approaching conflict-responsive lending through small LILs, as in the Magdalena Medio region of Colombia, had several advantages. It helped test and refine a participatory methodology in a volatile environment where the World Bank had limited knowledge of priorities and could join ongoing efforts spearheaded by respected civil society leaders. The Magdalena approach was then extended to several other severely affected regions and was instrumental in securing European Union financial support, which was then significantly scaled-up to cover other regions in Colombia.

Another illustration of the catalytic impact of Bank lending is provided by the ARMM Social Fund project in the Philippines, the design of which was largely adapted from proven approaches developed in Indonesia. The project delivered CDD in every municipality in ARMM, reaching almost 1 million people. The government of the Philippines considered the CDD approach an important instrument and used the project's network under separate government projects from 2010 through 2013.

Overall, the emerging lesson from Bank CDD projects in FCV areas is that these projects represent an important entry point for the World Bank to expand its engagement with the clients at an early stage of post-conflict reconstruction. These projects are an effective instrument of building local partnerships, but they should be seen as a step in a longer-term development assistance strategy, which complements CDD projects by interventions in other critical areas, such as infrastructure, local capacity building, and decentralization arrangements, among others.

\footnotetext{
1 The current set-up, when the Nairobi hub hosts mainly technical operational staff, with the management team re-located back to the HQ, presents a much more viable and useful model, as uniformly confirmed by IEG interviews.

2 Fragility Assessments: A Guidance Note. FCV CCSA and GPSURR, World Bank, 2015

${ }^{3}$ AARM Human Development Sector Study, The World Bank
} 
4 "The Search for Durable Solutions: Armed Conflict and Forced Displacement in Mindanao, Philippines" (2010); and "Violent Conflicts and Displacement in Central Mindanao: Challenges for recovery and development"(2011). World Bank and WFP

5 “How Poor Are Refugees? A Welfare Assessment of Syrians Living in Jordan and Lebanon,”.” World Bank and UNHCR, 2015.

${ }^{6}$ Reaching All Children with Education (RACE) program.

7 Böge, V., Fitzpatrick, C., Jaspers, W., Paes, W-C. 2006. Who's Minding the Store? The Business of Private, Public and Civil Actors in Zones of Conflict. Bonn: BICC. Brief 32

8 Porter Peschka, Mary. 2011. The Role of the Private Sector in Fragile and Conflict-Affected States. Background paper for the WDR 2011.

9 See CAO investigation of the IFC's investment with Dinant in Honduras.

${ }^{10}$ Sanasa Development Bank Ltd. (SDBL) has been able to increase its SME clientele by 7,160.

11 Nearly half of MIGA's guarantees in FY14 were for FCS countries, which represented a significant increase from 24 per cent in FY11 (MIGA Annual Report, 2015)

12 WB (2014). Intergovernmental Fiscal Relations in Fragile and Conflict Situations. 


\section{Subnational Conflicts}

This chapter reviews World Bank Group engagement in non-FCS (mainly middleincome) countries that experienced localized organized violent conflict with an ethnic or religious identity marker. In all countries reviewed violence has largely subsided (although not all conflicts are formally settled) and the review looks at the assistance provided by the World Bank during and after the hostilities.

The 2011 WDR found that the most potent of all drivers of violence was the experience, or perception, of injustice. When the ethnicity, geographical location, or religion of the affected group is easily defined, the potential for aggrievement is enhanced. The global history of violence is replete with cases of callous behavior by dominant officials that did not evoke rebellion. Famines offer one such example. ${ }^{1}$ Although such searing experiences damage the legitimacy of the ruling authorities, they do not translate into rebellion unless there is a clear animating ideology and space to organize.

When the state is inattentive or overextended, where there is a memory (or a myth) of former independence, and where the area of repression is relatively remote from the center of a state's authority, rebellions are more likely to emerge. In MICs, and absent serious external involvement, the state is generally able to manage such rebellions, containing them to their area of origin. By the same token, there is less of an impulse to resolve them decisively, often because the ruling elite has a vested interest in the distribution of power and resources in the area in question. Aceh (Indonesia) was an example of this prior to the tsunami, which then broke the pattern of the past, brought in massive external resources (and thereby new forms of rent), and provided all parties with an opportunity to reset the political agenda.

In Aceh, Mindanao, Northern Uganda, and Sri Lanka subnational conflicts arose as organizations representing distinct ethnic, tribal, or religious populationsminorities nationally but predominant in one region-used violence to press their demands for secession or at least much greater autonomy for regional governments that they could control.

The trajectories of the conflicts and their resolutions differed, as did the ways the World Bank Group operated, but the parallels between the four cases lead to some useful conclusions and lessons. Appendixes A.1-A.4 include brief historical sketches of the cases. 


\section{Conflicts Compared}

In Aceh and Mindanao, violent conflict largely ended when the insurgent organizations negotiated peace agreements with the national government, although in Mindanao some violence from outlier groups continues. In both cases the settlement included legal changes to allow extraordinary degrees of autonomy for the regional governments in those places and to allow the insurgent group to convert into a legally recognized political party that did (Aceh) or is expected to (Mindanao/Bangsamoro) win the election for the new regional government.

In Uganda, the violent conflict ended when the LRA was driven out of the country. The Acholi and Lango subregions of Northern Uganda, from whence LRA emerged, did not get any special increase of political autonomy after the conflict ended, although their public services improved somewhat. In Sri Lanka, the government defeated the Tamil Tigers at the end of a protracted and brutal civil war. Few of the known combatants survived. The predominantly Tamil provinces in the north and along the east coast have not received any particular political autonomy.

The 2004 tsunami hit hard on both Aceh and the Tamil regions of Sri Lanka. In Aceh (near the epicenter), the disaster and the flood of international aid that followed catalyzed the parties to reach and sustain the peace agreement. In Sri Lanka, by contrast, the large amount of donor funding made available did not contribute to a peace agreement and much of the funding was deferred or never used because the government (and Tamils) did not agree to a mechanism for local governments and communities to participate in the reconstruction planning. Then in 2006-07 the military campaign against the Tamils intensified, aiming for total victory.

The economic and social indicators in Bangsamoro (the Muslim-dominated part of Mindanao) and in Northern Uganda are the lowest in their nations. Aceh was and remains one of the poorest provinces in Indonesia. This not only fueled resentment, feeding into the insurgencies, but the correspondingly low institutional capacity in these locales also complicated their reconstruction and recovery.

\section{World Bank Group Strategies}

In all four countries, the World Bank Group's objectives and degree of focus on the conflict regions within the overall country strategies changed over time and especially after the end of the violent insurgency. Concerns about security during the active conflict often limited the World Bank presence in the field to essential personnel, but the World Bank staff were able to develop rapport and trust at the local level and effectively supervise especially the CDD-type projects. 
In Aceh and Mindanao, the insurgent organizations cooperated with the World Bank, whereas the national governments were often initially reluctant to admit publicly that they had a serious regional security problem that they themselves could not handle, to allow international support in the insurgent areas. Nonetheless, for Mindanao, Aceh, and Northern Uganda the national governments all eventually came to welcome the World Bank Group engagement and assistance and allow the terms of that to appear in the CAS/CPS. In Sri Lanka, the brief window of opportunity for dialogue and cooperation on development and reconstruction after the tsunami was not used.

In the Philippines, every CAS/CPS since at least 1999 has given some attention to the Mindanao region, although they only in halting steps acknowledged the centrality of the problem of organized violence. In 2002-05 CAS and 2006-08 CPS none of the four thematic areas related explicitly to the problems of conflict or Mindanao. Only 2009-12 CPS listed outcomes pertaining to Mindanao and violent conflict. The new CPS for 2015-17 lists five primary engagement areas, the fifth of which is "Peace, institution building, and social and economic opportunity." ${ }^{2}$

Despite underplaying conflict in the CASs of the early 2000s, Bank staff were engaging directly with the Bangsamoro Development Agency (BDA) and providing technical assistance to the agency's development efforts. As the World Bank's program in neighboring Aceh was winding down, many Bank staff who had worked on conflict issues there relocated to the Philippines to work on Mindanao in the late 2000s. ${ }^{3}$ This largely unforeseen continuity of Bank staff engagement has helped the World Bank to use staff expertise developed in Aceh, particularly in terms of using trust fund resources in a complex donor environment, and working simultaneously with representatives of the national and local governments, and insurgent groups.

In the Indonesia CASs and CPSs, the shift from little to lots of attention to Aceh after the tsunami was rapid. The 2001-03 and 2004-07 CAS (prepared before the tsunami) said little about Aceh. The CAS Progress Report of 2006 added a pillar for disaster risk management, which included support for a peace process in Aceh.

Reconstruction efforts in Aceh grew into a portfolio of grant operations, technical assistance, policy dialogue, and analytical work equal in scale to a full-fledged country program. Most of the World Bank Group activities were not officially related to the conflict. However, scaled-up field presence and expertise facilitated the implementation of key programs, often funded by other donors, which were essential to sustain the end to the conflict. The wind-down of the World Bank's program in Aceh was almost as swift as the build-up. Soon after the tsunami 
reconstruction was declared complete, the World Bank Group left Aceh, closing its office there in 2012.

In Uganda, the World Bank strategies for the late 1990s had little explicit mention of the conflict. The results framework of the strategy for 2005-09 mirrored that of the government's Poverty Eradication Action Plan (PEAP) - reduced number of casualties and IDPs. A completion report preceding the 2005 strategy recommended that the World Bank take more concerted action, stating that "in spite of the ongoing conflict in Northern Uganda, the World Bank needs to support government and development partners in addressing issues arising from the conflict in an integrated way, especially the humanitarian aspects." 4

In Sri Lanka Bank strategy documents of 2003, 2008, and 2012 examined the impact of the conflict on Sri Lanka's development to varying extents and from different vantage points. The 2008 CAS attempted to distill the salient lessons learned from the previous five years, and underscored the need for projects to remain "conflictsensitive" and avoid inadvertently feeding into ethnic tensions. The CAS also warned that the World Bank had to deftly manage reputational risks to avoid being perceived as a biased development partner in a very sensitive region. The strategy also introduced a conflict filter at the project level at the concept, design, and implementation stages.

The CPS for 2012-16 echoed the lessons of the WDR, though conflict does not feature as prominently in this report as it does in previous ones. It focuses on the economic transition and how the World Bank could support growth. The CPS does not unpack the sociopolitical dynamics of Sri Lanka after the war, despite recognition of its importance in the previous CAS. Without this lens, the CPS does not make a clear link between efforts to strengthen economic growth and the need to sustain a durable peace. 
CHAPTER 3

SUBNATIONAL CONFLICTS

Table 3.1. World Bank Group Program Adjustment Post-Conflict

\begin{tabular}{|c|c|c|}
\hline $\begin{array}{l}\text { Country, [year of } \\
\text { conflict end] }\end{array}$ & Before end of conflict & After end of major violence \\
\hline $\begin{array}{l}\text { Indonesia/Aceh } \\
\text { [2005] }\end{array}$ & $\begin{array}{l}\text { Poverty reduction; economic } \\
\text { development }\end{array}$ & $\begin{array}{l}\text { Same, plus: donor coordination, convening; } \\
\text { reconstruction; restitution for victims of } \\
\text { conflict; reintegration of ex-combatants }\end{array}$ \\
\hline $\begin{array}{l}\text { Philippines/ Mindanao } \\
\text { [2012] }\end{array}$ & $\begin{array}{l}\text { Poverty reduction; economic } \\
\text { development; building capacity }\end{array}$ & $\begin{array}{l}\text { Same, plus: donor coordination, convening; } \\
\text { reconstruction; restitution for victims of conflict }\end{array}$ \\
\hline Sri Lanka & $\begin{array}{l}\text { Poverty reduction; economic } \\
\text { development }\end{array}$ & $\begin{array}{l}\text { Same, plus: building public trust and social } \\
\text { cohesion }\end{array}$ \\
\hline $\begin{array}{l}\text { Uganda } \\
\text { [2003-4] }\end{array}$ & $\begin{array}{l}\text { Poverty reduction; economic } \\
\text { development; reduction of } \\
\text { violence; disarmament, } \\
\text { demobilization, and reintegration } \\
\text { of combatants }\end{array}$ & $\begin{array}{l}\text { Same, plus: help for IDPs and female victims } \\
\text { of violence }\end{array}$ \\
\hline
\end{tabular}

In these four countries, Bank objectives in the conflict zones depended heavily on what engagement the government was willing to allow. The World Bank pushed the envelope to do CDD projects in areas of ongoing conflict in Aceh, Mindanao, Sri Lanka, and Uganda, and in Mindanao to work with a wing of the insurgent organization. Such early engagement was relevant and useful for laying the foundation for post-conflict engagement. As the conflicts wound down, a reconstruction phase began, and the World Bank duly realigned its objectives to support the reconstruction and reconciliation.

\section{World Bank Group Instruments}

\section{Partnerships and Dialogue Arrangements, Convening Role of the World Bank}

In all four cases, the conflicts and the stories of the suffering from them aroused widespread international concern and offers of funding. Consequently, the World Bank was often called on to help coordinate the donor assistance. The World Bank took on this coordinating and convening role and to varying degrees made it the center of its own reconstruction and development programs in the conflict-affected regions.

In Aceh Indonesia, the World Bank led the Preliminary Damage and Loss Assessment, which provided the basis to organize the massive multilateral relief effort. The MDTF became the centerpiece of the World Bank's contribution to posttsunami recovery in Aceh. Formed in May 2005, the MDTF supported a diverse portfolio of projects in four areas of reconstruction valued at \$492 million: recovery of communities, reconstruction of large infrastructure, rebuilding governance, and 
sustaining the environment. The World Bank took the lead in selecting and implementing the activities funded by the MDTF. Eventually the MDTF pooled approximately $\$ 673$ million in pledges from 15 bilateral and multilateral donors. ${ }^{5}$

In Mindanao Philippines, the World Bank's reputation as a technocratic and politically neutral player, as well as its experience in Aceh, helped it play a convening role among donors, the governments, and the Mindanao Islamic Liberation Front (MILF). Bank projects and analytical work continued even during episodes of violence. The Multi-Donor Facility (MDF) for Mindanao Reconstruction and Development (\$83.7 million, 2007-15) exemplifies that role. The MDF followed a similar model as in Aceh. This was not accidental, because many of the World Bank staff and consultants from the Aceh team subsequently moved to Mindanao. The MDF financed projects to empower communities to recover from conflict and to promote participatory local governance. To date the project has delivered over 300 subprojects, providing over 500,000 people in conflict-affected communities in Mindanao with improved access to services and infrastructure. It also funds capacity building and planning activities of local government units.

MDF provided capacity-building support to the BDA, the development arm of the MILF, to prepare them for a role in government following the expected transition. This included support to prepare the Bangsamoro Development Plan (BDP, 2015), a comprehensive economic blueprint for the proposed Bangsamoro area. MDF assistance is now shifting to help identify priority projects and to support the government and MILF to establish a joint coordination mechanism to oversee implementation of the development plan.

\section{Box 3.1. The Bangsamoro Development Agency}

The BDA was created as part of the June 22, 2001, Tripoli Agreement between the Government of the Philippines and the MILF. The MILF Central Committee requested a civil society organization (composed mostly of medical doctors) to run the agency. It was mandated to determine, lead, and manage relief, rehabilitation, and development programs in the conflict-affected areas in Mindanao. In 2005 the World Bank began to work with the BDA, with the tacit approval of the Philippine government. The World Bank provided technical and financial support to develop the BDA as an institution through the Mindanao Trust Fund for Reconstruction and Development Program (MTFRDP). During the initial stages of the BDA other donors were reluctant to work with the agency but then began to do so after seeing its effective collaboration with the World Bank on the CDD program. While the final settlement (expected with the passage of the Bangsamoro Basic Law) is still pending, the BDA launched the Bangsamoro Development Plan (BDP, 2014), a roadmap for economic development of the Bangsamoro area. Currently, the BDA is the leading development agency for the Bangsamoro people. With 
the support of the World Bank and other partners, it helped deliver community development and livelihood programs to over 500,000 people in more than 215 villages in 75 municipalities across Mindanao. As of 2015, the BDA has over 300 staff operating with a Central Management Office based in Cotabato City, which oversees six regional offices across Mindanao.

Sources: BangasamoroDevelopment.org, MTF-RDP Annual Report, www.MTF.ph, World Bank September 2015.

To make efficient and timely use of what became a network of trust funds for Mindanao, the World Bank worked with the government, the MILF, and the United Nations to create the Facility for Advisory Support for Transition Capacities (FASTRAC) - an important instrument for the World Bank's engagement strategy in Mindanao, designed as a quick-response technical assistance mechanism to respond to the needs identified by the Government of Philippines and MILF and the formal transition bodies to help in the transition to Bangsamoro. FASTRAC came about as a response to the October 2012 Framework Agreement on the Bangsamoro (FAB).

After the FAB was signed, the United Nations and the World Bank mobilized a joint mission to assess how to support implementation of the Agreement, with a focus on building the capacity of the MILF.

FASTRAC built on the complementarity of respective mandates and comparative strengths of the World Bank and the United Nations and had two pockets of funding - one for each of the two institutions. This means the United Nations steps up with funds when the World Bank cannot provide direct support, such as initiatives on security and political transition. For the World Bank partnering with the United Nations via this facility expands the scope of its support beyond economic development and taps into the knowledge of the United Nations on political processes and the broader mandate that allows working with many different actors in the country. Despite some operational difficulties, FASTRAC is a good model of cooperation where the funding streams are separate but the decisionmaking is shared.

In Northern Uganda, the World Bank played an important role convening and organizing donors and development partners and spearheading the PRDP. This included chairing Donor Technical Group on Northern Uganda Rehabilitation and Development that still meets. The World Bank also chaired the Transitional Demobilization and Reintegration Program, a regional MDTF.

\section{FINANCING}

In Indonesia, the World Bank had had projects in Aceh since the late 1990s, with generic developmental objectives with little or no reference to the conflict. The KDP, 
a countrywide CDD program, gave the World Bank a strong presence on the ground. Before the tsunami, the project's implementation was adapted to Aceh circumstances - a larger share (about 95 percent) of subprojects went for community infrastructure, with only a small amount for individual grants - compared to about one-fourth for individual households in the rest of Indonesia. Local labeling of activities as "World Bank" rather than Government of Indonesia helped to sidestep local hostility to the central and provincial government. After the tsunami and the 2005 peace agreement, the institutional infrastructure of KDP played a critical role in implementing reconstruction and rehabilitation programs. Some KDP resources were reprogramed specifically for aid to victims of the conflict. The government funded Community-Based Reintegration Assistance for Conflict Victims (known as $B R A-K D P)$, adapted the KDP model to provide $\$ 22.7$ million to conflict victims.

In the Philippines, the largest financial support for Mindanao came through the MDF, discussed above. The ARMM Social Fund for Peace and Development Project (200214, \$61 million) had almost 1 million direct beneficiaries. The Mindanao Rural Development Project I (\$41 million, 1999-2005) and II (\$84 million, 2007-14) created job opportunities through rural infrastructure projects for roads and irrigation facilities as well as livelihood and micro-enterprise subprojects. There were 2 million direct project beneficiaries, about half of them women, and one-fourth IDPs.

IFC has also engaged with the private sector in Mindanao and had maintained an office in the provincial capital of Davao until 2013. The engagement was rather limited (six investments and five advisories). The successes with the private sector in the conflict areas of Mindanao have come mostly in rural areas, including the Unifrutti advisory service project in 2008. The proposed new IFC investment with Unifrutti is expected to create 4,000 hectares of new farms and generate 6,000-7,000 jobs, a large proportion of which will employ ex-combatants of MILF (Box 3.2).

\section{Box 3.2. IFC's Advisory Service and Client Engagement in Mindanao with Unifrutti}

Unifrutti has been active in attracting investors to Mindanao from leading corporations in the Philippines and providing advice on how to do investments in Mindanao. In addition to strong relationships between IFC, Unifrutti, and local government, project partners also got buy-in from high-level leaders within the MILF. This ensured security within the project's borders while operating in a highly volatile region. Meanwhile, Muslim groups in Mindanao viewed the project positively, because Unifrutti had a good record of establishing a longterm profitable venture in the conflict-affected areas of Mindanao, and it helped them to begin to be viewed as a respectable political party. Another success factor was the project team's emphasis on the assessment of the gender, environment, and peace and conflict risks during due diligence. For instance, peace and conflict risk assessment strengthened IFC's 
practice of providing assistance to the farms through third-party contractors and partner lead firms to minimize exposure of IFC staff to rebel groups.

Sources: IEG, IFC.

In Northern Uganda, the main operational engagement since 2003 has been the NUSAF I (2003-09, \$100 million) followed by the NUSAF II (2009-15, \$100 million). Both were CDD projects, with components for supporting vulnerable groups, postconflict reconciliation, infrastructure rehabilitation, conflict management, and developing local community institutions.

In Sri Lanka, the national education program (Education Sector Development Program, $\$ 60$ million) incorporated features to address fragility by expanding activities of the project to the northern regions and introducing initiatives such as psycho-social support programs, conflict engagement models, multiethnic classes, development of multiethnic curriculum materials, and multiethnic school linkage programs.

CDD was used as a mechanism for delivering support to marginal communities (Second North East Irrigated Agriculture Project (NEIAP II), and Community Livelihoods in Conflict-Affected Areas). The NEIAP compiled district social baseline profiles that became analytical insights to work with conflict-affected communities and laid important foundations for the various Bank projects that followed. Design documentation acknowledged recent experience in Bosnia and Herzegovina and used this experience in the formulation of project components, suggesting that it is not feasible to define an overall strategy a priori. A suite of projects delivered in the North East (North East Housing Reconstruction Program, Puttalam Housing Project, North East Local Services Improvement Project, and Emergency Northern Recovery Project) responded to the needs of post-conflict environments: cash handouts, reconstruction support, housing and/or shelter, community-based infrastructure, education support to get children back in schools, and capacity development programs to reengage regional authorities.

\section{ANALYTICAL AND AdVISORY WORK}

Indonesia. There was a considerable amount of AAA specifically on Aceh that started after the tsunami and the peace agreement. The Preliminary Damage and Loss Assessment (2005) provided the basis to organize the massive multilateral relief effort in Aceh through the MDTF. GAM Reintegration Needs Assessment (2005), conducted in partnership with $\mathrm{GAM}^{6}$ assessed the post-conflict process of reintegration, focusing on potential obstacles to peace; identified the needs and 
aspirations of former combatants, prisoners, and receiving communities; and helped develop programs and mechanisms to address these needs.

Of the many other analytic activities, three stand out. The Aceh Public Expenditure Analysis (PER, 2007) was led by the World Bank in collaboration with four Acehnese universities and with support of the acting governor of Aceh. Interviewees gave this report credit for guiding the recovery and reconstruction effort in Aceh, although it is not clear which of the report's 25 key recommendations were implemented. The Multi-Stakeholder Review of Post--Conflict Programming in Aceh (MSR, 2010) took stock of Aceh's post-conflict needs and provided recommendations to help consolidate peace and promote prosperity in Aceh. Conflict and Dispute Resolution in Indonesia: Information from the 2006 Governance and Decentralization Survey (2010) sought to explain national patterns of conflict and dispute resolution, the use of police services and the formal legal system, and connections between governance factors (corruption, bribery, and information about development projects) and conflict and dispute resolution. Other relevant AAA included a study on Violent Conflict in Indonesia (covering the whole country), a component of the 2010 Consolidating Peaceful Development Program; and Aceh Conflict Monitoring Updates in Conflict and Development reports.

IFC implemented advisory service projects in Aceh after the tsunami to help revive private sector activities. IFC's advisory service projects were developed under a new multi-donor initiative, the Private Enterprise Partnership for Aceh and Nias (PEPAN). FIAS7 cooperated with PEPAN to prepare an investment climate diagnostic and develop an investment promotion strategy for the region. PEPAN played a role in rehabilitating the shrimp sector in Aceh, and was the first international organization focused on providing technical advice to farmers, whereas others were focused on physical reconstruction of infrastructure.

The Philippines. Almost all the analytical activities in Mindanao have components for developing the institutional capacity of local governments and civil society since the chosen political solution involved devolution of authority and resources to local institutions. The central analytical output was the Joint Needs Assessment for Conflict-Affected Areas of Mindanao (JNA, 2005, 5 volumes). It was produced and published by the World Bank with the participation of a host of stakeholders. Coming at the beginning of the collaboration with the BDA, the JNA became the blueprint for the work together. The JNA recommended working through local government units, with nongovernmental organizations, and with CDD-type projects. Collaboration on the JNA brought the donors together to support the Multi-Donor Fund for Mindanao (2007-15), discussed earlier. 
Other analytical work complemented the JNA. Human Development for Peace and Prosperity in ARMM (2003) identified three critical factors that underpin the substantial disparities in basic human development indicators between ARMM and the rest of the country: extreme poverty, armed conflict, and historical disadvantage. The study was relevant and of good quality, but its impact was not clear. The ARMM Social Fund project, starting shortly before the study was published and then continuing thereafter, makes no reference to the study in its documentation. Gender and Peace-Building Experience in the Philippines report analyzed the gender dimension of the conflict in the Philippines and related gender policy to peace-building at the national level. Violent Conflicts and Displacement in Central Mindanao: Challenges for recovery and development (2011, joint with WFP) provided evidence about recovery needs and development strategies in the conflictaffected areas.

Uganda: The World Bank produced several AAA on the Northern Uganda conflict region - but no overall needs assessment in conjunction with the donor community. The more important ones were the Public Expenditure Review for Northern Uganda (PER, 2007) and the Uganda Post-Conflict Land Policy and Administration Options: The Case of Northern Uganda (2009). The PER estimated the total public resource flows to the wide North region and covered both on- and off-budget flows. The Land Policy paper addressed land tenure, one of the most pressing issues during and after the conflict in Northern Uganda (and throughout the country), aiming to inform the PRDP and the ongoing preparation of the National Land Policy. It recommended immediate actions in relation to IDPs and land policy. IEG learned that these recommendations were not fully taken on board by the government. In recent years, the intensity of analytical work related to Northern Uganda seems to have gone down sharply. IEG was unable to locate recent AAA on the conflict in Northern Uganda or an economic report that would provide a diagnostic and sound analytical underpinning for going forward.

\section{Gender AND CONFLict}

In addition to several common themes relating to gender impacts of conflicts, there were also specific characteristics in each country relating to the overlap of conflict and gender dimensions. In the Philippines, there was human trafficking of young women and children in displaced communities in the ARMM region. ${ }^{8}$ In Indonesia, some women faced sexual violence from soldiers, as a tactic of terror against their communities. ${ }^{9}$ In Uganda, many LRA rebels targeted women for forced marriages. In Sri Lanka, several thousand war widows in the North and the East are still without access to adequate resources, housing, or vocational skills and are often denied land rights and exposed to sexual violence and trafficking. ${ }^{10}$ 
Bank strategies emphasize conflict and gender issues in the latter half of the evaluation period (2010 onwards), except for Sri Lanka. Gender issues in conflictaffected areas were primarily addressed through involving women in CDD projects. Findings from focus group discussions in Indonesia (BRA-KDP project) suggest that women-headed households tended to be more actively engaged than other women in attending community meetings and participating actively since they were less likely to be represented by men. While former combatants have found full-time employment since 2006, certain groups, including women-headed households, have not benefited proportionally and are vulnerable to economic shocks. ${ }^{11}$

In Uganda, NUSAF I made systematic efforts to make the project gender-responsive. NUSAF II built on lessons on gender from NUSAF I by further developing and tracking gender equity outcome indicators and monitoring delivery of project benefits. In Sri Lanka, CDD projects in conflict-affected areas showed success in engaging women both in project implementation and as beneficiaries. There was no systematic coverage of gender issues in conflict-affected areas beyond CDD projects.

Analytical work on gender and conflict was thin, and where it existed, it was not translated into operations. In Indonesia, "Justice for the Poor" looked at reforms in religious courts including easier access for women but no specifics of this program are found in Aceh. Philippines is one of the few countries that included gender and conflict-related analytical work during the evaluation period. ARMM Human Development Sector Study suggested that more boys drop out of school in their early teens than girls, and observed that early dropout rates of boys may itself feed the supply of boys who take up arms. However, there were no follow-up programs that worked with youth who had taken up arms or were ex-combatants. Country Gender Assessments in the Philippines and Uganda did not focus on the gender and fragility.

\section{Assessment}

Indonesia: Among cases reviewed, Aceh was the clearest success in terms of ending the conflict. The tsunami shocked the government and GAM into making a peace deal that has lasted so far. Large funding for the physical reconstruction also created many business and employment opportunities for ex-combatants and potential insurgents. Current assessments see a low risk of a return to organized violence. The previously insurgent organization GAM has converted into a recognized political party, which is now in power as the government of the Aceh province, with a special degree of autonomy.

The willingness of both parties to change to peaceful strategies and the fortuitous flood of funding are the distinctive features of the case, but the World Bank was an 
important facilitator. The World Bank's high-capacity presence on the ground prior to the tsunami, through the KDP, and the willingness of regional management to try innovative arrangements enhanced the ability of the World Bank to play this facilitating role. The World Bank's presence in Aceh since the 1990s had developed local expertise and trust with GAM cadres in the field. With the wave of funding for emergency relief, the World Bank assumed a central role in coordinating donor efforts. The Government of Indonesia regarded the World Bank as a neutral and nonpolitical player, representing a technocratic approach to development. This contrasted with the United Nations, which, according to some, was perceived as more politicized institution and conveyed the undesirable impression that Indonesia had a security problem.

The World Bank's efforts in the post-tsunami period focused on repairing damage from the tsunami and the impact of organized violence. Although the damage and needs arising from the two overlapped, there was some differentiation, particularly because some donors preferred to focus on one more than (or even to the exclusion of) the other. The World Bank worked on both, through trust funds, essentially making the donor funding fungible for meeting whatever needs seemed most urgent. This work was not labeled as conflict prevention, but the creation of jobs and business opportunities in the reconstruction effort played an essential role in demobilizing and reintegrating ex-combatants.

The World Bank ended its presence in Aceh in 2012 after the tsunami reconstruction was declared accomplished. No institutional arrangement was left in place to monitor conflict risks in developmental programs. Some government officials, Bank staff, and others have questioned the wisdom of this hasty exit. Although to date major violence has not returned, some of the drivers of the original conflict remain, and governance capacity at provincial level remains weak and very thinly spread. The assets of the World Bank's social and human capital in Aceh were allowed to dissipate, although a number of Bank staff and consultants subsequently moved to support the World Bank program in Mindanao. IFC closed its office in Aceh in 2010. Since then, IFC has not been active in promoting private sector investments in Aceh, and a large number of early MOUs with investors have failed to materialize.

The Philippines. The World Bank Group's engagement in Mindanao is a good example of active and effective long-term World Bank Group engagement for FCV situations in MICs. The World Bank had the longest engagement in the conflict areas in Mindanao of all four cases reviewed, and the peace settlement itself has come in phases. In terms of the violence and conflict problem, the accord signed between the Government of the Philippines and MILF in 2014 was directly related to the goal toward which the World Bank's work in Mindanao aimed to contribute - peace and 
development in one of the poorest regions in the country. Intermediate steps were the ceasefire and other interim agreements, which not only led to the eventual accord but also provided respites from violence, even when there was another interim resurgence.

The World Bank's AAA, especially the 2005 JNA, played a pivotal role in coordinating development efforts in Bangsamoro. Even while some violent conflicts continued, the presence of this consensus blueprint for development helped the parties keep in mind that a peace settlement would bring a positive payoff.

As far as other indicators of progress (such as human development), reports of the early 2010s that used data from the 2000s, do not show improvement and sometimes register declines. Peace itself, largely in effect only since 2012, will likely influence positive effects, even before improvements in institutions and funding take effect. Cooperation with the newly formed BDA since 2005 was an achievement in itself that laid the basis for a parallel track of development cooperation alongside the negotiations for a political settlement that proceeded on a slower track. Unlike Aceh, the peace settlement in Bangsamoro/Muslim Mindanao is not yet finalized and there has been no formal transfer of power. The future of peace will to some extent depend on the success in the next steps -including setting up effective governance structures and generating growth and employment.

Uganda: The World Bank has long been a major player in the country and stepped in to provide critical assistance when needed. The military action of the government against LRA and the latter's failure to keep the loyalty of the local Acholi population were the main factors in driving LRA into exile and ending major violence. The World Bank can claim little credit for this. In IEG interviews, Bank staff reported little risk of reversion to organized violence. Local counterparts, on the other hand, said that there was some risk, as socioeconomic problems persist and, if not addressed, could give rise to other insurgent groups and violence.

NUSAF - the flagship operation in Northern Uganda - is generally viewed as a useful intervention that provided much needed infrastructure and support for income generation. However, insufficient consideration of whether the CDD design was relevant for the special environment of the IDP camps resulted in less than expected uptake of the community infrastructure component, as most people preferred private rather than public goods. People living in the camps were not all from the same villages, which made group formation and selection of a community infrastructure very difficult. Nevertheless, the conflict mitigation and community reconciliation component of NUSAF was an important part of helping communities begin the healing process. This component may have helped to reduce conflict and improve 
community relations. At the same time, pressure to rapidly disburse in a weak fiduciary environment was a contributing factor to substantial misuse of funds.

Sri Lanka: There are three key features to the World Bank's engagement in Sri Lanka that helped inform the work in the North East conflict areas: (i) incorporation of fragility features into the national education program; (ii) the use of CDD for delivering assistance directly to communities and forming strategic alliances between key stakeholders; and (iii) recognition that integration and coordination of key projects is essential. While many of the projects were delivered through different sector boards and by different task team leaders, there was a consistent narrative that informed the projects in Sri Lanka, and an understanding among the task team leaders of what had to be done and where the emphasis needed to be to make the projects work. This was due to pragmatic and flexible use of country strategy to inform the conflict response; steady confidence in local staff; and development of project systems that ensured that even when conflicts arose, the mechanisms could be switched on and off based on circumstances.

\section{Conclusions and Lessons}

- Sustained engagement in subnational FCV situations - through analytical work or CDD projects - ahead of the peace settlement and during the ongoing violence was helpful. The lessons learned and development of contacts with and credibility among the parties to the conflicts have important payoffs once there is a peace settlement (Mindanao, Aceh).

- Direct dialogue by the World Bank with an insurgent group can help the parties move toward a peace agreement. Initial approval of the government is needed, but the dialogue can continue even through periods of renewed fighting that interrupts the interaction between government and insurgents. This way, the World Bank's financial support for projects can start before the peace settlement and continue on at least a maintenance level during intervals when violence resurfaces.

- Comprehensive assessment of the situation with participation from both sides of the conflict - the government and the insurgent organization (or its development wing) - helps to set the stage for subsequent reconstruction and development efforts. Such exercises in Aceh and Mindanao helped greatly; the absence of one in Northern Uganda probably diminished the World Bank's effectiveness.

- $C D D$ projects have proven a useful entry point for the World Bank into the conflict-affected areas and a convenient tool for facilitating participation of local stakeholders. Three important features of CDD projects were (i) 
perception of the World Bank's role as impartial and technocratic player, (ii) sustained presence and engagement in the conflict-affected area, and (iii) Bank's support to building capacity in local organizations and partners, such as BDA in Mindanao.

- Flexibility of project design and ability of management at various levels (project and country) to take quick decisions is key. The World Bank adapted the KDP project to the circumstances of Aceh during the conflict, and reallocated resources quickly after the tsunami, as needs changed.

- Support to the education sector can be important in dealing with issues of fragility, particularly as they pertain to psycho-social issues among children and providing safe spaces for integration and community cohesion to develop. The Sector-Wide Approach (SWAP) program in Sri Lanka showed that national-level programs can effectively identify fragility issues and engage specific instruments that address these in relevant areas while still adhering to the commitments at the national level.

- Creating opportunities for employment_and local entrepreneurial success can help making a peace settlement last. This happened in Aceh, and while it was the massive donor funding after the tsunami that helped enable this, it is possible that even more modestly funded post-conflict programs could replicate this by giving priority to infrastructure projects executed by local firms and workers. This might come at the expense of some funding for human development projects, but these have a longer time to payoff, a longer term that the area might never reach if conflict were to restart.

- IFC engagement was relatively limited, especially when compared to the World Bank and other donors. Opportunities were sometimes missed due to the lack of coordination and communication between the World Bank and IFC. The One World Bank Group approach, including the co-location of offices, could have improved joint contributions. IFC was not flexible enough to make necessary changes to its instruments or staff incentives in FCV situations in non-FCS countries, despite the high demonstration effect of its active presence for the private sector.

- Continuity in Bank staffing policy in FCV situations in non-FCS was not common, but when it happened, the payoff was clear. The transfer of many Bank staff who worked on conflict and violence issues in Aceh, Indonesia, to the World Bank's Philippine country office resulted in the effective transfer of knowledge and expertise that benefited the program in Mindanao.

- Maintaining presence (even nominal) in former conflict zones may be necessary to help sustain peaceful development. Various sources - nongovernment organizations, donors, and former Bank staff-expressed concern that the World Banks's exit from Aceh was too sudden and too early, given the weak 
capacity of the local government and the potential risk of resuming the conflict and violence.

\section{References}

Advisory Consortium on Conflict Sensitivity (ACCS). 2013. Northern Uganda Conflict Analysis. London.

Alesina, Alberto, Arnaud Devleeschauwer, William Easterly, Sergio Kurlat and Roman Wazciarg. 2002. "Fractionalization. Harvard University. Boston.

Amnesty Commission. 2013. The Amnesty Commission Report. Kampala.

Gersony, Robert. 1997. The Anguish of Northern Uganda: Results of a Field-Based Assessment of the Civil Conflicts in Northern Uganda. Washington, DC (USAID).

Government of Uganda. 2004. Poverty Eradication Action Plan. Kampala.

Operations Evaluation Department (OED). 2000. Project Performance Evaluation of the Northern Uganda Reconstruction Project. Washington, DC.

- - - 2001. Uganda Country Assistance Evaluation. Washington, DC; World Bank.

Patrick Barron. 2011. “CDD in Post-Conflict and Conflict-Affected Areas: Experiences from East Asia." University of Oxford. Uppsala Conflict Database. Retrieved on June 18, 2015 from: http:/ / www.ucdp.uu.se/gpdatabase/search.php.

Uganda Bureau of Statistics (UBOS). 2002/2003 Uganda National Household Survey. Kampala.

- - - 2009/2010 Uganda National Household Survey - Socio Economic Module. Kampala.

Wane, Waly; Martin, Gayle. 2013. Education and health services in Uganda: data for results and accountability. Service delivery indicators. Washington DC; World Bank.

World Bank report, March 2006. GAM Reintegration Needs Assessment: Enhancing Peace through Community-level Development Programming. Washington, DC.

World Bank. 2013. Designing Community-Drive Development Operations in Fragile and ConflictAffected Situations: Lesson from a Stocktaking. Washington, DC.

- - 2009. Second Northern Uganda Social Action Fund - Project Appraisal Document. Washington, DC.

- - - 2007. Northern Uganda Public Expenditure Review (NUPER). Washington, DC.

- - -2006a. Uganda Country Assistance Strategy Complement Report (CASCR). Washington, DC.

$---.2006 \mathrm{~b}$. Uganda Joint Country Assistance Strategy (UJAS). Washington, DC.

---.2003 . Northern Uganda Social Action Fund Project Appraisal Document. Washington, DC.

- - - 1997. Uganda Country Assistance Strategy. Washington, DC.

\footnotetext{
${ }^{1}$ For example, the late 19th century famines in the Sertao in Brazil and in West Bengal under the British Raj, or the more recent famines in Bangladesh and Ethiopia. The contrasting history of peasant revolts in China, arising in a number of cases from famine, show how such grievances can translate into revolution (and dynastic overthrow, in China's case) if led with purpose and inspired by a resonant 'narrative.','

2 CPS 2015: "The [Bank Group] recognizes the window of opportunity afforded by recent progress with the peace process and will support social and economic development in conflict-affected regions. The [Bank Group] will scale up efforts to
} 
increase trust within communities and between citizens and the state in conflict areas and develop and implement a 'Peace Dividend' program for Mindanao/Bangsamoro."

${ }^{3}$ By most accounts, as related to IEG, this was coincidental.

4 World Bank, 2006a

5 The EU, the Netherlands, United Kingdom, World Bank, Sweden, Denmark, Norway, Germany, Canada, Asian Development Bank, USA, Belgium, Finland, New Zealand and Ireland

${ }^{6}$ GAM Reintegration Needs Assessment: Enhancing Peace through Community-level Development Programming, World Bank 2006.

7 Foreign Investment Advisory Service (FIAS) is a joint World Bank / IFC facility to assist countries to attract foreign direct investment (FDI).

${ }^{8}$ Gender and Livelihoods among IIDPs in Mindanao, Philippines, July 2013, The Brookings Institution

${ }^{9}$ http:// www.insideindonesia.org/women-and-the-war-in-aceh, October 2000.

10 ADB Sri Lanka Country Gender Assessment, An Update, 2015, pp.32.

11 Delivering Assistance to Conflict-Affected Communities-The BRA-KDP Program in Aceh, The World Bank, pp.56. 


\section{Violence Related to Crime and Drug Trade}

Manifesting differently in the two countries studied, drug-motivated criminal violence is a specific example of social and political disruption caused by external economic forces - in this case, the demand for cocaine.

A large MIC such as Colombia, with relatively durable public and nongovernmental institutions, can resist the penetration of its public space by criminals. This is not to underestimate the challenge to the state posed by the various Colombian cocaine cartels and rebel groups in the 1990s, which disrupted and terrorized public administration in urban and rural areas alike. In Honduras, criminal elements have been able to eviscerate the courts, the police, and the administration. In both countries, there are three important aspects of drug-driven violence that policymakers need to appreciate.

The first is that most of the violence associated with the drug trade occurs between rival cartels - the general public get drawn into and blighted by this violence, but they are not the principal victims (although spill-over effects such as prostitution and protection racketeering do inhibit healthy economic activity).

The second is that youth gangs form around the drug trade, providing the foot soldiers who carry out violence. This represents a serious challenge to states that are unable to provide adequate employment opportunities to young men ("adequate" meaning forms of employment that offer enough prospects of upward mobility to counteract the prestige and identity that comes with gang membership; short-term, labor-intensive job programs clearly do not fit this description).

The third is the way criminal profits can distort ideological motivation, as can be seen in the history of the FARC. Most long-running liberation movements in the post-Cold War world are sustained by illicit funds, making the resolution of conflicts more complex for peacemakers - who often must balance the acquisitive motivations of leaders against the desire of their followers for social and economic justice.

Colombian government efforts to counter the drug threat have been relatively successful. A small, relatively poor MIC like Honduras cannot hope to manage such a threat without enormous external assistance. In the case of drugs, though, the numbers are sobering: data from the 2011 WDR show that the amount of money spent by the United States and other regional partners on combatting the drug trade in 2010 amounted to less than one percent of the value added to the raw cocaine sold 
in North American markets that year. The economic muscle fueling this criminal industry is overwhelming.

The literature tends to identify four major drivers of conflict and violence in Colombia: political polarization; rural conflict, inequality, and lack of property rights; limited state presence; and illegal drug markets. (See Appendix A.5 for details.) Although the level of violence has been visibly reduced, it still has significant impact on the lives of people. In 2013 about 157,000 new families were displaced, and thousands of displaced households are still not able to repossess their land due to ongoing violence. According to UNHCR, the cumulative number of IDPs reached about 5 million by 2015, the highest of any country in the world.

During the past decade, countries in the Central America's Northern Triangle-El Salvador, Guatemala, and Honduras - experienced some of the world's highest crime and homicide rates. (See Appendix A.6 for details.) In 2011 the World Bank issued a major diagnostic report on crime and violence in Central America, summarizing lessons and identifying priorities for the future. ${ }^{1}$ This evaluation takes the 2011 study as a point of departure to examine the assistance of the World Bank to Honduras, as it was issued in parallel with and provided the analytical basis for the 2012 CPS. The 2012 CPS also introduced for the first time an explicit thematic pillar/objective focusing on citizen security. The 2011 report suggested several strategies to deal with crime and violence: (i) preventive measures, focusing on children and families; (ii) effective law enforcement; (iii) policies regarding drug trafficking; and (iv) coordinated regional approaches and international initiatives

\section{World Bank Group Response}

Colombia. This assessment covers the period since late 1990s. The World Bank interventions generally aimed at mitigating the impact of conflict and violence on households, farmers, and communities, as well as at addressing some drivers of conflict. These two goals were highly interlinked and their importance changed over time. During the period reviewed the World Bank started with mitigation activities at the local level (supporting communities under extreme duress) and, as the security situation gradually improved, started working with local institutions (with an emphasis on supporting the education sector). Eventually the World Bank moved to facilitating broader regional or national-level policies, with an emphasis on land titling and restitution.

The 1997-2002 CAS introduced for the first time a specific pillar to address the issue of violence. It acknowledged that the World Bank could no longer be on the 


\section{CHAPTER 4}

Violence Related to Crime and Drug Trade

sidelines, and emphasized small knowledge transfer operations. The World Bank started its involvement in the Magdalena Medio region with an objective to develop demand-driven projects in partnership with a large set of local partners at the community level. ${ }^{2}$ Magdalena Medio LIL, ${ }^{3}$ and Peasant Enterprise Zone LIL supported poor farmers who had fled to the agriculture frontier areas of Colombia. To prevent collapse of school services in communities with high levels of violence, the World Bank prepared Pasto Education and Antioquia Basic Education pilot projects. The goal was to enhance decentralization through improvement of institutional capacity of local education authorities.

The 2003-07 CAS period witnessed a temporary slowdown in the level of violence, which later intensified sharply. The authorities asked the World Bank to include a special Peace and Development pillar in the World Bank assistance. The new Peace and Development series of projects were envisaged as an extension of the Magdalena Medio project to other regions. Continuous strengthening of the education sector at the local level was seen as an important vehicle to support local governments. A major development during this period was the increase in the cumulative number of IDPs. The World Bank planned to support authorities' efforts to address their needs through expansion of the existing safety nets. Social Safety Net project (2006, \$191 million) allowed expansion of the existing FAMILIAS safety net to cover the IDPs. More prominence was given to the issues of property and land protection, an area that would become increasingly important over time.

The 2008-11 CPS initially envisaged focus on reintegration and reparation issues through expansion of the Peace and Development projects. However, the global financial and economic crisis changed the plans and large part of the World Bank lending moved toward budget support operations. The World Bank assistance concentrated on supporting FAMILIAS through a \$636 million Second Social Safety Net project. The World Bank remained active in mobilizing grants and donor trust funds. As the process of reconciliation and restitution began to take hold, these funds addressed issues of gender equity and protection of land and patrimony. AAA started to focus on reparation issues and the demobilization of ex-combatants.

The 2012-16 CPS aimed at protecting land rights for IDPs through the ongoing projects and grants, reflecting on the progress in security and reconciliation. A major development during this period was the passage of the 2011 Victims and Restitution Law, facilitating restitution of IDPs and the start of restitution claims, including the creation of a new Land Restitution Unit. The World Bank remained active in this area through Phase II of the State and Peace- Building Trust Fund and collaborated with the new unit on a 2013 Land Assessment. 
Honduras. The 2007-10 CPS period witnessed a 50 percent increase in the homicide rate (from 50 to 78 per 100,000 inhabitants) in just three years. The CPS completion report contains a major recommendation to address youth unemployment and ensure that students are incentivized to stay in school rather than to join gangs. It also recommends focusing on the quality of education, preparing youth for work, and slum upgrading. These recommendations appear relevant and consistent with 2011 Diagnostic Report.

The 2012-14 CPS has an explicit and detailed pillar to address crime and violence, entitled "Improving Citizen Security." The strategy envisages a series of activities, including: (i) supporting a new Integrated National Citizen Security and Coexistence Program through a programmatic series of Development Policy Credits (DPC); (ii) supporting violence prevention capacity of local governments and communities through implementing and scaling up the ongoing Barrio Ciudad project; (iii) enhancing employment opportunities for youth through the implementation of Mi Primer Empleo component of the Nutrition and Social Protection project; (iv) linking National Interventions to Regional approaches by strengthening the capacity of SICA (Sistema de Integración Centroamericana) in the area of crime and violence; and (v) expanding Honduras' major conditional cash transfer safety net, the Bono 10,000 Program. The CPS did not refer to coordination and division of labor with the Inter-American Development Bank (IDB), a major lender in Honduras, involved in the areas of security and justice, with much of its activities potentially complementary to the World Bank's work.

The CPS Progress Report (2013) states that "the Government of Honduras is making progress toward a comprehensive approach to citizen security," although the Implementation Completion Report (ICR) of the First DPC operation acknowledged that efforts in this area had been "marginal, sporadic and underfunded."

The Programmatic DPC Series. The First Programmatic DPC (2011, \$86 million) included a Citizen Security component to support a "paradigm shift" in the government strategy from law enforcement to prevention, calling for a more integrated approach to violence and relying less on the earlier "iron fist" policies. 4 Local governments have been at the forefront of these efforts and some municipalities developed citizen security plans - some of them with the support of the then ongoing Barrio Ciudad project.

The DPC included a series of prior actions, intermediate outcome indicators, and indicative triggers for the Second DPC. The specific policy steps supported by the prior actions were very modest and weak institutionally (easily reversed) relative to the ambitious paradigm defined in the strategy. The Second DPC (2014, \$55 million) 


\section{CHAPTER 4}

Violence Related to Crime and Drug Trade

did not follow up on the unfinished agenda of the first DPC, and there was no reference to crime and violence issues or to the "paradigm shift." The credit focused instead on supporting the Bono 10,000 (Honduras' main conditional cash transfer safety net program) - the largest single area of Bank financial support since 2010. The project documents do not address the links between the safety net and the objective of reducing conflict and violence in vulnerable communities.

Supporting improved security in urban communities. Between 1980 and 2000, Honduras experienced the highest rate of urbanization in Central America, resulting in a major mismatch between the demand and supply of basic public services. In the process, urban poverty and violence increased sharply. Surveys undertaken in Tegucigalpa in 2000 reported violence as the second most important problem (after water supply) affecting families in poor neighborhoods and the most important one in wealthier areas. In response, the government developed a strategy to mainstream crime and violence prevention into the urban development agenda. The World Bank assisted these efforts through the pilot Barrio Ciudad project (\$15 million, 2005-13), followed up by the Safer Municipalities Project (SMP, \$15 million, 2012).

The Barrio Ciudad project was considered a pilot intervention - it was the World Bank's first urban development project in Central America in more than 10 years and the World Bank's first explicit effort in addressing crime and violence prevention in Honduras. The project provided loans to eligible municipalities to invest in basic infrastructure. It had a very small component focusing explicitly on the reduction of homicide through special urban designs (improved lighting of streets, broader streets, etc.) and community initiatives to prevent local violence. The ICR (2013) rates the project outcome moderately satisfactory, but the evidence and performance indicators presented are weak. Originally actual measures of changes in the incidence of crime and violence in the target communities were to be used, but the ICR redefined the indicators in terms of change in perceptions. A major drawback is the lack of information on the specific subprojects implemented and their direction. There is no discussion on whether some of the subprojects were scaled-up and survived independently of Bank financing. For a pilot project that was intended to provide knowledge and lessons, little can be drawn from its experience.

The ongoing Safer Municipalities Project built on the approach developed in the Barrio Ciudad but had some important changes in direction. First, assistance for preventing crime and violence at the local level is the main objective of the program and it influences its design. Second, it integrates crime and violence prevention activities at the municipal and community levels. Third, the project tries to organize and coordinate the growing assistance from other multilateral and bilateral donors. A major direction of the project are efforts to directly target families, youth, and 
children at risk, and identify pilots in "hot spot" neighborhoods, in line with the 2011 report recommendations.

This is the only project focusing directly on crime and violence in Honduras following the "prevention paradigm." Project design includes an impressive M\&E system - a clear improvement relative to the Barrio Ciudad program - which, if properly implemented, will yield important lessons for the future.

\section{Assessment}

Colombia. This assessment identified four major themes/areas of World Bank Group engagement. The order they are listed below reflects the evolution of the World Bank response and its adaptation to the evolving situation: from supporting local communities and preventing the collapse of basic services under extreme situations to increasingly supporting programs and institutions of broader longerterm relevance.

Supporting cohesion of communities under stress (Magdalena Medio and Peace and Development projects): The CDD model, through series of relatively small and experimental operations, was one of the few possible points of entry for Bank assistance that could have been scaled-up and replicated. The approach was to help create collective decision-making and problem solving capacity within the communities. In some regions demand-driven projects had already been initiated by the Colombian civil society. The World Bank was able to join and support those efforts. The definition of community varied widely, often including a whole a municipality. The model was able to preserve and stabilize a minimum standard of living and rebuild social and human capital in a context of absence of government institutions at the local level. The subprojects were particularly successful in cases when incentives were created for participants to invest their own resources, join a productive chain, and achieve some minimum economies of scale. Land titling was critical, as it allowed farmers to borrow using land as collateral for investment.

The operational model used by the World Bank presumed moving from small learning and innovation projects (LILs) to larger operations, facilitating the participation of other donors and the government. Implementation required good knowledge of local conditions as well as plain courage on the part of the task team leaders. A major shortcoming of the series was the lack of systematic documentation on the nature and specific objectives of the subprojects, which undermined proper monitoring of progress and evaluation of results, as well as limited opportunities for 


\section{CHAPTER 4}

Violence Related to Crime and Drug Trade

learning. Some outcomes can be attributed using evidence from impact evaluations ${ }^{5}$ and qualitative assessments by IEG mission in the field.

\section{Box 4.1. Learning and Innovation Loans: The Magdalena Medio Series, 1998-2002}

The Region of Magdalena Medio was particularly affected by violence during the late 90s because of its strategic location. Guerilla and drug groups fought for the control of the region and its resources and state troops were mobilized to confront them. The municipality of Barrancabermeja became was one of the main five centers of urban violence in Colombia and by 2000 had one of the highest homicides rates in the world, about 250 per 100,000 per year. Rural areas were also heavily affected. While urban areas in the region were large receptors of IDPs, rural population decreased by 10.7 percent in the 1993-2005 period due to forced displacement. Parcels located in the basins of the Rio Magdalena became particularly attractive to mobilize troops, arms and drugs through the region. Displacements and the constant threats from armed groups deeply disrupted the rural economy, particularly small and vulnerable farmers.

It was during that period that a group of civil society leaders - the Catholic Church, Unions, the National Petroleum Company (ECOPETROL) and specialized nongovernmental organizations (NGOs) - got together to assess the main needs and challenges faced by the population in the region. The initiative was helped by the high moral reputation of these leaders and the perception of them being neutral by all parts involved in the conflict. It provided the basis for the creation of the Program for Development and Peace of the Magdalena Medio Region (PDPMM), initiated in 1995 and implemented through y the Consortium for Development and Peace of the Magdalena Medio (CDPMM). They developed a demand-driven approach with emphasis on development of skills and tools to allow communities to identify their priorities and build the capacity to achieve them. The ultimate goal was to foster development through a participatory approach at the local level that could eventually cover several municipalities to work on shared objectives.

In 1998 the World Bank decided to support the Magdalena Program through a \$5 million LIL, the Magdalena Medio Development Project, Phase I (MMDP-I), to help test and refine a participatory methodology and establish the basis for the design and implementation of an ambitious ten-year community-led, multisectoral development program. Broadly, the strategy responded to two potential opportunities: (i) obtain valuable knowledge from an ongoing program in a context of conflict; (ii) join and support an effort with a unique set of partners and actors available that point in time.

Shortly after the start of the PDPMM, other regions initiated programs with very similar goals and internal structure as the CDPMM Consortium. A follow-up Second Magdalena Medio Development Project was approved in 2001, and shortly after the Magdalena Program seem to have started to have some catalytic impact at the regional and national levels. The EU allocated $€ 50$ million to the Magdalena Program, which became the EU First Peace Laboratory Project (Laboratorios de Paz). During the following years, the EU significantly scaled-up the scope of the intervention covering other regions in Colombia. 
The 2002 National Development Plan explicitly recognized these regional demand-driven programs as important strategies to be supported to promote peace and development in poor areas subject to violence. The plan acknowledged the importance of working with the World Bank, the EU and UNDP on such approaches, based on the experiences so far, in particular the experience with the Magdalena Medio Program. PRODEPAZ, a network of partner organizations (POs) was created in 2002 to improve coordination efforts among different consortiums and organizations supporting these types of programs. PRODEPAZ became an important partner for the World Bank's subsequent Peace and Development operations that expanded to different regions with support from grass-roots organizations and local leaders.

Sources: IEG; Dávila Benavides, Nilson, "Desplazamiento Forzado en el Magdalena Medio 2005-2006," Revista Acción de Paz, No.3 (2007), Observatorio de Paz Integral Magdalena Medio and ACNUR.

As the security situation in Colombia improved and the state was able to gradually enhance its institutional presence at the local level, the focus of the government and the external assistance changed. The World Bank ended its assistance to this model in 2012. The authorities showed increased interest in assistance for decentralization and strengthening of local governments - as government institutions regain their standing in the conflict areas.

Education in the time of conflict (Pasto, Antioquia, Rural Education, and Antioquia Upper Education projects). The World Bank has shown significant commitment to support education in Colombia under very difficult circumstances. The conflict magnified the limitations of a highly centralized education system, with limited capacity at the local level. Teachers and social leaders were often targets of violent attacks. The flow of IDPs put pressure on local education systems, primarily at the basic level. To respond to these challenges, in 1997 the World Bank approved the Pasto Education Project (\$7.2 million) and the Antioquia Basic Education Project (\$40 million). The goal was to enhance decentralization by improving institutional capacity of local education authorities to continue education process despite the conflict.

The flexibility of project design allowed exploring exploration of new areas, such as curriculum reforms and building new partnerships with civil society. Here as well, a major shortcoming was the absence of basic performance indicators (for example, attendance, enrollment, and teacher absenteeism), which undermined the quality of the project evaluations and the learning that could have been derived from them.

As the intensity of violence gradually declined, the second generation of projects had broader coverage, and supported local government capacity and national government initiatives to enhance the role of schools in peaceful coexistence 


\section{CHAPTER 4}

Violence Related to Crime and DRug Trade

initiatives. The World Bank played an important convening role, and was successful in disseminating knowledge, and helping to create new partnerships with NGOs and donors, most notably through the Education for Peace Partnership.

Refocusing safety nets and reaching IDPs. The World Bank provided significant financial and technical assistance to Colombia's main conditional cash transfer program - Familias en accion (FAMILIAS) from its inception in 2001. The Second Social Safety Net project (\$636 million), approved in 2008 during the global financial crisis, was disbursed against the expansion of cash transfers. A major development was the waiving of the means testing requirements for the IDPs. The coverage of displaced households increased from 40 thousand in 2005 to 350 thousand in 2010, and to 500 thousand in 2013. The share of these households in FAMILIAS almost doubled, reaching 20 percent of the total. Today FAMILIAS may be reaching about one-third of the total displaced population. An in-depth impact evaluation ${ }^{6}$ found positive results, not only on education and health outcomes, but also empowerment of women.

Land patrimony protection, titling, and restitution (Protection of Land and Patrimony of IDPs project series). High inequality and uncertainty in the ownership of land in poor rural communities has been both a cause and consequence of conflict and violence in the rural areas of Colombia. The World Bank has continually focused on this area and tried to adapt its activities to the changing intensity of the conflict over time. During the late 1990s, at the peak of the violence, it focused on small activities aimed at protecting vulnerable farmers in isolated regions with no presence of the state - to learn from these interventions so they could be replicated and scaled-up at a later stage (the Peasant Enterprise Zone for Peace Project, 1998).

As the security situation began to improve, the institutions of the state strengthened, and legislation on restitution was introduced, the World Bank changed its focus to more systemic activities that could assist institutions in charge of land protection and land restitution. The centerpiece of the assistance in this area was the Protection of Land and Patrimony of IDPs project series financed by the SPF that spanned the period of 2002-2014. It started with a small Phase 1 ( $\$ 0.8$ million) and then expanded over time to a larger Phase 3 ( $\$ 8$ million), in the process helping mobilize a threefold increase in government and donor resources.

In the initial stage, the World Bank provided institutional capacity assessment and brought international expertise in the fields of cadaster and land registry. The methodology developed with the help of the World Bank project was piloted in 13 municipalities in five regions. These activities were scaled-up at the next stage, reaching additional regions and specific groups of IDPs. In addition, the project 
developed complementary measures for women and ethnic groups: it identified barriers and constraints in protecting women's land rights and made recommendations. By 2011 the Colombian government made land restitution a national policy and created the Agency for Land Restitution. According to IEG interviews in the field and views expressed by many government officials, these changes were largely based on the World Bank's inputs.

At the end, Bank support to land patrimony protection, titling, and restitution combined courage and determination by counterparts, generated volunteerism, and had significant catalytic effects that proved to be of major systemic importance over time. It started with a very small pilot phase and then expanded, mobilizing a significant amount of government and donor support-spanning over more than 10 years. It proved to be critical when the security situation improved, and households started returning to their land. It was perhaps the most successful activity undertaken by the World Bank if measured by size of the intervention relative to the eventual impact.

Overall, Bank interventions made useful contributions to the peace and reconciliation agenda of the Colombian authorities. The World Bank successfully played a catalytic role and stuck with a consistent vision for many years, and was able to build up slowly from small opportunistic interventions to activities that have national impact. The World Bank played an important convening role and was successful in disseminating knowledge. It helped to create new partnerships with NGOs and donors, as well as facilitated involvement of government agencies, but more importantly it facilitated and built up on the existing partnerships, with the critical input of Bank's national staff in Colombia. These partnerships are likely to be sustained beyond the project activity - which is an important legacy of the World Bank. Speed and flexibility of response, in particular in disbursement and procurement, allowed the World Bank to move quickly (often ahead of other donors). This way, in some cases, the World Bank was able to provide a "liquidity cushion" to many of the joint initiatives. Those were also the contributing factors for the World Bank's successful financial support to Colombia's main safety net during the global crisis, a period that also coincided with a massive growth in the volume of IDPs.

Honduras. The 2011 diagnostic report, the 2011 CPS, and the First Programmatic DPC had a common forceful message and strategy: the need for an integrated strategy ( $\mathrm{a}$ "paradigm shift") emphasizing prevention and a need to assist at the family level, focusing on parenting, youth at risk, and school-based programs, 
complemented with strengthening conflict resolution and citizen security approaches at the local level.

However, most of the later operations did not follow up in this strategic direction. The Second DPC, approved in 2014, does not refer directly to crime and violence and does not follow up on the specific actions and policy steps addressed in this area by the earlier operation and charted by the CPS. A significant share of the World Bank's financing during that period focused on supporting the expansion of the Bono 10,000 safety net. ${ }^{7}$ However, the main objective of reducing extreme poverty through the Bono 10,000 program was not linked to the problem of crime and violence, despite its severity in Honduras. Project documentation describing assistance to Bono 10,000 does not attempt to synchronize interventions that address both poverty and violence, and how to exploit complementarities.

There is no evidence that the World Bank had a significant convening and catalytic role working with other donors or coordinating with the IDB, which had a sizable program in this area. Perhaps such activities did take place informally, but if they did, they were not recorded in the general documentation.

The ongoing Safer Municipalities Project is now the main lending activity addressing specifically groups at risk, but given its relatively small size, the impact is likely to be limited, unless it is scaled-up in the future. Successful scaling up requires learning at an earlier stage, which depends on having a robust M\&E system incorporated into the project design, which seems to be the case this time. Learning from the Barrio Ciudad experience was undermined by its weak M\&E.

The new Programmatic Approach to Citizen Security in Central America (2014) presents an opportunity to systematically expand the assistance to groups at risk in Honduras and work with other donors. The Programmatic Approach takes stock of developments since the launch of the 2011 report, and identifies critical areas of emphasis as seen today. Some of them have specific relevance to Honduras. This is a welcome effort which should inform the next strategy (CPF) for Honduras. The Programmatic Approach reaffirms two critical areas of particular relevance to Honduras: (i) community-based approaches to violence prevention and meaningful participation of groups and risk; and (ii) strong emphasis on youth violence prevention, focusing on youth development, child welfare, juvenile justice, and similar areas.

In the end, the large lending program to support the expansion of the Bono 10,000 safety net, combined with a few much smaller projects targeted to communities, was 
not consistent with the forcefulness in which the "new paradigm" was advocated in the CPS and the first Development Policy Credit.

Concentrating the World Bank's support on the safety net programs may have been be the most efficient way to reach the most vulnerable groups. It may have had some indirect impact in preventing and reducing violence. But this connection and the appropriate balance between supporting safety nets and targeted interventions at the local level to reduce violence should have been elaborated in project and strategy documents. Wholesale support to Bono 10,000 may have preempted some critical programs more targeted to prevent violence. The possibility of scaling Safer Municipalities and deriving operational priorities from the new Programmatic Approach presents now an opportunity to focus more directly on the groups at risk and informing the new World Bank Group strategy for Honduras.

\section{Conclusions}

Honduras and Colombia are quite different in per capita income levels, institutional development, political stability, and the importance of nongovernmental institutions. Although violence in both countries was linked to drug traffic, in the case of Honduras it was compounded by the emergence of powerful gangs that could move freely across Central America and Mexico. The international component of the problem is more severe and less under the control of the authorities than in case of Colombia. Furthermore, in Colombia violence affected specific regions and was more localized and perhaps more predictable. Being a small country with very porous borders, Honduras was affected by violence across the whole country and society. In addition, the intensity of violence in Honduras, measured by the number of violent deaths has been much more severe. During 2000-10 the annual number of violent deaths was about 25 per 100,000 inhabitants in Colombia, with a strong declining trend reaching half that number in recent years. In Honduras, it increased drastically from about 50 to 90 deaths per 100,000 inhabitants, almost 10 times higher than in Colombia. ${ }^{8}$ Thus, the challenges for the authorities and the World Bank are also probably higher. Nevertheless, some of these differences do accentuate learning in various areas.

- Application of the demand-driven community development model in Colombia through a series of relatively small and experimental operations was highly relevant, particularly during the earlier period of extreme conflict and violence. This approach eventually allowed gradual scaling up and replication in other communities. An important conclusion is that small 
lending operations and pilots can generate significant amount of new knowledge and high levels of externalities.

- Successful implementation required excellent knowledge of local conditions as well as determination, commitment, and plain courage on the part of the World Bank staff and the Colombian counterparts, which often had to operate in unsecure environments. Many projects (such as the Magdalena model) mobilized significant volunteer support in advising the communities and assisting in the design and implementation of the subprojects, which was critical for success. The World Bank helped the process and provided quick and early support through financing and technical assistance.

- Importance of civil society engagement. In Colombia, civil society was actively involved at the community level in conflict-affected areas-experimenting with many local initiatives prior to the World Bank involvement. The World Bank was able to capitalize on that knowledge and the level of trust developed in conflict-affected communities. The Catholic Church, NGOs, volunteers, and community members in high standing had already been involved in CDD-type activities since the 1990s. Many of the World Bank staff were familiar with these efforts and knew the local conditions well. All of this helped the World Bank's initial efforts at the community level, as critical partnerships were established with these organizations early on. It also facilitated the scaling up efforts later. These features are not apparent in projects in Honduras and may have been a constraint to their success.

- Balance between budget support and small pilots. Large budget support operations tend to overshadow smaller innovative pilot interventions. In an FCV context, the small pilots were quite important for identifying working solutions to the most urgent needs of the communities under stress and create conditions for scaling up successful interventions. At the same time, they are often risky, time-consuming, and costly to implement. Achieving a proper combination of these two approaches is not easy yet quite important. Specialized grant programs to top-up operational budgets for small pilot programs in FCV situations could be a way of dealing with it.

- Link between safety nets and community approaches - In Colombia the budget support operations to fund the expansion of the safety net incorporated some modifications in eligibility to reach people most affected by the conflict. A similar approach could have been applied in Honduras, with necessary adjustments to local conditions - as part of the many projects to expand Bono 10,000 .

- MEE - In both countries community-level projects had very weak M\&E frameworks, which undermined the assessment of results and diminished the 
learning potential from the projects even though many of them had been designed as pilots.

- The convening role of the World Bank in Honduras seems to have been limited compared to Colombia. Little is reported on work with the IDB, which had an important program on issues of violence and conflict. This seem to have changed with the new Programmatic Approach to Citizen Security in Central America, where the World Bank is working closely and coordinating with donors.

- Regional approaches - The problems of drug trafficking and gangs are quite common and interlinked with other countries in Central America and Mexico. Therefore, the World Bank may need to focus more on regional programs in this area, including regional projects or joint AAA work across the relevant countries.

\section{References}

Acemoglu, Daron, James A. Robinson, and Rafael J. Santos. "The Monopoly of Violence: Evidence from Colombia." Journal of the European Economic Association 11 (January 1, 2013): 5-44. doi:10.1111/j.1542-4774.2012.01099.x.

Bank, World. Violence In Colombia: Building Sustainable Peace and Social Capital. Washington, D.C: World Bank Publications, 2000.

Castañeda-Dower, Paul, and Tobias Pfutze. "Land Titles and Violent Conflict in Rural Mexico." Working Paper, Submitted for Publication, 2015.

Chacón, Mario, and Universidad de los Andes (Bogotá, Colombia) Centro de Estudios sobre Desarrollo Económico. Dinámica y determinantes de la violencia durante "La violencia" en Colombia. CEDE, Centro de Estudios sobre Desarrollo Económico, 2004.

Dube, Oeindrila, and Juan Vargas. "Commodity Price Shocks and Civil Conflict: Evidence from Colombia*". The Review of Economic Studies, February 15, 2013, rdt009. doi:10.1093/restud/rdt009.

Grossman, H. I. "Kleptocracy and Revolutions." Oxford Economic Papers 51, no. 2 (April 1, 1999): 26783. doi:10.1093/oep/51.2.267.

Holmes, Jennifer S., and Sheila Amin Gutiérrez de Piñeres. "Violence and Sectoral Development in Colombia." In Economic Development Strategies and the Evolution of Violence in Latin America, edited by William Ascher and Natalia Mirovitskaya, 95-124. New York: Palgrave Macmillan, 2012.

Pastrano, Andres*Moser. "Colombia - Essays on Conflict, Peace, and Development." The World Bank, March 9, 2004.

http://documents.worldbank.org/curated/en/2004/03/828325/colombia-essays-conflictpeace-development.

Thoumi, Francisco E. "Illegal Drugs in Colombia: From Illegal Economic Boom to Social Crisis." The ANNALS of the American Academy of Political and Social Science 582, no. 1 (July 1, 2002): 102-16. doi:10.1177/000271620258200108. 


\section{CHAPTER 4}

Violence Related to Crime and Drug Trade

World Bank. 2011. World Development Report 2011: Conflict, Security, and Development. Washington, DC: World Bank.

Youngers, Coletta A. Drugs and Democracy in Latin America: The Impact of U.S. Policy. Edited by Eileen Rosin. Boulder, Colo: Lynne Rienner Publishers, 2004.

1 "Crime and Violence in Central America : A Development Challenge," World Bank, 2011

2 The program shared some characteristics with the CDD model. It was developed for a territory or region which may be significantly broader than a community, but sharing important commonalities as far as the conflict is concerned. In contrast with CDD, the funding did not flow directly to the community but to the Consortiums in charge of implementation, often designated as the partner organizations (PO).

3 The Magdalena Medio series were accompanied by a parallel EU program, the so-called Laboratorios de Paz

4 "Iron fist" approach of the first half of the 2000s hardened penalties, allowed for the detention of juvenile criminals in high security prisons, and lowered the age of legal responsibility to 14 years.

5 For the case of Magdalena Medio LILs and the Peace and Development series, an impact evaluation prepared by the Government found a positive effect on food security and consumption among population affected by the conflict. Impact regarding exposure to violence was not measured. Guarín, Sergio et al., "Evaluación de Impacto de los Programas Paz y Desarrollo y Laboratorios de Paz: Línea de Base e Impactos Preliminares", National Planning Department, Colombia, 2008. Attanasio, Orazio, et al., Evaluación de impacto de los programas de Paz y Desarrollo y Laboratorios de Paz, INFORME FINAL, National Planning Department, Colombia, 2011.

${ }^{6}$ Government of Colombia 2008: Programa de Familas en Acción: Impacto en Capital Humano y Evaluación Beneficio Costo del Programa, Evaluación de Políticas Públicas series, Numero. 6.

7 Social Protection project to support the expansion of BONO (\$40 million) approved in 2010, was followed- up by two additional financing projects approved in 2013 and 2015, totaling \$37 million.

8 The highest death rate in Colombia was experienced in 2002, about 40 deaths per 100.000 inhabitants. 


\section{Failure of Governance and State Legitimacy}

Violence in parts of Nigeria (Delta) and Pakistan (Balochistan, FATA, and KP provinces) - two large and globally important MICs - is a form of subnational organized violence, but it differs from the cases described earlier in that they reflect lack of loyalty with and popular legitimacy of national and local government rather than primarily reflecting state hostility toward local minorities. (See Appendixes A.7-8 for details on the history of these conflicts.)

The two cases differ in important ways. The Niger Delta is intermittently in rebellion, but history shows that when the rents from oil are more fairly distributed between local and national elites, peace can be maintained. Identity and the perception of injustice can become a fulcrum for violence (as in the Biafra civil war in the 1960s), but can recede when rent extraction is better balanced. As in all the cases examined in this study, external economic and or political drivers matter. In this case they are manifested in the actions of the major international oil companies, but since the oil companies share common cause with federal and local elites seeking a stable rent regime, their contribution is not necessarily destabilizing.

In Pakistan, the central government has always had difficulty extending its writ in the mountainous tribal areas - this problem long predates the modern state. Local elites have resisted incorporation into a national polity, seeing few benefits to joining a modernization process that would erode their power and influence. Religious extremism further complicates this picture, but does not determine it - these forces have not to this point shown an ability to threaten the one institution of the state that demonstrates real competence, the army - not least because the funds they can attract have not empowered them to the same extent as extremists in Iraq and Syria.

\section{World Bank Group Response}

Nigeria. During the reviewed period, the World Bank moved from a policy of not sending staff to the Niger Delta to preparing and implementing a conflict-responsive project in four Delta states. Ending a six-year hiatus, the World Bank re-engaged with Nigeria in 1999 after civilian government was restored following decades of military rule. However, it was only the 2010-14 CPS that included conflictresponsive lending to the Niger Delta, after heavy fighting between armed militias and the government gave way to an amnesty in October 2009. 
Non-involvement (1999-2009). The conflict in the Niger Delta does not feature prominently in the series of interim strategy notes (ISNs, 2000-04) issued after reengagement. They refer variously to pollution associated with oil industry activities being a flashpoint for political unrest; the sentiment that the Delta population was not receiving an adequate share of natural resource wealth; and ethnic conflicts around oil resources in the Delta being much better financed through theft of oil. The strategy notes mention growing youth unemployment contributing to social instability. The documents relied mainly on the existing literature since the World Bank, due to its earlier disengagement, had done no independent diagnosis of the conflict. Except for CDD projects, no lending was envisaged in the Delta. This was to persist for the rest of the decade. In 2002-03 the World Bank, together with other donors, supported a Strategic Conflict Assessment prepared by the Institute for Peace and Conflict Resolution in Nigeria.

The 2005-09 CPS mentions that the World Bank was increasingly introducing conflict avoidance and resolution mechanisms in its projects and cites the FADAMA ${ }^{1}$ project as one that includes specific mechanisms to resolve conflicts over land use. The CPS states that the causes of violent conflict identified in the Strategic Conflict Assessment of 2002-03 largely remained and observes that "Nigeria remains vulnerable to resurgence of conflict. The extraction of oil in the Niger Delta provides a particular force." The CPS Progress Report (2008) takes the view that adjustments in the program would be made to reflect, inter alia, an increased emphasis on Niger Delta issues. It notes that conflict in the Niger Delta threatened stability in the region and Nigeria's economy.

Gradual engagement (2009-2015). The 2010-13 CPS was prepared at a time of heavy fighting between militias and government forces over control of the Niger Delta. The CPS Progress Report (2011), prepared when the amnesty had become wellestablished, observes that "in the troubled states of the Niger Delta, the potential for deeper engagement going beyond CDD projects was to be explored." The World Bank expected that, in these states, extensive fiduciary work would establish a basis to strengthen governance and institutions over the longer term. Thus, both the admittedly fragile peace, as well as the government's eagerness to harness donor support to demonstrate early wins in areas such as youth employment in the wake of the amnesty, had removed the constraints to Bank lending to the Delta states.

The World Bank appeared to have taken the lead in going into the Delta states in support of the government's amnesty and development program, with other donors such as the European Union and the United Kingdom's Department for International Development (DFID) following. The CPS Progress Report described the preparation of the SEEFOR project (\$200 million) in Bayelsa, Delta, Edo, and 
Rivers states. SEEFOR was approved in 2013 as the main vehicle of Bank support of the government's development program in the Niger Delta. It used the provision of youth employment as a point of entry to strengthen generally weak PFM systems in Bayelsa, Edo, Delta, and Rivers states. The project had been under preparation for two years and state commitment to move forward had emerged only in small steps. ${ }^{2}$

Pakistan. World Bank Group engagement and interest in conflict-affected regions of Pakistan has varied considerably from one CAS cycle to another. From 2000 onwards there was regular reference to the challenges of the North-West, but the heightened focus on specific FCV projects and engagement has been evident only since 2010. Thus, much of the relevant overview relates to events between 2010 and 2015.

In the 2010-13 CPS, the security issue is taken up more explicitly as a development challenge to be addressed. One of the four pillars of the CPS was to improve security and reduce the risk of conflict. The CPS focused on the conflict in KP and FATA, identifying the need to respond to the most vulnerable and marginalized populations. The absence of employment opportunities and inadequate livelihoods in these areas were considered to be fertile ground for militant groups to flourish. Addressing security was one of the transformational outcomes the CPS prioritized, and the formulation of the MDTF for KP, FATA, and Balochistan was seen as the key tool in responding to the security challenge.

A Post-Crisis Needs Assessment (PCNA, done jointly with the United Nations, European Union, and ADB) was undertaken to serve as the guide for Bank support in FATA and KP. Expected support included agriculture, technical and vocational training, social protection, and governance programs designed to enhance the legitimacy of the state. Based on the PCNA, the World Bank Group took the lead in establishing and managing the MDTF. ${ }^{3}$ To support priority interventions in Balochistan, a comprehensive Balochistan Development Needs Assessment was also carried out.

The 2015 CPS is responding to the effort by the government to develop a comprehensive development framework of 4Es: Energy, Economy, Extremism, and Education. In addition to challenges from militancy, sectarian and ethnic violence, and rising crime, the CPS notes uncertainty over the post-2014 transition in Afghanistan and possible spillovers. Feedback from stakeholders for the CPS consultations indicated that the foremost priorities to create conducive conditions for economic and social progress include: in $\mathrm{KP}$-improving the security situation and creating jobs; in Balochistan - water scarcity, transparency, and sharing benefits 
from natural resources, girls' education and access to finance; in FATA - governance and constitutional reforms.

\section{Assessment}

Nigeria: The World Bank's limited financial leverage with the Nigerian authorities meant that opportunities for engagement were demand-driven, and the Nigerian government (at least in the beginning) was not keen to involve the international community in its internal conflicts. Furthermore, the World Bank's ability to do so did not depend solely on the federal government, since the Nigerian states have considerable autonomy.

Another reason for the World Bank's noninvolvement until after the amnesty in 2009 and the buyoff of over 20,000 ex-militants was the serious security situation. In addition, since governance was a core theme of the CPS, the World Bank was increasingly engaging with the Nigerian states that had demonstrated a commitment to improved governance. The states of the Niger Delta did not fulfill this criterion and lending to them was seen as a risk. Hence, once security considerations permitted, involvement in the Delta in the interest of mitigating conflict required the World Bank to trade off the benefits of demonstrating early wins against the costs of operating in a governance-challenged environment.

At the same time, the World Bank has been implementing CDD projects in the Delta states for some considerable time. Since the governments of the Delta states did not meet the criteria for Bank engagement, the only agents with which the World Bank felt it could engage were communities. The fact that the community associations managing the CDD subprojects also included members of militant groups, offered some security assurance for the World Bank project teams.

The return of an uneasy peace to the Niger Delta in the wake of the 2009 amnesty and the government's desire to demonstrate early successes there provided the donor community with the opportunity to implement conflict-responsive programs. The SEEFOR project combined a youth employment component targeting youth from disadvantaged backgrounds, in which the state governments were most interested, with a component to strengthen PFM. There is no particular connection between the two components. The youth employment component will be judged to have delivered an early win if those graduating from the program and equipped with vocational skills pass a market test, where success implies finding employment or becoming entrepreneurs. In contrast, the results from the PFM component will 
take considerable time to materialize. So far, the project has been extremely slow to take off since approval in 2012, and there are no results to report.

The World Bank's analytical and advisory work on the Niger Delta has focused on PEMFARs, using them as an engagement and motivation tool before the project preparation in the states participating in the SEEFOR. Given the prominence of the conflict in the Niger Delta and fragility of peace, an economic report on the causes of the conflict would have deepened the World Bank's understanding of the region's economy and provided a sounder analytical basis for conflict-responsive lending.

There were no projects or AAA to mitigate the negative environmental impact of oil spills and gas flaring in the Niger Delta. While in the past (prior to the amnesty) this was explained by the security conditions in the Delta, the World Bank is still reticent to get involved in this area.

Pakistan: This evaluation identified three major themes or areas of engagement. Each theme includes specific lending operations, technical assistance, and partnerships.

Education in conflict. ${ }^{4}$ Bank interventions sought to ensure continued access to education, in particular for girls, and development of institutional structures at the provincial level. The capacity-building components that funded training for teachers and staff, student achievement testing, and M\&E, was instrumental to the successful implementation of the project. The education team has seen a shift in priorities regarding the education portfolio and acknowledged that the appetite for working in difficult regions has grown. This has been partly driven by the priorities of the World Bank strategy, but also by the performance of the provincial government and its continued interest in education programs.

National and Regional CDD and Social Development Projects as complementary fragility tools. ${ }^{5}$ The link between CDD, social protection programs, and the World Bank's strategy in Pakistan was fundamental to its impact in the areas of conflict. Historically, national-level projects have not had the same reach in the North-West Frontier Province (NWFP), Balochistan, and KP, but they have informed the nature of the World Bank's engagement. PPAF II implementation was affected by several factors, including rising conflict, insecurity, and political instability across the country. Nevertheless, the bulk of project objectives were achieved, and new partnerships with and financing from multilateral and bilateral organizations and the corporate sector were established, creating enough momentum to carry the project into a third phase. 
While the success of the PPAF project series was widely acknowledged, the diversity of needs in the conflict-affected areas made it increasingly apparent that specific projects were required to supplement national programs and respond to the specific conflict drivers in FATA and KP. In discussions with program staff, there was acknowledgment that the formality of the PPAF model worked against any momentum established in conflict regions. Negotiations and partnerships took considerable time and there was inadequate flexibility in the system to respond to project inputs that either worked or failed. There was a clear sense that these regions required specific projects tailored to their needs.

The NWFP CIP-II project was an early attempt at responding to the particular needs of the conflict-affected regions. The project faced many logistical delays and its impact was limited. The experience highlighted that implementing a communitybased project through a local government system that has been introduced recently, needs sustained commitment at all levels and a major emphasis on institutional and behavioral change. This was missing, and the project failed to meet expectations. In addition, both project documentation and feedback from project staff indicated that CIP-II did not consider how it could be strategically linked to the PPAF.

The KP-SADP project made a more explicit effort to strengthen the capacity of the poor to improve their livelihood options through access to social and productive infrastructure using participatory approaches. The project has been moving slowly, but has paid attention to consultations with relevant stakeholders to ensure a degree of ownership and the institution of appropriate project structures. A meeting with the key field staff for this project showed that while security remains a burden, the decision-making process that relies on a 75 percent majority for investment projects was bringing consensus to how funds were disbursed.

In reflecting on the link between national and regional social development and CDD projects in Pakistan, it is apparent that the lack of integration and strategy with how the investments worked in fragile regions has prevented the World Bank program from achieving better results. Much of the focus of these projects was on delivering commitments rather than identifying expected changes and using these to determine a way forward. The country team stressed that in the rural areas of northern Pakistan, projects cannot hope to shift the value system simply through the provision of assets and services. There are entry points for change, but they need to emerge through persistent engagement and committed partnering.

In the KP-SADP, changing the way things are done has led to considerable impact. Examples of this include sewing workshops where women were encouraged to take other women along as their chaperones. This negotiated arrangement took time to 
organize, but it resulted in more than 3,500 women being trained in communities where they were previously restricted outside of the household. Shifting the mindset of younger community members was having a big impact on change. Where youth representation was encouraged, there was an emerging debate about shifting away from families having to make the huge financial commitments to funerals and weddings.

But observations of this kind were not being adequately tracked or monitored. Thus, the opportunity in linking the various threads of the social development portfolio in Pakistan was about identifying the range of entry points for innovation and using these to better respond to the radically different needs of those in the conflictaffected regions.

MDTFs as strategic tool for development assistance. ${ }^{6}$ The introduction of the MDTF for $\mathrm{KP}$ and FATA led to a significant shift in the strategy and approach to working in the conflict regions. The reviewed projects financed by the MDTF all sought to offer an alternative model to working in the fragile regions.

Both emergency recovery projects had greater strategic oversight that came with the World Bank's MDTF responsibilities and renewed urgency in dealing with the regional instability. Third-party monitoring became an integral part of the MDTF setup as did the promotion of sustained beneficiary participation. The MDTF committed significant resources to project preparation and supervision. The World Bank drew on a long history of similar projects in close cooperation with other parts of the World Bank Group to identify priority needs and approaches. Activities proposed were to be identified in the PCNA and where possible to draw direct links between the full range of MDTF instruments.

The Revitalizing Health Services in KP project was designed as a pilot in six districts to be scaled-up further. What was missing from the engagement was the necessary sophistication in the monitoring systems to illustrate how effective the pilot was likely to be and the features needed for the project to be scaled-up. The FATA Rural Livelihoods project intended to complement the recovery projects by reaching the unserved and underserved low-income communities in a phased manner. The project was consistent with the intentions of the PCNA in adopting a rights-based approach, with an emphasis on empowerment, nondiscrimination, consultation, and participation.

One of the pillars in the MDTF strategy was to enhance the development of a vibrant and active economy, thereby addressing the core strategic objective of stimulating employment and livelihood opportunities, as highlighted in the PCNA. The 
Economic Revitalization of KP and FATA project sought to innovate by looking to technological advancements such as geo-referencing for physical verification and mobile phone-based voice messaging for beneficiary participation, tracking, and verification. These measures were intended to provide a useful alternative in crisisaffected areas where the World Bank's supervisory capacities are challenged due to limited access.

Overall, the projects funded through the MDTF offered a useful vehicle for support to the conflict-affected regions, but Bank staff and development partners identified two persistent issues that kept it from being more effective. First, while the responsiveness of the World Bank and its projects were appreciated by partners, there was inadequate programmatic oversight and strategy in how the MDTF sought to deliver impact. The quality of Bank management and engagement on the MDTF was acknowledged by a wide range of partners, particularly regarding the PCNA process, but linking initial projects to a cohesive strategy reflective of engagement on fragility was problematic. There was also concern regarding the integration of MDTF and non-MDTF Bank projects. This left the MDTF as an efficient vehicle for support to the conflict regions, but without a clear strategic vision.

\section{Conclusions}

Bank programs in Pakistan and the Nigerian Delta aimed at helping to deal with the consequences of violent conflicts (destruction of infrastructure and lack of services), promote social cohesion, and address some of the drivers of violence (such as youth unemployment). The main causes of fragility that were at the heart of developmental challenges in these large and complex countries were often beyond the reach of the World Bank - often even in terms of initiating dialogue on sensitive topics such as distribution of rents and religious extremism.

The World Bank's understanding of discourse on violence in both countries has evolved over the years, reflecting the way that the World Bank is gradually becoming more comfortable focusing on the political economy of subnational violence and developing analytical and operations instruments to address it. CDD has been used as a form of information-gathering and contextual learning.

Nationwide CDD projects allowed the World Bank to maintain a presence in the conflict regions even when security conditions were highly unsettled. These projects were seen as serving local communities rather than governments and ensured 
relative security for Bank staff working on them. They were not, however, the forum for addressing the causes and consequences of the insurgencies.

The experience in Pakistan showed that even with small regional commitments and relatively high cost, implementation of nationwide education programs in conflict zones, adjusted to local realities, can deliver important developmental outcomes and contribute to progress on conflict mitigation. Lack of integration of investments in fragile regions with national programs and strategy can limit the efficacy of those programs.

Many Bank projects combined two essential elements: meeting community needs (infrastructure, employment, services) and capacity building. The latter has a much longer gestation period compared to the former and depends to a larger extent on collaborative and committed local and central government counterparts.

MDTFs are a vital strategic tool in conflict regions, and they require a diverse and specific skill set. This includes the ability to liaise and interact effectively with donors, effectively link MDTF projects to other projects in the World Bank portfolio, establish, build, and maintain relations with regional governments in difficult circumstances, as well as the foresight to see how different project priorities fit with longer-term strategic planning.

\section{References}

Francis P., Lapin D. and P. Rossiasco. 2009. Securing Development and Peace in the Niger Delta: A Social and Conflict Analysis for Change (Woodrow Wilson Center for International Scholars, Washington, DC).

Nossiter, A. 2010. “Far from Gulf, a Spill Scourge 5 Decades Old.” New York Times, June 16.

SDN. 2015. Communities not Criminals: Illegal Oil Refining in the Niger Delta.

United Nations Environmental Program. 2011. Environmental Assessment of Ogoniland.

United Nations Development Program. 2007. Niger Delta Situation Assessment and Opportunities for Engagement, Mission Report. (Restricted circulation), United Nations Development Program, Abuja.

World Bank. 2000: Nigeria: Country Strategy Note (May).

- - - 2001. Nigeria Interim Joint Strategy Update (May).

---.2002 . Nigeria Interim Strategy Update (February).

-- .2003. Nigeria: Environmental Degradation, Impacts on Poverty and Options for Sectoral Harmonization.

---.2004 . Nigeria Second Joint Interim Strategy Progress Report.

- - - 2005. Country Partnership Strategy, 2005-09 (June). 
CHAPTER 5

FAILURE OF GOVERnANCE AND STATE LEgitimacy

--- .2005. Nigeria Strategy Completion Report Review (Operations Evaluation Department).

---.2005 . Nigeria: OED Strategy Completion Report Review.

- - -.2008. Country Partnership Report Progress Report, 2005-09 (February).

---.2009 . Nigeria: IEG CASCR Review (Independent Evaluation Group, July).

- - - 2009. Country Partnership Strategy, 2010-13 (July).

- - - 2011. Country Partnership Strategy Progress Report (September).

- - - 2011. NIGERIA: State Level Public Expenditure Management and Financial Accountability Review: A synthesis report (January).

---.2011 . NIGERIA: Socio Economic Assessment (July).

- - - 2012. State Employment and Expenditure for Results Project (SEEFOR): Project Appraisal Document, February.

- - - 2013. Nigeria Economic Report No. 1, May.

- - - 2013. NIGERIA: Where has all the Growth Gone?: A Policy Note.

---.2014 . Nigeria Economic Report No.2, July.

- - -2014. Nigeria: IEG CPSCR Review, Independent Evaluation Group, April.

${ }^{1}$ FADAMA is a series of nationwide CDD projects launched in 1992, including three phases (1992-99; 2003-09; and 200817)

2 The SEEFOR project was approved by the World Bank's Board in 2012 and became active in 2013.

${ }^{3}$ The MDTF is supported by 11 donors (Australia, Denmark, EU, Finland, Germany, Italy, Sweden, Turkey, UK and USA) collectively contributing $\$ 159$ million.

4 Balochistan Education Support, 2006-14, \$24 million; Promoting Girls' Education in Balochistan, 2012-15, \$10 million

5 Poverty Alleviation Fund Projects (PPAF II 2004-11, \$570 million; and PPAF III 2009-16, \$250 million); NWFP Community Infrastructure Project II (CIP, 2004-09, \$37 million); KP Southern Area Development Project (SADP, 2013-15, \$18 million)

${ }_{6}^{6}$ KP Emergency Roads Recovery Project (2011-15, \$26 million); FATA Emergency Recovery Project (2012-15, \$16 million); Revitalizing Health Services in KP (2012-15, \$10 million); FATA Rural Livelihoods (2012-15, \$12 million); Economic Revitalization of KP and FATA (2011-15, \$20 million). 


\section{Externally Imposed Fragility}

The Lebanon and Jordan cases demonstrate how small MICs can become inadvertent victims of a violent and unstable neighborhood. Both countries have been exposed to the consequences of the proxy struggles waged by global and regional powers in Syria and Iraq, and the dire social consequences that these rivalries have brought to pass in the form of a "refugee shock." They contain the highest proportion of refugees-to-native population in the world today (Lebanon hosts 232 refugees per 1,000 of its native population, Jordan 87 per 1,000). ${ }^{1}$ Both countries have also shown surprising social and political resilience in accommodating numbers of refugees that would strain the boundaries of sociopolitical acceptability in much wealthier and more stable Western European countries, where the prospect of a much smaller hosting ratio ${ }^{2}$ is evoking a significant political backlash. Both countries argue that they are providing a global public good by hosting the refugees, and that they are responsible for preventing an even larger influx into Western Europe. They also argue that their state resources are stretched, and that if they do not receive more adequate direct support (refugee relief funds) as well as indirect forms of relief (for example, to enable the types of fiscal expansion necessary to accommodate large numbers of new entrants into the schooling and health systems), they may not be able to survive this shock indefinitely.

This chapter reviews World Bank Group assistance to Lebanon and Jordan to cope with the inflow of millions of refugees from Syria. Unlike earlier described situations, where the World Bank was helping to deal with either the consequences of conflicts or their underlying causes, in Lebanon and Jordan it is helping the extremely stressed systems of two high MICs to cope with an externally imposed and still evolving humanitarian crisis.

Therefore, the review of World Bank Group portfolio and work programs in these two countries is very selective and only refers to those parts that were either designed specifically to address the impact of Syrian refugee crisis, or were modified to accommodate the refugee presence. It is important to note that in both countries the World Bank is not providing assistance directly to refugees (shelter, food, jobs), which is a prerogative of the United Nations agencies and NGOs, as the governments of Lebanon and Jordan explicitly refuse to borrow funds for humanitarian assistance. Instead, Bank assistance is directed to mitigate the impact of the refugee inflow on country systems and those Lebanese and Jordanian communities whose livelihoods were affected by the crisis. 
Hence, this review covers a relatively short period (2011-present) while most activities are still ongoing. The two country programs are reviewed in tandem, although the political and economic dynamics and client relationship have been very different: Jordan has been peaceful and stable for several decades and has a strong government in control of the situation, while Lebanon has periodically been in general turmoil since the 1970s, including a series of civil and cross-border wars. The World Bank has a sustained and long-lasting partnership with both countries, but is not a major player in terms of financial leverage, and its presence on the ground is modest.

The Syrian crisis. Violent repression of peaceful antigovernment demonstrations by Syrian state security forces in March 2011 morphed into an armed rebellion of an array of groups fighting the government and each other. The insurgence escalated to a full-blown civil war that has killed over 220,000 people and left hundreds of thousands injured. The war led to massive displacement of civilian population (approximately 11 million), creating the largest humanitarian crisis since World War II. The United Nations estimates that 7.6 million people are internally displaced and nearly 4 million have crossed the border to the neighboring countries (mainly Jordan, Lebanon, and Turkey).

As the conflict enters its fifth year with no end in sight, the humanitarian situation is constantly deteriorating. Syrian refugees arrive with limited economic resources that are quickly depleted. Without formal residency rights and access to work permits they can only depend on (limited) humanitarian assistance and informal labor to secure their livelihood. The associated financing needs increased from $\$ 836$ million in 2012 to $\$ 7.4$ billion in $2015 .^{3}$ Actual funding received never matched the requirements and was actually on a downward slope relative to the needs (Figure $6.1)$. 


\section{Figure 6.1. Syrian Refugees-Funding Requirements and Coverage}

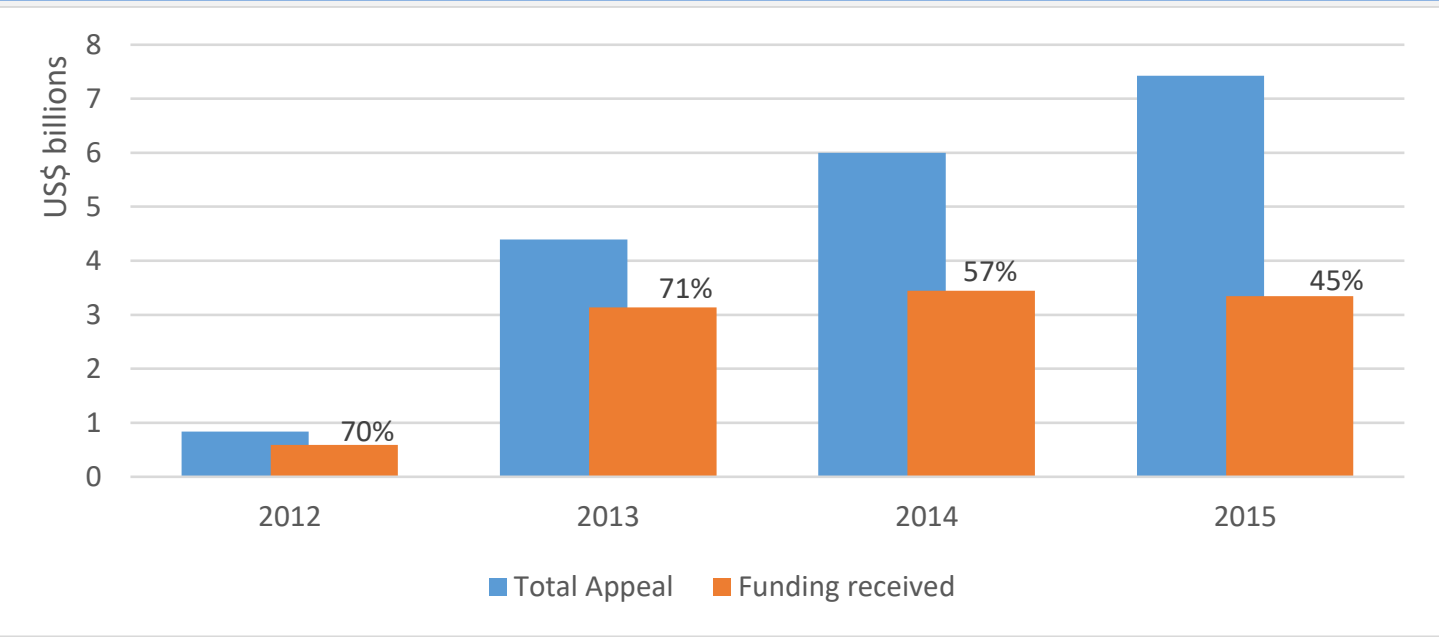

Source: FTS OCHA

Impact on Jordan and Lebanon. Four years after the start of the influx, the crisis is now taking a heavy toll on the economy and society, with a potential for further worsening in the next few years. Jordan has had a generally positive experience in absorbing the previous waves of refugees from Iraq in 2003-04 (estimated at 500,000$700,000)$ that have even proven to be beneficial to the economy because of the high level of skills of many refugees and inflow of Iraqi capital. However, there are strong views that the net impact of Syrian refugees is largely negative with serious implications for the country's future development.

Two camps (Azraq and Za'atari) were built in Jordan to offer shelter and ensure security. However, today only about 14 percent of the registered refugees live in the camps, ${ }^{4}$ while the rest reside in local communities, mainly in the north of the country. The Government of Lebanon did not authorize the establishment of camps, and most refugees have settled in the north and east, already the poorer parts of the country.

In a region that already hosts millions of Palestinian and Iraqi refugees and Egyptian migrants, ${ }^{5}$ the large scale of refugee inflow has led to de facto demographic changes that can seriously disturb the social balance in both countries. The government of Jordan estimates the total number of Syrians living in the country at 1.4 million, most of which are displaced because of the Syrian crisis. In some municipalities and villages, Syrians now account for more than half of the local population. Such an extreme and sudden demographic transformation threatens social cohesion of the communities. ${ }^{6}$ Similarly, in Lebanon the 1.2 million registered refugees (most of them Sunni Muslims) account for almost one-fifth of the total population-a 
potentially major shift in already complicated and fragile multiconfessional fabric of Lebanon.

The perception of a deteriorating security situation has undermined consumption and investment, which has dragged down economic growth. The impact of the Syrian crisis depressed growth in both countries to around 2 percent since 2011 compared to 7-8 percent in 2007-08. The dramatic increase in supply added considerable pressure on the already fragile labor markets, increasing unemployment, with considerable impact on youth and unskilled workers, putting pressure on wages and increasing informal employment. One of the key concerns is the availability of affordable housing for low-income groups of local population, as increased demand pushed rents upwards. ${ }^{7}$

In Jordan, many communities have grown overnight without having the necessary infrastructure in place. In early 2014 municipal authorities reported that they were unable to meet the needs for solid waste collection and disposal. The large influx of refugees has further exacerbated the already very serious water scarcity. For Jordan, one of the world's driest countries, this is a major concern that borders on disaster.

Recognizing the serious humanitarian aspects, both countries allowed Syrian refugees access to public services, notably basic health and education. This has placed a serious burden on these services with a reported deterioration of quality. In 2013, 40 percent of schools in Jordan were considered crowded. In Lebanon, a second shift was introduced in many schools to serve the increasing number of children. Similar issues confronted the health sector.

The resources that Lebanon and Jordan had to allocate to meet the needs of refugees put a strain on public finances that neither of the two countries can afford. In its "Response Plan" prepared in 2013, the Government of Jordan estimated the additional fiscal burden at $\$ 850$ million per annum. This raises serious challenges in a country with already very high and unsustainable fiscal deficits. In Jordan, the debt-to-GDP ratio reached 86 percent in 2014, breaking the constitutionally allowed ceiling of 60 percent. In Lebanon, public finances were structurally weak prior to the Syrian refugee shock. The debt-to-GDP ratio fluctuated in the vicinity of 130 percent after 2012, and fiscal deficit widened by $\$ 2.6$ billion during 2012-14.

In summary, as the crisis persists, Jordan and Lebanon seem to have reached a critical saturation point, which is further exacerbated by humanitarian aid fatigue within the donor community. So far there have not been many reports of open hostility toward the Syrians. In part this is because in many places that Syrians have settled they already had tribal ties, or there were existing Syrian communities. 
Nevertheless, there is a potential for future conflict as the situation continues to deteriorate and the current sympathy toward the plight of the refugees wears off. ${ }^{8}$

\section{Box 6.1. Lebanon Economic and Social Impact Assessment Findings}

The Lebanon ESIA, prepared with the help of the World Bank in 2012, forecasted a refugee influx of 1.6 million by the end of 2014. The report estimated that in the 2012-14 period, the conflict would (i) cut real GDP growth by 2.9 percent each year; (ii) push 170,000 Lebanese into poverty (in addition to 1 million currently living below the poverty line) and double the unemployment rate to above 20 percent, most of them unskilled youth; and (iii) depress government revenue collection by $\$ 1.5$ billion while simultaneously increasing expenditure by $\$ 1.1$ billion due to the surge in demand for public services, bringing the total fiscal impact to $\$ 2.6$ billion. The report estimated that the surge in demand for public services would initially result in decline of access to and quality of service delivery, which would require additional spending of $\$ 2.5$ billion for stabilization. The report indicated that the impact of the Syrian conflict was particularly pronounced in trade and tourism sectors. This report was discussed at the first meeting of the International Support Group for Lebanon on the margins of the United Nations General Assembly meetings in September 2013.

Source: World Bank, IEG

\section{World Bank Group Response}

The World Bank's emergency response in Jordan and Lebanon provided analytical tools to be used for strategic decision-making and to set up financing mechanisms to channel emergency response to the most affected sectors: municipal services, health and education; and assistance to vulnerable groups. The main instruments of additional emergency assistance were the $\$ 150$ million emergency loan and a $\$ 54.3$ million grant in Jordan, and an MDTF in Lebanon that attracted pledges for $\$ 74.5$ million.

Pre-crisis Bank programs in Jordan and Lebanon targeted medium- and long-term development needs including improved fiscal management, human capital development, improved business environment, and social safety nets. Jordan's CPS 2012-2015 was drafted at a time when the extent of the Syrian crisis could not have been anticipated. The CPS Progress Report (2014) noted that the original focus on fiscal management, growth, and competitiveness had to be complemented with strengthening resilience and mitigating vulnerability. In Lebanon, the CPS Progress Report (2013) ${ }^{9}$ reasserted the relevance of the current strategy but scaled back two of its goals, considering regional instability and political volatility. In both countries, 
the World Bank was also trying to leverage additional grant resources, including from the SPF, and donor financing.

Financing. In Jordan, the World Bank provided a fast-disbursing emergency loan (Mitigate the Impact of Syrian Displacement on Jordan, \$150 million, 2013) to help maintain access to healthcare (immunizations) and basic household goods (subsidized bread and LPG cylinders) for vulnerable households. The Emergency Services and Social Resilience project (ESSRP, \$54.3 million, 2013) was financed through an MDTF leveraged by an initial $\$ 10$ million from the SPF. The project supported nine municipalities most affected by refugee inflow in addressing the most pressing needs, including solid waste removal, water management, and rehabilitation of roads. It is planned to expand to include 16 municipalities. Additionally, the World Bank tried to factor in the Syrian refugee crisis into some existing programs (Second Education Reform for the Knowledge Economy - ERFKE II), and explored opportunities for leveraging additional grant financing, following the successful model of the ESSRP. Neither effort materialized by the time of this report was prepared.

In Lebanon, the World Bank set up an MDTF with $\$ 10$ million seed capital from the SPF which attracted pledges from several bilateral donors for a total of $\$ 74.5$ million. The objective of the MDTF was to help mitigate the impact of the refugee inflow on the hosting communities through three separate sector interventions. However, because of the Lebanese authorities' inability to ratify the grants due to a political standstill in the parliament and the cabinet, as well as delays in setting up the MDTF, the first project has just started and the other two are still not operational. There were some other minor initiatives, including \$1.2 million financing through the SPF for capacity building and support to local communities hosting refugees; and scaling up the National Poverty Targeting Program.

Analytical Work. In both countries, following a request by the authorities, the World Bank prepared ESIAs that became widely accepted reference documents for policy decisions and coordination of donor support. In addition, the World Bank prepares regular semiannual briefs on the economic and social developments in Jordan and Lebanon.

In Jordan, the World Bank was part of the government effort to develop the National Resilience Plan (2014-2016) and later the Jordan Response Plan (JRP), jointly with many donor partners. However, the World Bank's day-to-day interaction with the authorities in Jordan was often constrained by its small presence in the country - the World Bank does not have a formal office and is represented by two operations staff, hosted by IFC office in Amman. Perhaps indicative of that was 
the World Bank's rather limited (and temporary) participation in the JRP sectoral working groups..$^{10}$ In Lebanon, the World Bank worked with the government on the Lebanon Road Map of Priority Interventions for Stabilization, and then set up the MDTF to finance parts of the Road Map.

Gender issues. The massive influx of refugees in Jordan and Lebanon has altered the gender dynamics. Since many men are away at war, or have been killed, women's roles have changed in the household, community, and the workplace. More than a quarter of Syrian refugee households across the region in Lebanon, Jordan, and Turkey are headed by women. Nevertheless, World Bank Group engagement on gender and conflict issues in Jordan and Lebanon has been limited. Its primary focus was on issues like closing gender gaps in primary and secondary enrollment, labor force participation, and an increase in the number of femaleheaded households due to migration (Lebanon), and a conflict lens remains missing.

\section{Assessment}

Overall, the World Bank's emergency assistance to Jordan and Lebanon included relevant and timely analytical work that was widely used by the governments and partners, and flexible financial instruments that attracted additional donor financing - albeit far from the identified needs. The choice of strategic areas was relevant in both countries: at the national level helping the stressed and overcrowded health and education systems, and at the municipal level building capacity and improving resilience of local authorities to face increased demand for services.

At the same time, it quickly became clear that the World Bank's traditional financial instruments applicable in the context of high MICs such as Jordan and Lebanon (IBRD loans) were not well suited to respond to a humanitarian emergency, such as the Syrian refugee crisis. The $\$ 150$ million emergency loan to Jordan helped to relieve pressure and address some urgent needs, but there was little appetite from the client to continue in the same vein. The World Bank tried various alternatives, including use of several grant facilities and leveraging additional funding from donors, with modest success. In Lebanon, the MDTF is still not fully operational, after several years of crisis, generating doubts among donors about its effectiveness. The SPF grant facility was useful in providing seed money, allowing the World Bank to identify some initiatives, and generated some goodwill among donors, but the amounts were miniscule compared to the needs. 
Social protection. The $\$ 150$ million emergency loan for Jordan disbursed swiftly and used country systems to the degree possible. The loan achieved the objectives of maintaining universal access to essential health care services (immunization for children in particular) and basic household needs (subsidized LPG and bread). The subsidization prevented price increases (by 35 percent) for these basic goods, which could have pushed about 45,000 people into poverty.

In Lebanon, the World Bank helped to scale up the successful National Poverty Targeting Project (NPTP) with an \$8.2 million grant (2014), which became an independent stand-alone operation, the Emergency National Poverty Targeting Program. The objective of the project is to expand the coverage and enhance the social assistance package of the NPTP to the population affected by the Syrian crisis. It introduced new benefits such as food assistance through an electronic card system, currently implemented by the WFP for more than 800,000 refugees. The overall package of assistance includes health coverage, education aid, and an e-card food voucher program.

Municipal Services. The World Bank's assistance for municipal services in most affected municipalities in Jordan is making a difference, although sustainability remains a concern. The ESSRP leveraged donor funding around the World Bank's initial grant, mobilizing total of \$54 million. Municipal grants were allocated to subprojects that were identified in consultation with local communities through a participatory process that involved public debate, followed by approval by municipal councils. Subprojects included a wide range of services and activities that were defined in a positive eligibility list of expenditures (the most popular items were solid waste management and infrastructure, mainly roads). The project included cooperation with the UNDP (training on public participation/consultation and the identification of needs) and nongovernmental organizations. Direct beneficiaries of the project included over 1 million people-exceeding the 790,000 initially planned. The project's scope is planned to expand to reach 16 municipalities. An IEG mission visit to two of the municipalities that have received assistance from the project indicated a strong support for the effort. The Lebanon MDTF's first project (Municipal Services Emergency Project, \$10 million) has only recently become effective. It is expected to help the host communities to address urgent priorities (water, sanitation, roads, and community activities).

Health and Education. In response to the increasing demand for health and education services, the World Bank supported the health sector in Jordan as part of the $\$ 150$ million emergency loan. In the education sector situation was different. The World Bank's flagship 10-year multi-donor program (ERfKE II, 2009-15, \$408 million) that supports the government's education reform program, did not factor in 
the 130,000 Syrian students that entered the system after the crisis, despite the 2014 CPS Progress Report's expressed intention to do so.

In Lebanon, there are two MDTF projects in the pipeline, designed to help health and education sectors: (i) the Emergency Primary Healthcare Restoration Project (\$21 million); and (ii) the Emergency Education System Stabilization Project (\$32 million). Neither of them is operational yet. In the meantime, the World Bank responded to education sector needs through two components of the much smaller 5M: Displaced People in Jordan and Lebanon technical assistance project (2012-15, $\$ 2.4$ million). The project integrated 2,600 children into the system; upgraded classrooms for 5,000 students and offered schooling benefits to 7,400 parents in Jordan; and is helping build capacity in the Ministries of Education and Social Affairs in Lebanon.

IFC Program. There have been no IFC projects aimed directly at addressing the impact of the Syrian crisis in Jordan or Lebanon. Investments in potentially related spheres - microfinance or small and medium enterprise development-did not have specific links to refugee or host communities' problems. At the same time, IFC is trying to use its current product mix to address unemployment and absorb the growing labor force through investment in financial intermediaries (Middle East Micro Credit Company and FINCA Jordan) and support for micro, small, and medium enterprise development through the Middle East and North Africa Transition Fund (\$3.2 million, 2015).

\section{Conclusions}

Jordan and Lebanon - both high middle income, but resource poor and heavily indebted countries - have been hosting millions of Syrians fleeing the civil war at the expense of their already stressed national systems (health, education, and infrastructure) and public finances. Social cohesion of many communities is under stress, and the fragile multiconfessional and ethnic fabric is threatened (especially in Lebanon) by the new demographic challenge. The outlook on the resolution of the crisis in Syria remains extremely bleak, making the timetable for voluntary repatriation of the refugees more and more remote and unpredictable. Both countries have clearly reached the limit of their capacity in hosting a large refugee population.

The World Bank's effort to help mitigate the impact of the crisis can be qualified as the best it could do with the instruments at its immediate disposal. The country department continues to do a commendable job with the resources available to it 
and has been a loud voice in various circles advocating for the needs of the countries. The World Bank prepared timely and comprehensive needs assessments for both countries, widely used by the governments and the international community. Emergency financing was channeled to relevant sectors: municipal services, health, education, and assistance to vulnerable groups.

However, the World Bank's financial response to the crisis was inadequately small. The presence of the World Bank played a catalytic role (including management of and provision of seed capital for MDTFs), attracting additional donor resources, but its effectiveness (if measured by amounts attracted and compared to the needs) was quite low.

One of the main challenges for the World Bank in Jordan and Lebanon was finding appropriate financing instruments. IBRD loans by their nature were not the best choice (they disburse slowly, are relatively expensive, and both countries are highly indebted), but the only one handily available. This option was exhausted fairly fast in Jordan by providing a $\$ 150$ million emergency loan. In Lebanon, the situation was complicated by internal political crisis and a stalemate in the parliament (parliamentary vote is required for loan approval in Lebanon) and the cabinet.

Budget support was the most important priority that the World Bank has supported appropriately. Given further fiscal pressures from the large increase in population from the refugees, the World Bank is one of the very few significant sources for filling the budget deficit. But it further exacerbates the already high level of debt that is now approaching 100 percent of GDP in Jordan and is close to 140 percent in Lebanon.

Both governments are reluctant to borrow on IBRD terms for addressing a crisis they did not cause in the first place. They believe, quite understandably, that since the crisis has been externally imposed, it should be the responsibility of the international community to bear most of the costs. The response of the international community to the continuous pleas of Jordanian and Lebanese authorities to co-finance the global public good of hosting Syrian refugees so far has fallen far short of the needs. In this situation, the World Bank was using various alternative sources and mechanisms (including the IBRD surplus, and various trust funds) to come up with a response, albeit at a very limited scale. While highly commendable, these efforts are a far cry from the needs of the two countries.

An important lesson from Lebanon and Jordan experience is that the World Bank management - with the political and financial support of its shareholders - urgently needs to develop financial mechanisms or fast-response facilities to be used in 
similar situations. It also needs to use its global convening power more effectively and encourage others to do so. A recent initiative announced in October $2015^{11}$ is a step in that direction, albeit a much delayed one - as it was clear at least since 2013 that Lebanon and Jordan were in for an unprecedented refugee crisis. Scaling up existing and functional facilities such as the SPF is another option, as its current use without catalytic effect raises questions about efficiency, given the small size and high transaction costs.

In a volatile country environment, a strong local presence is imperative to establish a monitoring mechanism that will allow quick strategy and program readjustment, and carry out an effective convening function. The World Bank's existing regional presence is modest, ${ }^{12}$ and it may need more staff resources to cover all countries it is dealing with. The country department currently covers Syria, Iraq, Iran, Lebanon, and Jordan - which suggests the need to look holistically at the problems of conflict in Syria and Iraq and their spill-over effects. The World Bank needs to approach this not as a country-specific issue, but as a subregional issue of the highest corporate priority.

Another lesson is related to the importance of focusing on long-term developmental challenges. The emergency element in the Syrian refugee crisis attracted the world's attention to the plight of the displaced population. The World Bank played a positive (though limited) role in addressing the most burning issues within its immediate reach. A bigger question, however, is how to deal with the longer-term problems facing the countries and the region. While appropriate for the short-term crisis, Bank assistance is not likely to fundamentally alter the fragility profile of both countries. It is highly likely that most Syrians will stay in Jordan and Lebanon for a long time, even in the unlikely event that war ends soon and a stable government emerges. ${ }^{13}$ In both countries the refugee inflow exacerbated many already existing and well-known fundamental systemic challenges, such as unsustainable public sector expenditures and high unemployment. Therefore, there is a high probability of a short-term crisis becoming a serious long-term development challenge. World Bank Group strategy as currently designed falls short of dealing with it.

Finally, the Jordanian and Lebanese experience points to the importance of maintaining a credible and robust macroeconomic framework to withstand impacts from unforeseen crises. The World Bank is likely to be an important institution (in addition to the International Monetary Fund) to provide financial support when a crisis does occur. But absent a sustainable macro framework, the ability of the World Bank to increase its support will be limited. Without more drastic structural reforms, Jordan and Lebanon will continue to be vulnerable to events like the Syrian crisis. 
1 Forbes Statistica

2 For example, 1 million refugees would translate into 12/1000 ration in Germany

3 UNOCHA Financial Tracking Service.

${ }^{4}$ REACH January 2015.

5 There are 2 million registered Palestinian refugees in Jordan, of which 370 thousand still live in camps. The war in Iraq in 2003 has displaced some 800,000 Iraqi immigrants into Jordan. In Lebanon, UNRWA reports 450,000 Palestinian refugees, 50 per cent of which live in camps.

${ }^{6}$ Syrians are viewed as more "liberal" by the conservative Jordanian communities of the north.

7 NRC, The shelter situation of refugees from Syria in neighboring countries. June 2014.

${ }^{8}$ See "Social Cohesion and Intergroup Relations: Syrian Refugees and Lebanese Nationals in the Bekaa and Akkar", Charles Harb and Rim Saab, American University of Beirut, 2014.

${ }^{9}$ Lebanon 2011-14 CPS Progress Report.

10 The World Bank initially led the task force for municipal livelihood which was later taken over by USAID.

11 A joint initiative of the World Bank Group, IsDB, and the United Nations was announced during the October 2015 WBIMF annual meetings. The proposed financing initiative consists of two mechanisms to support countries impacted by conflict and economic slowdown, as well as those affected by large numbers of refugees and IDPs: (i) guarantees from donor countries to issue special bonds to finance economic recovery and reconstruction projects; and (ii) grants from donor countries to provide concessional finance to middle income countries of the region hosting the bulk of refugees. Source: http://www.worldbank.org/en/news/press-release/2015/10/10/new-joint-initiative-to-mobilize-additional-support-forrefugees-in-the-middle-east-and-north-africa.

12 Regional office covering Mashreq (Iran, Iraq, Jordan, Lebanon, and Syria) is located in Beirut, Lebanon. There is no formal Bank office in Jordan, and a few project staff are hosted by IFC representation.

13 According to UNHCR, even after the end of the conflict voluntary repatriation of refugees can take up to 17 years. 


\section{Conclusions and Recommendations}

\section{Conclusions}

World Bank Group strategic approach. The World Bank Group understanding and discourse on conflict and violence has evolved over the years, reflecting the way that the World Bank is gradually becoming more comfortable focusing on the assessment of the political economy of subnational and regional violence in MICs and developing analytical and operations instruments to address it. The 2011 WDR was a critical step in this direction, as it presented a broadly applicable and relevant analytical framework for engagement.

The incidence of violent conflicts in MICs with established institutions suggests that violence and conflicts are not primarily a low-income country problem and that impoverishment is not the sole driver of conflict and violence. Localized FCV situations in relatively stable and economically successful countries pose particular and sometimes unique challenges. MICs are less likely to feel obliged to engage on the sensitive political issues associated with subnational conflict, thus placing a greater premium on World Bank Group diplomatic skills and appreciation of the local political economy.

Sustained engagement of the World Bank Group in conflict areas ahead of peace settlements and during the ongoing violence has been critical. The experience, contacts, and credibility acquired in this process had important payoffs once there was peace. Concerns about security during the active phase of conflict often limited the World Bank Group presence in the field to essential personnel, but the World Bank staff were able to develop rapport and trust at the local level and effectively supervise projects. The courage and commitment of local counterparts and Bank staff were essential for success. Maintaining a presence (even nominal) in former conflict zones is essential to help sustain peaceful development. In some cases, the end of major violence led to rapid and complete withdrawal of the World Bank, although the drivers of the original conflict and weak governance capacity were unchanged. In many instances, the problems have much deeper regional roots and the World Bank needs to develop a more holistic view of these problems and their spill-over effects.

Involvement in the interest of mitigating conflict has required the World Bank Group to trade off the benefits of demonstrating early wins against the costs of operating in a challenging environment. It often has been more attractive for the 
World Bank Group to engage where it believes it can achieve strong impact (emergency response) than in situations where the problems are more intractable.

World Bank Group emergency assistance is appropriate for short-term crises, but its strategic comparative advantage remains in helping countries to tackle longer-term developmental challenges. In some countries reviewed in this report, the World Bank Group FCV-related strategy still falls short of dealing with the core drivers of violence - regional conflicts and governance-perhaps out of reluctance to compromise lending volumes.

World Bank Group definitions, measurement metrics, and policy application are still somewhat inconsistent along the full spectrum of countries experiencing FCV (more pronounced in the non-FCS group). In this regard, the role of the new structural unit, the FCV CCSA - the focal point on FCV in the World Bank Group, currently serving as a knowledge hub and advisory service provider - needs to be given considerable authority over policy matters. At the same time, the new unit needs to find a way to maintain a closer connection to operational work, which will maximize the impact of transfer of knowledge that sits within the CCSA.

The CPIA index, despite its usefulness on some aspects, has many deficiencies when used as the main tool for assessing fragility or forecasting the risk of societal breakdown. The low-income country cut-off excludes MICs, where much of today's FCV situations are occurring. A new multidimensional marker system would deliver much more nuanced results and would permit a degree of prediction that the current CPIA does not. At the same time, the new "flag and outcome" system will have a much-diminished impact if it cannot be published, tracked, and discussed openly.

The institutional and staff incentives for engagement in conflict situations and risktaking seem to be lagging the spirit of World Bank Group's strategic approach to FCV, as reflected in various Bank documents, including the 2011 WDR. Continuity in Bank staffing policy across the countries experiencing FCV has not been observed frequently, but when it happened, the payoff was clear, resulting in effective transfer of knowledge and expertise.

World Bank Group Instruments. The World Bank's strategies were relatively fast to respond and adjust to FCV situations, particularly in emergencies, as demonstrated in strategy and analytical outputs, but the World Bank's operational response was often constrained by the lack of choice in instruments at its disposal and depended to a large extent on donor financing and the presence of large MDTFs. 
The CDD model was widely considered an appropriate tactic to establish presence in conflict areas, increase community involvement in programming, encourage community ownership of projects, and foster social cohesion. Projects with a CDD design were a useful point of entry for the World Bank Group in conflict-affected areas, used also as a form of information-gathering and contextual learning, allowing the World Bank to maintain a presence even when security conditions were highly unsettled. Early engagement was particularly relevant and useful for laying the foundation for post-conflict collaboration. These projects were seen as serving local communities rather than governments and ensured cooperation and security for Bank staff working on them. They were not, however, a forum for addressing the causes and consequences of violence. The broader lesson is that the success of CDD projects in conflict zones is highly context-specific, and that these projects give the World Bank an opportunity to acquire the local knowledge necessary for more ambitious efforts to alter the political economy of the area.

Small pilots were useful for identifying working solutions to the most urgent needs and creating conditions for scaling up successful interventions. At the same time, they are often risky, time-consuming, and costly to implement. Specialized grant programs to top-up operational budgets for small pilot programs in FCV situations could be a way of dealing with it.

Investments in education can be important in dealing with issues of fragility, particularly as they pertain to psycho-social issues among children, providing safe spaces for integration and community cohesion to develop, and dealing with the problem of "lost generations" in more protracted conflicts. Implementation of nationwide education programs in conflict zones, adjusted to local realities, can deliver important developmental outcomes and contribute to progress on conflict mitigation.

Analytical and advisory work was relevant and high quality, and contributed to awareness and understanding of the issues and main challenges. Most of it was part of larger studies (often in partnership with donors), such as needs assessments, political economy analyses, and core economic diagnostics. However, the operational follow-up was uneven and depended on particular country circumstances. That was particularly true for ongoing conflicts and follow-up on diagnostic studies.

FCV-specific diagnostic work (fragility assessments, conflict filters) was generally useful and relevant, but not particularly common in non-FCS group of countries. The utility of fragility assessments in non-FCS environment is somewhat limited by the fact that they are not mandatory, and the decisions on their preparation and 
sharing with the client governments is at the discretion of the country teams. Experience with the conflict filter product differed from country to country. Nevertheless, application of a conflict filter to Bank projects could, with suitable customization, be useful in countries where ethnic or other divisions carry the potential for igniting violent conflict-although its role should not be overestimated.

PFM diagnostics used by the World Bank in its programs in conflict-affected regions seem to have been deployed in an ad hoc manner, tailored to the country's circumstances. Some areas, such as policy advice on budgeting and governance arrangements in the security sector and fiscal decentralization in FCV situations, deserve more attention, especially since the World Bank does have strong capacity for and experience with such analysis.

World Bank Group engagement in supporting private sector development in FCV situations in non-FCS was limited. Bank (IBRD) PSD-related activities focused mainly on livelihoods, small infrastructure, and employment schemes, while IFC concentrated its efforts on post-conflict reconstruction. There were only a few examples of FCV-related Bank-IFC coordination at all stages - from conflict mitigation to post-conflict support.

In general, IFC's FCV-related strategy and corporate targeting focuses on the countries included in the FCS list, and its activities in situations of localized FCV in MICs were limited. In most cases reviewed by this evaluation, IFC has deployed standard instruments, with little adaptation or innovation. At the same time, where IFC was able to find a niche and identify clients, its contribution was relevant and effective. Business volumes and financial returns of projects remain key performance metrics in IFC. Advisory services are under pressure to link to IFC's investments, which makes it difficult to provide a stand-alone advisory service in an FCV context. There are few incentives for staff to undertake riskier and generally smaller projects in these countries.

MIGA's PRI can help facilitate foreign direct investment when a country faces FCV situations. MIGA products (WCD or NHSFO coverage) could benefit from information exchange with the FCV CCSA, particularly regarding the use of country-level fragility assessments.

Weak MEE frameworks undermined the assessment of results in many of the cases observed, and diminished the learning potential from the projects even when they were designed as pilots. Failure to properly record even the positive experience is an indicator of lack of incentives to maintain institutional memory. Despite efforts to account for FCV factors in project design and implementation, they were rarely 
captured in results. Only a third of observed programs recorded fragility-specific outcomes, and only a quarter of them had M\&E systems specifically designed to track FCV issues. Generally, more positive outcomes of FCV-related interventions (compared with the rest of the portfolio) point to the perception of risks to outcomes in conflict-affected regions to be exaggerated.

The World Bank Group's focus was limited on gender issues in conflict-affected areas reviewed by this evaluation: few programs were designed or implemented taking into consideration gender disparities, and the little analytical work done was not translated into operations.

Partnerships. The World Bank-United Nations institutional partnership was not systematic and its frequency and effectiveness varied across the countries and themes. The existing system did not encourage building such partnerships because of perceived high transaction costs, lack of strong staff incentives, incompatibility of the fiduciary and legal frameworks, and competition for influence and limited donor resources at the country level. The main reasons behind successful partnership initiatives were clear division of labor (easier cooperation with specialized United Nations agencies) and personal initiative and experience of the field staff (prior work experience in the other institution was always a plus). A more nuanced strategic and technical dialogue is needed to delineate respective roles and comparative advantages, and ensure a common understanding of key strategic issues that the two institutions can work on jointly. Clear guidance in this regard can significantly facilitate the work of the teams on the ground to avoid unnecessary competition and focus on effective collaboration.

Multi-donor trust funds are a vital strategic tool in conflict regions, and they require a specific skill set that includes the ability to liaise and interact effectively with donors, link MDTF to other projects in the World Bank portfolio, the foresight to see how different project priorities fit with longer-term strategic planning, and the ability to establish, build, and maintain relations with regional governments in difficult circumstances.

Global thematic trust funds (such as the SPF and the Global Program of Forced Displacement) were helpful in supporting synergies in the FCV context, as the funding available through them allowed the flexibility and agility needed for partnering in post-crisis context. However, these funds are fragmented, which diminishes their impact, particularly in the MIC context. Since many FCV initiatives depend on trust fund financing, more strategic alignment of those funds would lead to less fragmentation, better targeting, and better results. Scaling up highly functional facilities, such as the SPF, would be essential, as their current use without 
much catalytic effect in MICs raises questions about efficiency, given the small size and high transaction costs.

\section{Recommendations}

This evaluation recommends the following:

WORLD BANK GROUP STRATEGIC APPROACH

- Review the institutional setup and interaction of various World Bank Group units dealing with FCV matters to ensure that the FCV CCSA drives substantive thinking on strategy and policy in this area across the World Bank Group. This would also entail closer operational engagement of CCSA staff with and across the World Bank Group members (including IFC and MIGA), and regional and thematic departments.

- Develop a new multidimensional publicly disclosed system of markers and flags for monitoring and measuring fragility, including in non-FCS countries. Linked to this, integrate fragility assessments as part of the SCD/CPF process to be applied systematically in countries where conflict and violence or externally imposed fragility constitute a significant impediment to attaining the strategic objectives of the World Bank Group.

- Scale up regional presence and outlook, including through regional projects and joint analytic and advisory work across relevant countries, and ensure World Bank Group sustained presence in FCV-affected areas, monitoring the fragility profile of the countries/Regions.

WORLD BANK GROUP ENGaGEMENT TOOLS

- Develop new financial mechanisms or fast-response facilities to be used when outbreaks of violence or external threats jeopardize resilience in MICs. Improve strategic alignment and use of global FCV thematic trust funds, while boosting their agility. Options to consider include using these funds for co-financing small pilot programs in FCV-affected areas with potential of scaling-up.

- Within the new SCD/CPF model, develop a broader strategic approach to interventions in FCV-affected areas, expanding sector interventions beyond the CDD model, and improving coordination and information sharing within the World Bank Group, with particular attention to private sector development activities (through a more customized approach to risk assessment, project mix, policies and procedures), public financial management (including fiscal decentralization and broader use of diagnostic 
tools), education, and gender (including integration of conflict-specific gender issues in project design and implementation). Strengthen M\&E frameworks by including FCV-related outcome indicators.

\section{PARTNERSHIPS}

Develop institutional incentives for collaboration and strategic thematic guidance on partnering - particularly with the United Nations but also with other partners. Introduce systematic communication and staff exchange programs to increase the level of collaboration. 



\section{Appendix A. History of Conflicts and Violence}

\section{A.1 Mindanao, Philippines}

Moros ${ }^{1}$ live on the large island of Mindanao (mostly on the western side now) at the southern end of the Philippine chain and on several small islands between Mindanao and Indonesia and Malaysia to the west. Violent conflicts between the Muslim Moro population in Mindanao and the central authorities date back to when the Spanish took over Philippines after Magellan's arrival (16 $6^{\text {th }}$ Century) and started Christianity in the rest of the island chain. The conflict flared up with variations after the United States took over from Spain in 1898 and after independence in 1946. The military government of Marcos reignited the conflict in the 1970s with a program of settling large numbers of Christians in Mindanao. This and the attendant displacement of Moros from land prompted the formation of insurgent organizations.

Four overlapping categories of groups in Southern Philippines have been fighting with the government and with each other in recent decades: Moro separatists, Islamist militants, Communists (operating nationwide), and bandit and kidnapper gangs. ${ }^{2}$ These labels reflect motivations, not clear organizational distinctions, but such categories can help discern what drives conflict and violence at different times and places, and what might reduce it. Within the context of this evaluation, focused on the Mindanao, there are two main drivers of conflict: ethnic/religious separatism and criminality. Some of the local disputes between Moros and Christians are over land titling, which also feeds into the wider political conflict. The conflicts in Mindanao are thus multidimensional. Figure A.1.1 shows the Heidelberg Conflict Indicators for various pairs of organizations and how they vary over time.

The MILF has been the largest among groups fighting with the government and with each other since the late 1990s. ${ }^{3}$ All occasional truce agreements have broken down within a year or two, with the exceptions of the 1990s-peace deal with the Moro National Liberation Front (MNLF), which resulted in creation of the Autonomous Region in Muslim Mindanao ${ }^{4}(\mathrm{ARMM})$ and the current deal with MILF, in effect since 2012 and signed into formal agreement in 2014. 


\section{Box A.1.1. Mindanao Conflict Timeline}

- 1970 - Moro National Liberation Front (MNLF) founded

- 1972 - Pres. Marcos declared Martial Law to contain insurgencies

- 1984 - Moro Islamic Liberation Front (MILF), a breakaway from MNLF, founded

- 1990 - Autonomous Region of Muslim Mindanao (ARMM) established

- 2000 - War between the army and MILF under Pres. Estrada intensifies

- 2003 - Pres. Arroyo brokers peace talks with MILF

- 2008 - Supreme Court declares the peace talks unconstitutional; conflict intensifies

- 2011 - Pres. Aquino resumes secret negotiations with MILF in Narita, Japan

- 2012 - Negotiations for Bangsamoro Framework concluded

- 2014 - Comprehensive Agreement on the Bangsamoro signed

- 2015 - Mamasapano incident (January), over 60 dead (police, MILF and civilians)

- 2015 - The deadline (June) passes for adopting Bangsamoro Basic Law. No new deadline established (unofficially until after the 2016 presidential elections).

Source: BDA, World Bank

According to the 2014 agreement, an autonomous region will be set up, to be known as Bangsamoro Autonomous Region, before President Benigno Aquino steps down in 2016. When implemented, it will give the Muslim-dominated area greater political powers and control over its resources. Bangsamoro replaces the ARMM, with its own government. The next steps would be for Congress to pass the Bangsamoro Basic Law and to hold a referendum to decide which provinces would be part of the autonomous region under the new law. MILF is essentially a government-in-waiting and, notwithstanding the January 2015 shootings $^{5}$ (the so-called Mamasapano incident) usually works with the government to maintain peace. The MILF has since the early 2000s clarified its ethic-religious identity, while disavowing any connection with international terrorist organizations and criminal activity. At times, it has conducted join operations with the military to suppress criminal gangs. Observers in 2015 were optimistic about implementation of the peace plan, but it is only just starting, and the more radical and violent groups (Abu Sayyaf, BIFF, NPA, others) have vowed to continue the fight. 


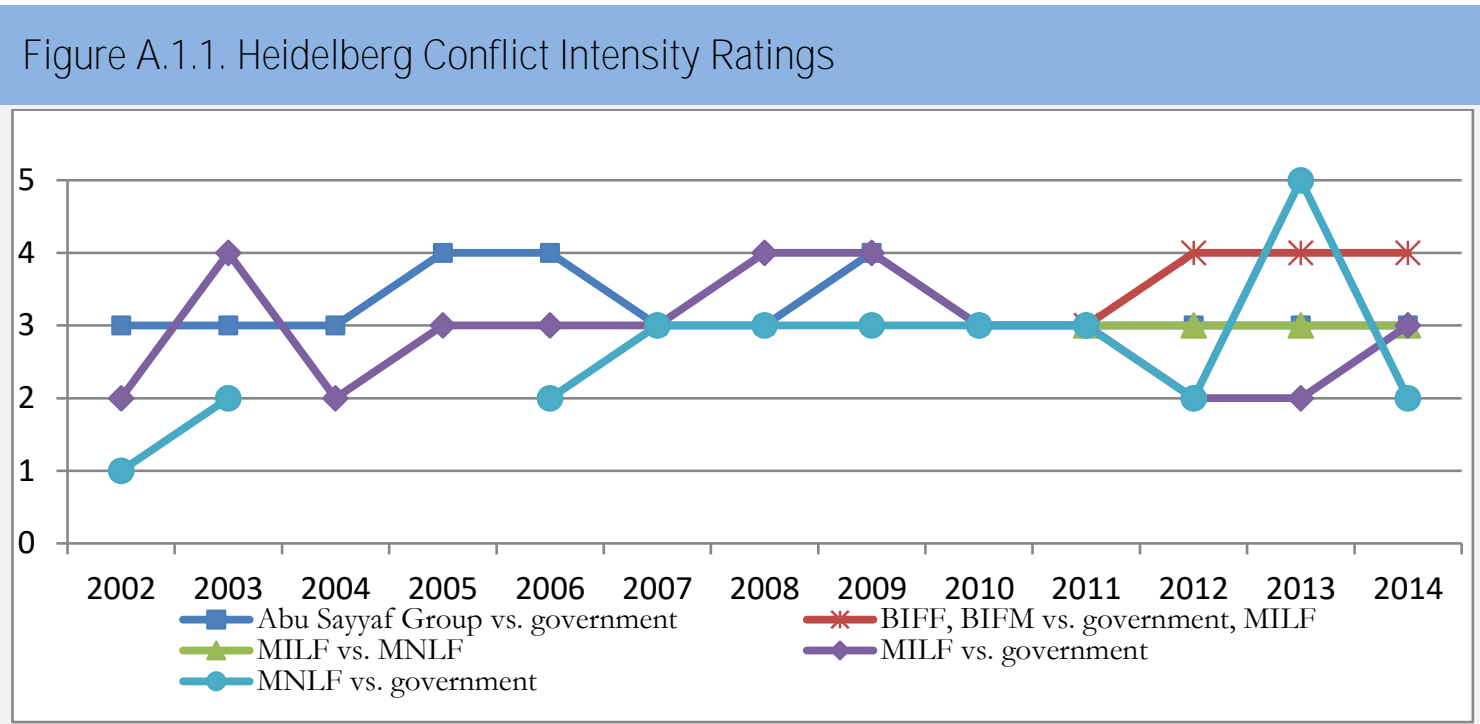

Source:

Since the early 1990s, organized violence in Mindanao has claimed more than 160,000 lives and displaced 3.5 million people since $2000 .{ }^{6}$ The numbers of displaced peaked in 2008, when an estimated 600,000 people were forced from their homes, making the Philippines the country with the highest number of newly displaced that year.

Table A.1.1. Human Development Indicators in ARMM and all Philippines

\begin{tabular}{lll}
\hline & & $\begin{array}{l}\text { PHILIPPINES } \\
\text { NATIONAL } \\
\text { AVERAGE }\end{array}$ \\
INDICATOR & ARMM & 32.9 \\
\hline Percent below the national poverty line (2006) & 61.9 & 23 \\
\hline Infant mortality (2006) per thousand & 34 & 85 \\
Percent households with safe water supply (2014) & 58 & 94 \\
Percent households with sanitary facility (2014) & 85 & 71 \\
Elementary school completion rate (2007-08) & 40 & 59 \\
Secondary school net enrollment (2008-09) & 30 & 71 \\
\hline Secondary school completion rate (2007-08) & 42 & \\
\hline
\end{tabular}

Source: World Bank

\section{A.2 Aceh, Indonesia}

Aceh is a province at the western tip of Sumatra, the western most major island of Indonesia. Population of Aceh is Sunni Muslim, like the rest of Indonesia, but follows a more conservative version of Islam, ${ }^{7}$ and takes pride in its distinctive culture. The conflict between Aceh and the central government dates to 1970s, when local elites resisted the efforts of President Suharto to bring all the country into a 
relatively homogeneous national culture. The main perceived threats to Acehnese religion and culture were from the "neo-colonial" government in Jakarta and the rising number of Javanese migrants. Aceh is also a major producer and exporter of natural gas, but the central government was keeping most of the revenue.

\section{Box A.2.1. Aceh Conflict Timeline}

- 1976 - Free Aceh Movement (GAM) established

- 1989 - Aceh is declared a Military Operations Area, martial law imposed

- 2000 - Peace talks between the government and GAM

- 2002 - Cessation of Hostilities Agreement (CoHA) signed

- 2003- Military attacked CoHA offices leading to collapse of agreement

- 2004-Pres. Yudhoyono elected in October, pledges to seek peace in Aceh.

- 2004-170,000 people are killed and 500,000 left homeless by tsunami (December)

- 2005- Government of Indonesia and GAM signed Helsinki Memorandum of Understanding in August, giving Aceh greater autonomy

- 2005-12 - More than $\$ 7.2$ billion of aid pledged, including $\$ 700$ million MDTF

- 2012 - World Bank leaves Aceh with the closure of MDTF

The Free Aceh Movement (GAM) raised this issue in its proclamation in 1977 and took its first military action right after the start of liquid natural gas sales from the Aceh region. Intermittent conflicts, punctuated with short-lived ceasefire agreements, caused an estimated 15,000 deaths since 1977 and displaced hundreds of thousands of civilians. GAM almost always lost the battles, and government forces almost eliminated it in the late 1970s and again in the late 1990s. GAM survived partly because the military's violent intrusions and corrupt presence increased local support for the insurgency. The fall of Suharto's military government in 1998 allowed GAM to revive again, as the exit of the military from Aceh left a power vacuum, until the military came back again the next year. Temporary ceasefires alternated with military emergencies and vows to eliminate GAM once and for all.

In 1999 the new Jakarta government implemented a nationwide government decentralization, which created, empowered, and funded local governmentsdistricts and sub-districts (Kecamatan). It deliberately by-passed and thus effectively dis-empowered the provincial level governments - the Aceh level-leaving them as administrative offices of the national government in Jakarta. It did not allow regional political parties. This 'big-bang' decentralization, as it became known, did not satisfy the autonomy demands of GAM. 


\section{Figure A.2.1 Heidelberg Conflict Intensity Rating}

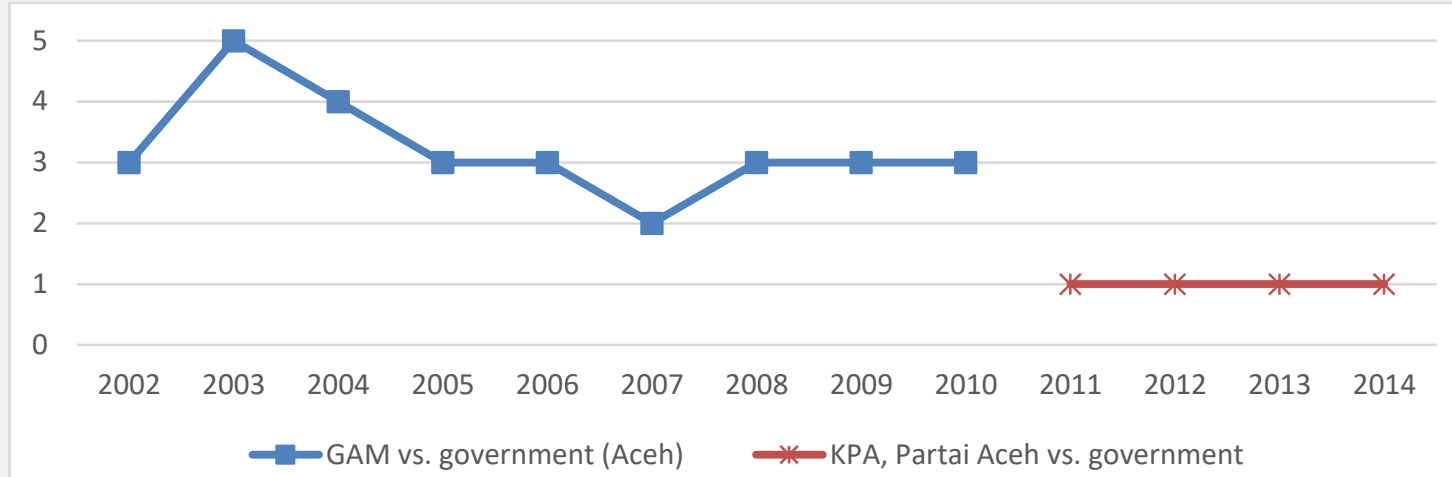

Source:

In late 2004 GAM and the Government of Indonesia made a peace deal again, which might or might not have survived in the normal course of events. The devastating impact on Aceh of the earthquake and tsunami in December 2004 created a whole new reality, attracting worldwide attention, and massive relief effort and funding. GAM and the national government, which had recently transitioned toward democracy and wanted international approval, both saw this as an opportunity to reach a peaceful settlement. They signed a peace agreement in August 2005 that allowed for some autonomy for the Aceh region, but did not go so far as independence. The Jakarta government enacted the Aceh Government Legislation, covering special rights agreed upon in 2002 and allowing the Acehnese to establish local political parties to represent their interests at national and local levels. Violent conflict between GAM and the government ceased quickly after the agreement. Although most reconstruction funding was not specifically linked to post-conflict assistance, the large number of well-funded post-tsunami projects provided opportunities for many entrepreneurial ex-combatants and insurgent leaders quickly to find gainful employment and contracts in the legal economy. GAM has become the political party for the Aceh region. Many, although not all, victims and ex-combatants from pre-2005 have received economic assistance.

A unique feature of Aceh's experience is that just as the peace agreement was signed, the tsunami reconstruction effort bought in a tidal wave of funding for that reconstruction. Aceh's fiscal resources have increased dramatically since 1999: after decentralization and the Special Autonomy Status, the amount of funds managed directly by the Acehnese province and local governments increased several-fold. Nonetheless, Aceh remains one of the poorest provinces in Indonesia. 


\section{A.3 Northern Uganda}

Northern Uganda has a protracted history of armed conflict and recurrent violence between rebel groups and the government - the most recent civil conflict in this part of the country started after Museveni came to power in 1986. For this analysis, the main conflict of interest during the 2000-2014 time period is the conflict with the LRA. 8 This conflict has been well documented and researched, a brief overview and analysis of the drivers and consequences is provided here. ${ }^{9}$

The LRA is a cult-like organization currently led by Joseph Kony. Conflict with this group in Uganda began as a pro-Northern Uganda movement led by the Acholi people following the civil war that led to Museveni's rise to power in 1986. In the late 1980s the LRA turned on the same population whose interests it purported to advocate and the Acholi population became the target of LRA attacks, at times in retaliation for actions taken by the Ugandan army. The LRA is notorious for brutal tactics including maiming, torturing, raping the Acholi population and abducting children and forcing them to serve as child soldiers, porters, or in the case of some young women, war wives. This conflict has affected the lives of hundreds of thousands of Ugandans in the Northern region - estimates include 20,000 casualties and 1.6 million IDPs.

The conflict was most intense in during the 2002-2004, and during this time the government began moving civilians into camps in conflict affection regions order to provide better security. The count of IDPs reached its peak in 2006. There have been no major outbreaks of violence in Uganda since peace talks started in 2006 and the LRA was pushed out of Northern Uganda. After 2008, IDPs were gradually transferred out of camps, this was mostly completed by 2011. After the LRA was pushed out of Uganda they moved between the Democratic Republic of Congo, the Central African Republic, and South Sudan.

From pre-colonial times the Northern Acholi people were characterized by a warrior tradition, which resulted in the British government heavily recruiting among the population to serve as army, police, and prison guards. Historical analysis suggests that Acholi were exploited by their colonizers for uniformed services and unskilled labor, while central Ugandans were the beneficiaries of commercial and educational activities (Gersony 1997, ACCS 2013, Kustenbauder 2010). Post-independence there were a series of violent conflicts between highly militarized political factions that loosely aligned with regional and ethnic groups in a struggle for national power. During this period, all sides committed atrocities in a tit for tat cycle. A legacy of this violence is the residual feelings of distrust on the part of the Acholi toward the ruling President and his National Resistance Movement Party (comprised mostly of people from the Banyankole tribe). ${ }^{10}$ These negative sentiments contributed to initial 
Acholi support for the LRA in the late 1980s before it eroded after the Acholi population became the target of the LRA.

\section{Figure A.3.1 IDPs and Returned IDPs: Uganda 2006-2011}

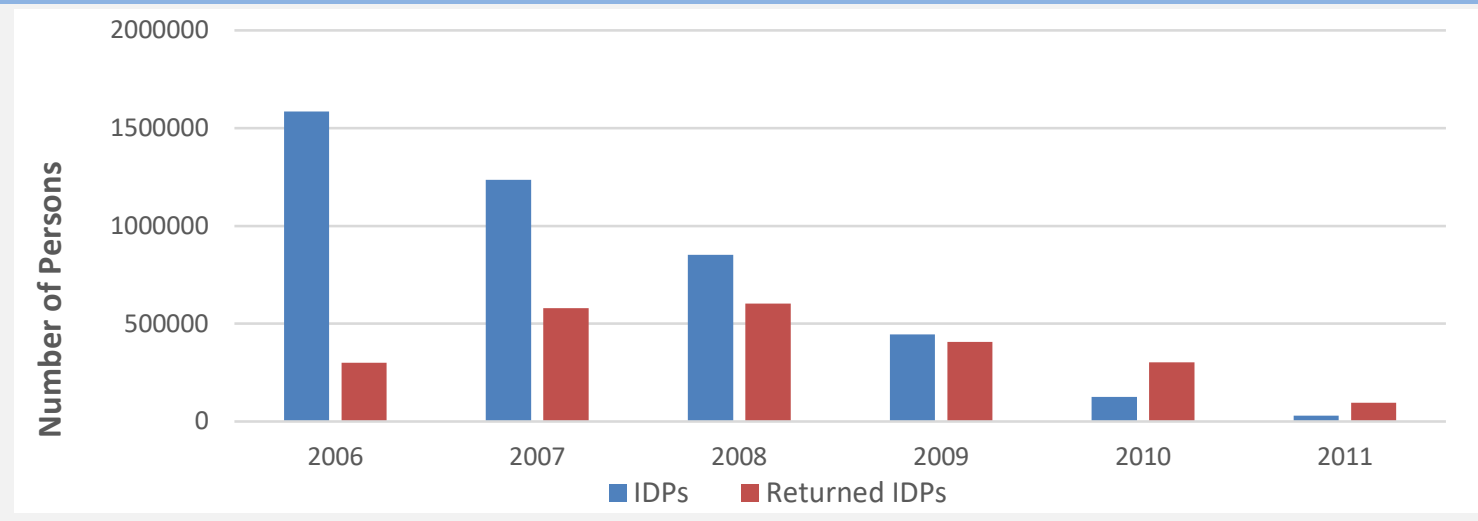

Source: UNHCR Population Statistics Database-earliest year of data is 2006

Some have described perceptions in Uganda of a "marginalized north-prosperous south divide" (Gersony, 1997). Historically, this has been attributed at least in part to the legacy of colonization described above. The status of the North was worsened by over 20 years of conflict and as a result, the Northern region currently lags across most income and nonincome indicators. As of 2009/2010 the Northern region comprised 20 percent of the population, but contributed 38 percent of the share of the population of Uganda living under the national poverty line (UBOS, 2009), ${ }^{11}$ this did not change substantially from data collected in 2005/2006. Additionally, there are poverty concentrations in the conflict-affected sub-region of mid-northern Uganda. ${ }^{12}$ In 2009/2010 this sub-region comprised 9.8 percent of the population but contributed 16.1 percent to the portion of the national population living under the poverty line (UBOS, 2009). It is difficult to gauge how poverty has changed in the conflict-affected regions as data from these areas was not included in the national household survey in 1999/2000 and 2002/2003.

LRA numbers are reported to be dwindling, though as previously mentioned the organization has been active outside of Uganda - in the Democratic Republic of Congo, Central African Republic, and Southern Sudan, where Joseph Kony is rumored to be residing. In early 2015 a LRA commander, Dominic Ongwen, surrendered to US troops in the Central African Republic and is awaiting trial at the International Criminal Court. As of 2012 the numbers of the LRA were reported to have reduced to between 200 and 700 followers, but the organization was still considered a threat. ${ }^{13}$ There is still no official peace agreement and there remains an International Criminal Court warrant for the arrest of Joseph Kony. 
APPENDIX A

HISTORY OF CONFLICTS AND VIOLENCE

\section{A.4 Sri Lanka}

Sri Lanka was embroiled in violent conflict between the Sinhalese-dominated central government and militant Tamil forces (the Liberation Tigers of Tamil Eelam, LTTE) fighting for a separate state since 1984. Isolated incidences gave way to a civil war between the government and the LTTE in 1983 and continued through 2009. Despite attempts to solve the conflict through negotiations, it proved intractable. In 2009, the conflict ended with a decisive victory of the government.

The consequences of the conflict remain apparent today. There are approximately 73,700 (nonresettled) IDPs ${ }^{14}$ spread throughout a country whose land and infrastructure remain heavily damaged. The Tamil-dominated Northern and Eastern Provinces, which saw the heaviest fighting, face considerable challenges rebuilding. The conflict had a substantially negative impact on Sri Lanka's economic and social development and incurred a tremendous human cost, resulting in 40,000 civilian deaths. $^{15}$

Conflict Drivers. The tension between the Sinhalese and Tamils finds its roots in Sri Lanka's colonial past and the years immediately following independence. There was a perception that the British government often "favored" the Tamil minority, breeding resentment in the majority population. This was reinforced by policies that, according to Sinhalese nationalists, disproportionately increased the power of Tamils in society. After independence Sinhalese nationalists became frustrated that independence did not immediately translate into more power and status, leading to the promulgation of increasingly discriminatory policies. These dynamics can be seen through the evolution of education and language policies, which differentiated Sinhalese and Tamil interests.

Land: The Northern and Eastern Provinces, which are Tamil-majority territories, is a sparsely populated dry zone. After independence, the government decided to settle poor Sinhalese farmers from densely populated wet zones into this region, viewing the process as the "reclamation and recreation in the present of the glorious Sinhalese Buddhist past," and a vital component of rebuilding Sri Lanka. These irrigation settlements were directly sponsored and monitored by the state, leading Tamils to further associate the government with Sinhalese interests and feel increasingly marginalized. Consequently, the idea of a "traditional Tamil homeland" became powerful in the Tamil political lexicon. A separate and independent state soon became the objective of the LTTE and Tamil separatists.

Political Authority: Tamil political leaders were pushing for greater political autonomy in the Northern and Eastern Provinces through a federalist structure. 
Though numerous pacts had been written to define a framework for devolution, they were never implemented. Disillusionment with the democratic process and nonviolent politics fueled the militarization and radicalization of Tamil politics in the early 1970s. This frustration culminated in the Vaddukoddai resolution of May 1976, calling for the Northern and Eastern Provinces to secede and form Tamil Eelam. The LTTE was also founded at this time, sharing the platform of the resolution. Isolated incidences gave way to a civil war between the government and the LTTE in 1983 and continued through 2009.

Post-Conflict. The government's focus on defense and large-sale infrastructure since the end of the conflict has at different times inflamed the historic tensions surrounding land and political authority. Without a sustainable political settlement to the conflict, many of the social aspects that often accompany peace- and statebuilding efforts were neglected in favor of growth-generating investments in infrastructure.

\section{A.5 Colombia}

The literature tends to identify four major drivers of conflict and violence in Colombia:

Political Polarization, originating in a period known as La Violencia, (1940-1950s) when an extreme level of political polarization led to violent confrontation between the Liberal and Conservative parties. An agreement reached in the 1960s entailed a power-sharing strategy that excluded other political groups, which evolved into two distinct armed groups, the FARC and the ELN (National Liberation Army). In response, the authorities allowed the emergence of paramilitary groups to confront those two. Conflict and tensions remained latent but intensified sharply at the end of the 1990s.

Rural conflict, inequality and lack of property rights. Historically the level of conflict and violence has been particularly high in rural areas. Unclear land property rights and very high inequality in land distribution worsened over time. Drug traffickers and paramilitaries snatched significant areas of rural land in the 1980s and 1990s to launder their profits and contributed to the displacement of farmers. Some 70 percent of displaced farmers did not hold a formal title.

Limited state presence. Colombia has been historically characterized by a high institutional capacity at the national level, but low levels of accountability in state institutions and social cohesion at subnational levels. The vacuum of power has 
been eventually filled by nonstate actors. It has also generated incentives for drug producers to move into those areas.

Illegal Drug Markets. The increasing demand for cocaine during the 1980s increased its output and Colombia became the largest cocaine exporter in the world. The increase in drug production and trafficking encouraged organized crime and violence that started to peak at the end of the 1990s. The long-term sustainability of guerilla activity is closely associated with their increasing involvement in the drug industry. It created a mutually reinforcing dynamic between guerrilla, paramilitary groups, and drug cartels.

Recent developments and outlook. To confront the sharp escalation of violence, in 2002 the newly elected President Uribe started to reinforce the army to confront several illegal armed groups. It resulted in a gradual reduction in the incidence of armed clashes and related deaths. In 2010 President Santos introduced initiatives to institutionalize the process of restitution and reconciliation. The 2011 Victims Reparation and Land Restitution Law introduced a legal process to formally identify the victims of the conflict and the restitution of patrimony lost due to the violence. Peace negotiations with the FARC started by the end of 2012.

Although the level of violence has been visibly reduced, it still has significant impact on the lives of people. In 2013 about 157,000 new families were displaced, and thousands of displaced households are still not able to repossess their land due to ongoing violence. According to UNHCR, the cumulative number of IDPs ${ }^{16}$ reached about 5 million people by 2015, the highest of any country in the world. Figures A.4 and A.5 show the trend in both the number of deaths resulting from the armed encounters and the number of displaced persons - which are correlated, not unexpectedly.

\section{Figure A.5.1 Deaths from the Armed Conflict, 1990-2010}

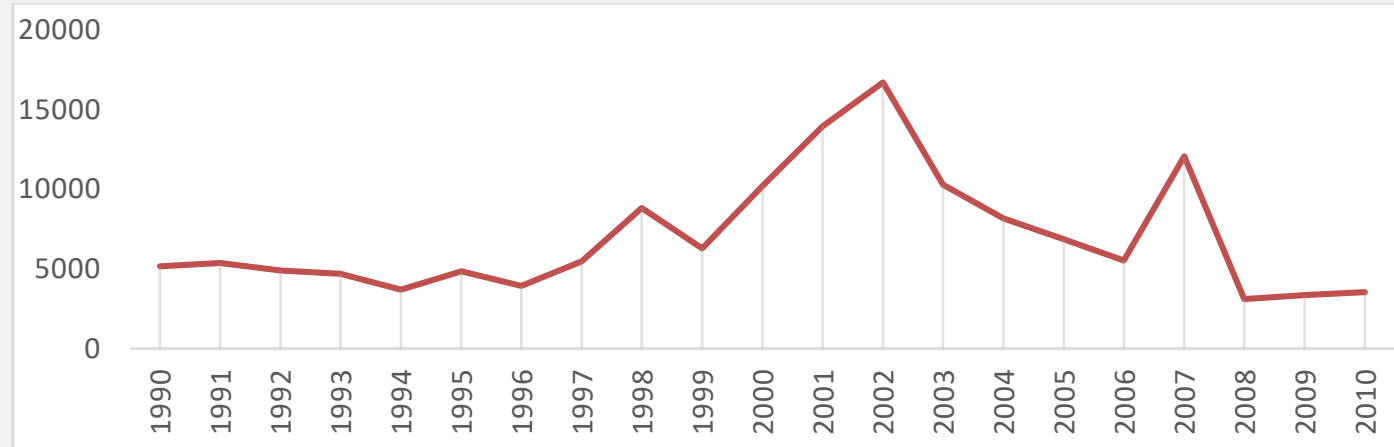




\section{Figure A.5.2 IDPs, 1990-2014}

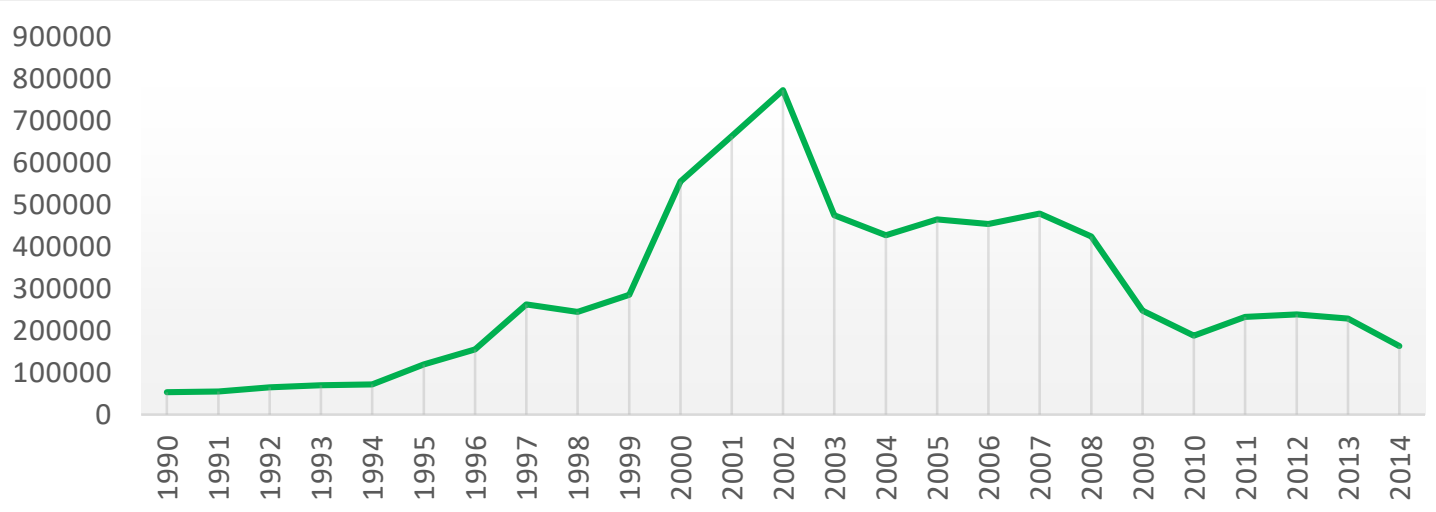

Source: Data from RUV, figure IEG

\section{A.6 Honduras}

During the last decade, countries in the Central America's Northern Triangle - El Salvador, Guatemala, and Honduras - experienced some of the world's highest crime and homicide rates. Drug trafficking through the Central American drug corridor expanded sharply and became a major driver of crime and violence. Drug trafficking increased the incentives for corruption in the criminal justice system and tarnished the image of state institutions. The resulting lack of trust in institutions encouraged citizens to take the law into their own hands. The increase in crime and violence has been particularly sharp in Honduras during the late 2000s, when the homicide rate rose exponentially and surpassed by a large margin the homicide rate of the neighboring countries (see Figure A.6.1).

\section{Figure A.6.1 Homicide Rate per 100,000 Population}

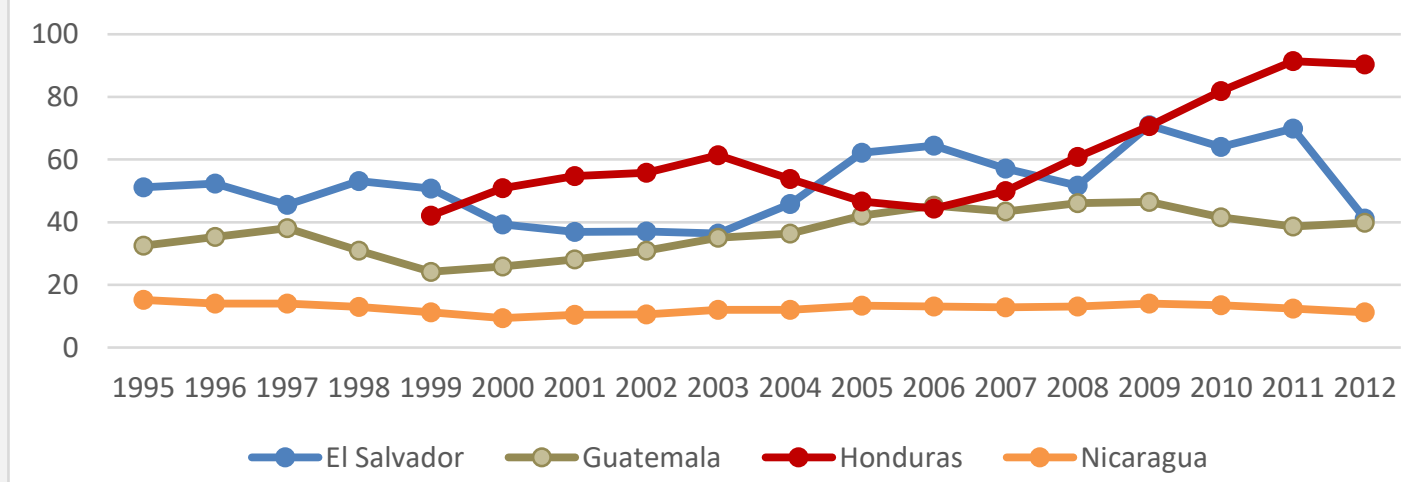

Source: United Nations Global Study on Homicide. 
In 2011 the World Bank issued a major diagnostic report on crime and violence in Central America, summarizing lessons and identifying priorities for the future. ${ }^{17}$ The study responded to the sharp increase in violence during the 2000s, when the homicide rates doubled in all three countries. It examined major trends in the indicators of violence, its economic costs, provided analysis of the main drivers, and made recommendations for possible strategies across several fronts. It recognized the interaction among the many drivers and the need to combine several of these strategies. This evaluation takes the 2011 study as a point of departure to examine the assistance of the World Bank to Honduras, as it was issued in parallel with and provided the analytical basis for the 2012 CPS. The 2012 CPS also introduced for the first time an explicit thematic pillar/objective focusing on citizen security.

\section{Box A.6.1. Main Drivers of Crime and Violence in Central America}

Drug trafficking is the most important single factor behind the rising violence in the region. About 90 percent of cocaine flowing to the United States comes through Central America, with its value about 5 percent of the region's GDP.

Youth violence and gangs. By 2011 they were 900 gangs in Central America, with estimated 70,000 members, accounting for about 15 percent of homicides.

Availability of firearms because of past civil wars. There are about 4.5 million small arms in the region-most of them illegal.

Weak criminal justice institutions. In Honduras 65 thousand criminal complaints were filed, 49 thousand were investigated, but only one thousand ended up in a conviction. This weak performance limits the efficacy of punishment and prevention. Underreporting is a major issue due to the lack of trust in the institutions.

Source: World Bank 2011

\section{A.7 Nigeria, Delta Region}

Niger Delta is in Nigeria's South-South geopolitical zone and contains 15 percent of the country's population (estimated 170 million in 2013). Oil was discovered in the Delta in commercial quantities in 1956. Nearly two dozen international oil companies operate in joint ventures with the Nigeria National Petroleum Company, producing around 2.3 million barrels of crude oil per day, making Nigeria the largest oil producer in Africa and the eleventh largest producer in the world. Oil accounts for 90 percent of export earnings, 75 percent of consolidated government revenue and 25 percent of GDP. The centrality of oil has made securing access to and control over an increasing proportion of oil revenue the main locus of political struggle in the Niger Delta. Violent conflict raged in the Delta from the 1990s through 2009. 


\section{Box A.7.1. Niger Delta Conflict Timeline}

- 1990 - Movement for the Survival of the Ogoni People (MOSOP) issues the Ogoni Bill of Rights. An unrelated protest brings the first major military action against civilians.

- 1995 - Ken Saro-Wiwa, MOSOP leader, is executed along with eight others.

- 1997-2003 - Three successive waves of violent ethnic clashes occur in the Warri area

- 2004 - Conflict ignites between the Niger Delta People's Volunteer Force and Nigerian government troops.

- 2005 - Multiple resistance and armed groups join under the umbrella Movement for the Emancipation of the Niger Delta (MEND).

- 2009 - Sharp decrease in oil production falls because of continued heavy fighting between militias and the government. Government offers amnesty buy-out to over 20,000 ex-combatants. The Disarmament, Demobilization, Reorientation and Reintegration program put in place (to continue until the end of 2015).

Source: World Bank

One of the main causes of the violent conflict in the Niger Delta is distribution of revenues from oil resources. The claimants to resources are Nigeria's federal government and those of the states in its South-South geopolitical zone-Akwa Ibom, Bayelsa, Cross-River, Delta, Edo, and Rivers. ${ }^{18}$ Per capita total federal transfers (including not related to oil) to Delta states are two-and-a-half times the national average. This, however, had little impact on the availability and quality of public goods in the Delta, including security, education, health, infrastructure, etc. This situation has raised questions about the lack of transparency and accountability in the use of public funds, adding to the overall sense of disaffection among the population of Delta states.

There is also the sentiment that the Delta population is not receiving an adequate share of the natural resource wealth, while bearing the costs of producing it. Little has been done to address the toxic environmental legacy of oil exploration borne by host communities. Up to 546 million gallons of oil have poured into the ecosystems of the Niger Delta over 50 years of production - nearly the equivalent of an Exxon Valdez spill every year (Nossiter 2010). Soil, forests and waterways have been ravaged and traditional livelihoods such as agriculture and fishing threatened by oil spills and gas flares. ${ }^{19}$ In line with findings elsewhere, environmental degradation has had a stronger deleterious impact on the poor than the rich. ${ }^{20}$

This set of issues has eluded peaceful resolution. The Movement for the Survival of Ogoni People (MOSOP) was formed to contest environmental degradation in the Ogoniland community of the Niger Delta. Although MOSOP espoused nonviolence, 
conflict broke out between ethnic groups, the government and communities and between oil companies and communities. The government resorted to force to crush protests. A trial led to the hanging of the MOSOP leaders in 1995. The army, navy and paramilitary force continued to be regularly deployed even after the restoration of a civilian government in 1999 .

Militant groups, sometimes in collusion with poorly-paid security personnel, engaged in oil theft (known as "bunkering" in Nigeria), which is estimated at between 70,000 and 300,000 barrels a day, or around 10 percent of Nigeria's oil production. The proceeds from bunkering and other criminal activities, such as kidnapping, were used to finance the insurgency, which was targeted toward government and the oil companies. Engaging in criminal activities was attractive for the massive numbers of unemployed youth, who have seen little return to education and training. Two-thirds of the population is under 30 , and youth male unemployment in the Delta states is above the national average of 20.9 percent. ${ }^{21}$ Groups organized into protection rackets were paid off by oil companies to discourage attacks on oil pipelines.

By 2005 violent community conflicts in Rivers, Bayelsa and Delta state typically numbered between 120 and 150 per year, and over 50 armed groups with an estimated 20,000 to 25,000 armed youths were operating in the oil producing region (UNDP 2007). Hostage-taking and attacks on oil facilities became increasingly common with the formation of the umbrella militant group called the Movement for the Emancipation of the Niger Delta (MEND). Escalating unrest led to very significant losses in oil production beginning in late 2005 and until amnesty was offered to combatants in mid-2009.

Since 2009, a negotiated settlement involving amnesty and a Disarmament, Demobilization, Rehabilitation, and Reintegration program has been in place. Militants who handed in their weapons were pardoned and paid around $\$ 400 \mathrm{a}$ month until they found legitimate work. ${ }^{22}$ Furthermore, oil companies pay local groups to protect pipelines and oil wells. A fragile peace, punctuated by very occasional outbreaks of violence, currently reigns.

Historically, the reaction of the government to the periodic crises of the Delta has been a combination of use of force, buying off militants through the redistribution of revenue, promise of jobs for ex-combatants, and the creation of new development institutions. Little has been done differently since the amnesty in 2009 to tackle the multiple underlying drivers of conflict in the Delta, including (i) improving transparency in revenue flows; (ii) tackling the problem of youth unemployment; (iii) addressing the toxic environmental legacy of oil exploration; and (iv) reducing 
criminal activities such as oil theft and kidnapping. Should the regular payments to ex-combatants as part of the amnesty program come to an end in 2015 (as they are currently planned to), these problems can reignite the conflict in the Delta.

\section{A.8 Pakistan: Balochistan, FATA, and KP provinces}

Along Pakistan's western border with Afghanistan, localized conflicts have threatened both national and regional stability in recent years. Government engagement with militants in the Federally Administered Tribal Areas (FATA), Khyber Pakhtunkhwa (KP), and Balochistan provinces can be traced to a complex web of issues that originate in Pakistan's independence and complex relationship with Afghanistan. ${ }^{23}$

FATA, KP, and Balochistan are both geographically and politically removed from the central government. Existing on the periphery has negatively influenced the state/citizen relationship; people in these regions report feeling disenfranchised by the government, and seek to empower themselves by redefining their relationship with Islamabad. As the central government has struggled to set the parameters for a federalist state, they are also increasingly concerned with the instability posed by war in neighboring Afghanistan. Due to the flow of Afghan fighters into Pakistan, and the spill-over of the coalition fighting, a historically tense situation in FATA, KP, and Balochistan has become militarized.

The conflicts in FATA, KP, and Balochistan are distinct, but they are both the result of a failure of governance where the center has distanced itself from the realities of the population and this has undermined the state's legitimacy. The lack of visible progress on a range of socioeconomic issues, coupled with a limited number of institutions to meaningfully engage with the government, has disillusioned the population. Militant groups have capitalized on this anger enjoying varying levels of public support.

The conflict has resulted in considerable economic and human cost. The Post Crisis Needs Assessment (2011) notes that the conflict in KP/FATA alone has caused 2.3 million IDPs; damage in physical and social infrastructure; decreased tourism; and has negatively affected economic activity. These results not only constitute a humanitarian crisis, but also undermine the Pakistani state's ability to govern an area with important security implications for the country and the broader region. Armed conflict is considered as one of the key reasons for drop in foreign direct investment from $\$ 5.3$ billion in 2008 to $\$ 744$ million in 2012. The annual cost of conflict in Pakistan is estimated at no less than 2 percent of GDP. 
APPENDIX A

HISTORY OF CONFLICTS AND VIOLENCE

Weak state presence is frequently cited as a key driver of this conflict and a source of resentment in the population. Exploiting the population's cynicism and alienation, militant groups have (sometimes successfully) presented themselves as a viable alternative to the state and a source of social and economic stability, particularly through the provision of access to justice and limited civil services. FATA, KP, and Balochistan are among the poorest provinces in Pakistan with some of the lowest social indicator scores. FATA is consistently ranking last in the country for key human development indicators, with KP not far behind. The government's inability (and perceived disinterest) to comprehensively address these problems has frustrated residents in the region, which has few opportunities for economic improvement. A lack of formal educational opportunities, the result of forced school closures and a disorganized national educational system, has further constrained employment opportunities. Poverty, the lack of jobs in the formal economy, and the absence of courts has increased participation in criminal activity such as drug and arms trafficking and has incentivized men to join militant outfits.

In Balochistan, one of the sources of tension has long been the sharing of resource benefits, contributing to Balochs feeling alienated from the central government and the democratic process. Balochs have long seen the relationship between the province and the central government to be exploitative. Balochistan is the largest producer of natural gas in Pakistan, and has been paid a fixed royalty for its natural gas "exports" to other provinces, which has depreciated in real terms over the years. Consequently, Balochistan is no longer remunerated for the full value of its exports. The limited profits that are received go directly to plant and distribution network owners, who frequently live outside of Balochistan -in essence, the income generated in Balochistan is rarely returned to the community. The province remains dependent on the center for transfers, which have shrunk in recent years because of declining energy prices, contributing to the deterioration of the local economy. The government has not meaningfully engaged with Balochs on how to address these concerns. Instead, the military has cracked down on militant groups while political leaders refuse to engage with nationalist groups, who they claim are undermining the central government's authority.

\footnotetext{
1 The Moro people is a population of indigenous Muslims in the Philippines. The term "Moro" originated from a term used to refer to the Muslims of Andalusia in southern Spain (known as the "Moors") during the Reconquista and applied to the native Muslims within the conquered Philippine islands by the Spanish invaders.

2 The main violent insurgent organizations in recent years include: (i) Moro Islamic Liberation Front (MILF, a breakaway from MNLF, placing more emphasis on Islam for its identity); (ii) Moro National Liberation Front (MNLF); (iii) New Peoples' Army (NPA), the military wing of the Communist Party of the Philippines; (iv) Abu Sayyaf, extremist MNLF breakaway group; (v) Bangsamoro Islamic Freedom Fighters (BIFF), a breakaway from MILF.
} 
3 Those include: (i) Moro Islamic Liberation Front; (ii) Moro National Liberation Front (MNLF); (iii) New Peoples' Army (NPA), the military wing of the Communist Party; (iv) Abu Sayyaf, extremist MNLF breakaway group; (v) Bangsamoro Islamic Freedom Fighters (BIFF), a breakaway from MILF.

${ }^{4}$ In 1989 the Autonomous Region of Muslim Mindanao (ARMM) a region of about 4 million people was created, following a constitutional mandate to provide for an autonomous area in Muslim Mindanao. A plebiscite in 14 provinces and 11 cities resulted in only four provinces choosing to join the Autonomous Region of Muslim Mindanao, which was officially inaugurated in November 1990.

${ }^{5}$ In late January 2015, a breakaway group from MILF, along with some MILF regulars, attacked Philippine police, who had arrested two suspected terrorists. 44 police died in the attack, along with 18 of the MILF and 4 apparent civilians.

${ }^{6}$ Source IDMC (Internal displacement monitoring center), www.internal-displacement.org

${ }^{7}$ Aceh is the only province in Indonesia that applies Islamic sharia law.

${ }^{8}$ Other ongoing conflicts include between the government and the Allied Democratic Forces - National Army for the Liberation of Uganda, and cattle rustling along the border with Kenya.

${ }^{9}$ For an analysis of incentives and the history, politics, and religious factors relating to the conflict see Kustenbauder 2010 and Gersony 1997.

${ }^{10}$ For example, there are also feelings of distrust or apathy toward the Acholi, possibly fueled by an incident in 1983 when Acholi soldiers brutalized civilians and killed 300,000 civilians and military forces under the command of Milton Obote (Kustenbauder, 2010).

11 Poverty estimates for Uganda relayed in this report were calculated using a method that established a threshold based on the cost of meeting caloric needs, given the food basket for the poorest half of the population and some allowance for nonfood needs.

12 Gulu, Amuru, Kitgum, Pader, Apac, Oyam, Lira, Amolatar and Dokolo

$13 \mathrm{http}$ //www.theguardian.com/world/2012/mar/24/joseph-kony-african-union-brigade?newsfeed=true

14 Internal Displacement Monitoring Centre: Sri Lanka. Over 430,00 IDPs have been resettled by the government

15 International Crisis Group "Sri Lanka's North: The Denial of Minority Rights"

${ }^{16}$ Colombia defines IDPs as those individuals forced to migrate within the national territory, leaving their usual locality of residency or economic activity when their lives, physical integrity, personal safety or freedom have been harmed or directly threatened by the armed conflict. Data on IDPs is available from the Registro Único de Población Desplazada (RUPD) and the Registro Único de Victimas (RUV)

17 "Crime and Violence in Central America : A Development Challenge”, World Bank, 2011

18 Three other states - Ando, Imo and Ondo- produce oil in marginal quantities. Although geographically close to the Niger Delta, they do not belong to the South-South zone.

19 A United Nations Environmental Program (UNEP) report on oil and gas pollution in Ogoniland in the Niger Delta published in 2011 calculated that a complete cleanup of the small Ogoni region alone would cost \$1 billion and take 30 years.

${ }^{20}$ A survey of rural households in the Niger Delta showed that the poorer half of the sample derives 60 percent of its income from environmental resources such as water and fuelwood. [Source: World Bank (2003)].

${ }^{21}$ Akwa Ibom 21.7 percent, Bayelsa 42.9 percent, Cross River 21.6 percent, Delta 35.9 percent, Edo 37.7 percent, and Rivers 38.9 percent

22 Those who led the insurgency have reportedly received multimillion dollar payouts.

23 This section draws from the following sources: Pakistan's undeclared war; FATA - A Most Dangerous Place; PAKISTAN: Post-Conflict Needs Assessment (PCNA FATA/KP); International Crisis Group: Pakistan: The Forgotten Conflict in Balochistan. 


\section{Appendix B. A Snapshot of Fragility, Conflict, and Violence beyond the Harmonized List}

The below figure illustrates the extent to which FCV pose challenges to countries beyond the Harmonized List. The criteria underpinning the list is expanded by lifting the lowincome countries cut-off and including additional markers of conflict and violence. ${ }^{1}$ The resulting data shows that while fragility is often associated with LICs, which only account for half of the countries where fragility, conflict, and high levels of violence affect development outcomes. A substantial number of countries with FCV do not currently have access to IDA resources. Overall, FCV to various extents impact the development outcomes of almost 2 billion people, one-quarter of which are living in extreme poverty. Of the 2 billion people, the vast majority are living in Low-MICs (38 percent) and Upper-MICs (37 percent) countries, and only 25 percent in low-income countries. (Source: FCV CCSA)

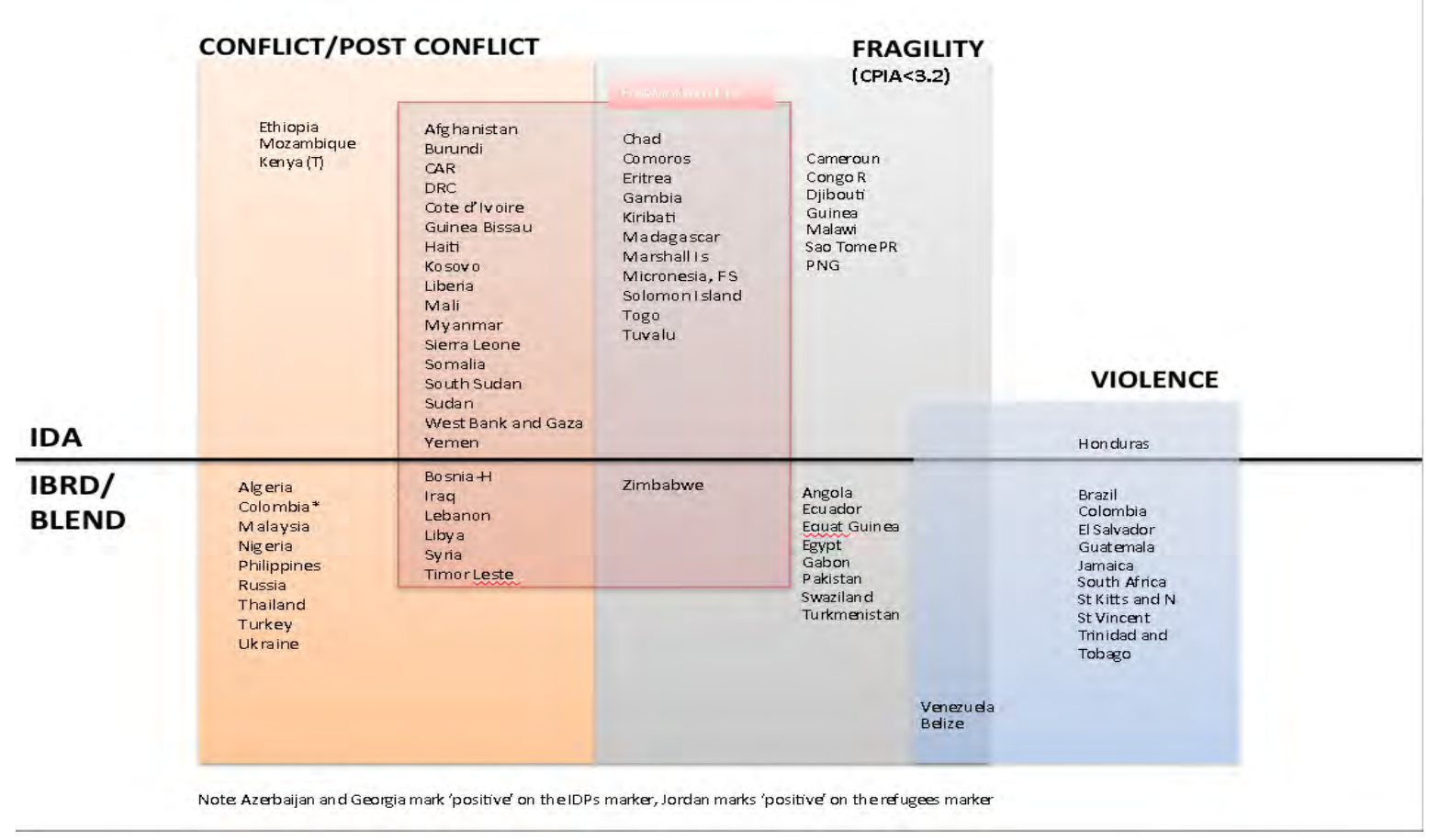

\footnotetext{
${ }^{1}$ Lifting the low-income countries cut off allows including IBRD/Blend countries with a CPIA rating below 3.2. As additional conflict markers, we include countries with more than 25 battle-related or terrorism-related deaths. As violence marker, we include countries with levels of intentional homicides well above the WHO level of 'epidemic of homicides' (i.e., 25 per 100.000 population, rather than 10 per 100,000 population). Battle-Deaths and intentional homicides are also part of the suggested Post-2015 framework of Sustainable Development Goals (SDGs). In addition, we include countries with UN Department of Political Affairs (DPA) and Border missions.
} 


\section{Appendix C. Reference Tables}

Table C.1. List of World Bank Lending Projects

\begin{tabular}{|c|c|c|c|c|c|c|c|c|c|c|}
\hline Country & Proj ID & Project name & $\begin{array}{l}\text { Agreement } \\
\text { type }\end{array}$ & $\begin{array}{l}\text { Fiscal } \\
\text { year }\end{array}$ & $\begin{array}{l}\text { Closing } \\
\text { FY }\end{array}$ & $\begin{array}{l}\text { Project } \\
\text { status }\end{array}$ & Sector board & $\begin{array}{l}\text { IBRD } \\
\text { commit } \\
\text { amt }\end{array}$ & $\begin{array}{l}\text { IDA } \\
\text { commit } \\
\text { amt }\end{array}$ & Grant \\
\hline Colombia & P006891 & CO ANTIOQUIA EDUCATION & IBRD & 1998 & 2007 & Closed & Education & 40.0 & - & \\
\hline Colombia & P046031 & CO MAGDALENA MEDIO & IBRD & 1998 & 2001 & Closed & Social Development & 5.0 & - & \\
\hline Colombia & P046112 & CO PASTO EDUCATION & IBRD & 1998 & 2004 & Closed & Education & 7.2 & - & \\
\hline Colombia & P053243 & $\begin{array}{l}\text { CO PEASANT ENTERPRISE } \\
\text { ZONES (LIL) }\end{array}$ & IBRD & 1998 & 2004 & Closed & $\begin{array}{l}\text { Agriculture and Rural } \\
\text { Development }\end{array}$ & 5.0 & - & \\
\hline Colombia & P050576 & CO YOUTH DEVELOPMENT & IBRD & 1999 & 2003 & Closed & Social Protection & 5.0 & - & \\
\hline Colombia & P050578 & CO RURAL EDUCATION APL I & IBRD & 2000 & 2007 & Closed & Education & 20.0 & - & \\
\hline Colombia & P057692 & $\begin{array}{l}\text { CO 2nd Magdalena Medio } \\
\text { Project (LIL) }\end{array}$ & IBRD & 2002 & 2004 & Closed & Social Development & 5.0 & - & \\
\hline Colombia & P089443 & CO Social Safety Net Project & IBRD & 2006 & 2009 & Closed & Social Protection & 86.4 & - & \\
\hline Colombia & P104507 & $\begin{array}{l}\text { CO Social Safety Add'l } \\
\text { Financing }\end{array}$ & IBRD & 2007 & 1900 & Closed & Social Protection & 104.8 & - & \\
\hline Colombia & P052608 & $\begin{array}{l}\text { CO Antioquia Secondary } \\
\text { Education Projec }\end{array}$ & IBRD & 2008 & 2014 & Closed & Education & 20.0 & - & \\
\hline Colombia & P082908 & $\begin{array}{l}\text { CO (APL2) Rural Education } \\
\text { APL II }\end{array}$ & IBRD & 2008 & 2016 & Active & Education & 40.0 & - & \\
\hline \multirow[t]{2}{*}{ Colombia } & P101277 & $\begin{array}{l}\text { CO (AF)Peace and } \\
\text { Development II }\end{array}$ & IBRD & 2010 & & Closed & Social Development & 7.8 & - & \\
\hline & & & & & & & Total & 346.2 & - & - \\
\hline Honduras & P082242 & $\begin{array}{l}\text { HN Nutrition and Social } \\
\text { Protection }\end{array}$ & IBRD & 2006 & 2013 & Closed & Social Protection & - & 20.0 & \\
\hline Honduras & P088319 & HN (CRL) Barrio-Ciudad Project & IDA & 2006 & 1900 & Closed & Urban Development & - & 15.0 & \\
\hline Honduras & P124157 & $\begin{array}{l}\text { HN Employment Generation in } \\
\text { Poor Urban N }\end{array}$ & RETF & 2011 & 2015 & Closed & Urban Development & - & - & 2.5 \\
\hline
\end{tabular}




\section{ApPendix C}

\section{REFERENCE TABLES}

\begin{tabular}{|c|c|c|c|c|c|c|c|c|c|c|}
\hline Country & Proj ID & Project name & $\begin{array}{l}\text { Agreement } \\
\text { type }\end{array}$ & $\begin{array}{l}\text { Fiscal } \\
\text { year }\end{array}$ & $\begin{array}{l}\text { Closing } \\
\text { FY }\end{array}$ & $\begin{array}{l}\text { Project } \\
\text { status }\end{array}$ & Sector board & $\begin{array}{l}\text { IBRD } \\
\text { commit } \\
\text { amt }\end{array}$ & $\begin{array}{l}\text { IDA } \\
\text { commit } \\
\text { amt }\end{array}$ & Grant \\
\hline \multirow[t]{2}{*}{ Honduras } & P130819 & HN Safer Municipalities & IDA & 2013 & 2019 & Active & Social Development & - & 15.0 & \\
\hline & & & & & & & Total & - & 50.0 & 2.5 \\
\hline Indonesia & P079156 & ID KECAMATAN DEV. 3 & IDA & 2003 & 2010 & Closed & Social Development & 204.3 & 45.5 & \\
\hline Indonesia & P095883 & $\begin{array}{l}\text { ID Reconstruction of Aceh Land } \\
\text { Admin Pro }\end{array}$ & RETF & 2005 & 2009 & Closed & $\begin{array}{l}\text { Agriculture and Rural } \\
\text { Development }\end{array}$ & - & - & 25.0 \\
\hline Indonesia & P092019 & $\begin{array}{l}\text { ID Kecamatan Development } \\
\text { Project 3B }\end{array}$ & IDA & 2005 & 2010 & Closed & Social Development & 80.0 & 80.0 & \\
\hline Indonesia & P100218 & $\begin{array}{l}\text { ID-Aceh-Infra. Reconstr } \\
\text { Enabling Program }\end{array}$ & RETF & 2006 & 2012 & Closed & Urban Development & - & - & 42.0 \\
\hline Indonesia & P097605 & ID SPADA in Aceh and Nias & RETF & 2007 & 2012 & Closed & Social Development & - & - & 25.0 \\
\hline Indonesia & P101785 & $\begin{array}{l}\text { ID-Aceh Infra. Reconst. Facility } \\
\text { (IRFF) }\end{array}$ & RETF & 2007 & 2013 & Closed & Urban Development & - & - & 100.0 \\
\hline Indonesia & P109024 & $\begin{array}{l}\text { Aceh Economic Dev Financing } \\
\text { Facility }\end{array}$ & RETF & 2009 & 2013 & Closed & $\begin{array}{l}\text { Financial and Private Sector } \\
\text { Development (I) }\end{array}$ & - & - & 50.0 \\
\hline Indonesia & P118977 & $\begin{array}{l}\text { Nias Rural Access and } \\
\text { Capacity Building }\end{array}$ & RETF & 2010 & & Closed & Social Development & - & - & 10.0 \\
\hline Indonesia & P118813 & $\begin{array}{l}\text { ID-JSDF Sustaining Women's } \\
\text { Leadership }\end{array}$ & RETF & 2010 & & Closed & Social Development & - & - & 1.9 \\
\hline \multirow[t]{2}{*}{ Indonesia } & P110635 & $\begin{array}{l}\text { Nias Livelihoods \& Econ. Dev. } \\
\text { Program }\end{array}$ & RETF & 2011 & 2013 & Closed & Urban Development & - & - & 8.2 \\
\hline & & & & & & & Total & 284.3 & 125.5 & 262.1 \\
\hline Jordan & P132097 & $\begin{array}{l}\text { 5M: Displaced People in Jordan } \\
\text { / Lebanon }\end{array}$ & RETF & 2013 & 2015 & Closed & Social Development & - & - & 2.4 \\
\hline Jordan & P145865 & $\begin{array}{l}\text { Mitigating Impact of Syrian } \\
\text { Displacement }\end{array}$ & IBRD & 2014 & 2015 & Closed & Social Protection & 150.0 & - & \\
\hline \multirow[t]{2}{*}{ Jordan } & P147689 & $\begin{array}{l}\text { JO-Emergency Services\&Social } \\
\text { Resilience }\end{array}$ & RETF & 2014 & 2017 & Active & Urban Development & - & - & 50.0 \\
\hline & & & & & & & Total & 150.0 & - & 52.4 \\
\hline $\begin{array}{l}\text { Kyrgyz } \\
\text { Republic }\end{array}$ & P098949 & VIP 2 & IDA & 2007 & 2015 & Closed & Social Development & - & 15.0 & \\
\hline
\end{tabular}




\begin{tabular}{|c|c|c|c|c|c|c|c|c|c|c|}
\hline Country & Proj ID & Project name & $\begin{array}{l}\text { Agreement } \\
\text { type }\end{array}$ & $\begin{array}{l}\text { Fiscal } \\
\text { year }\end{array}$ & $\begin{array}{l}\text { Closing } \\
\mathrm{FY}\end{array}$ & $\begin{array}{l}\text { Project } \\
\text { status }\end{array}$ & Sector board & $\begin{array}{l}\text { IBRD } \\
\text { commit } \\
\text { amt }\end{array}$ & $\begin{array}{l}\text { IDA } \\
\text { commit } \\
\text { amt }\end{array}$ & Grant \\
\hline $\begin{array}{l}\text { Kyrgyz } \\
\text { Republic }\end{array}$ & P123044 & EMERGENCY RECOVERY & IDA & 2011 & 2014 & Closed & Economic Policy & - & 70.0 & \\
\hline $\begin{array}{l}\text { Kyrgyz } \\
\text { Republic }\end{array}$ & P125425 & $\begin{array}{l}\text { Economic Recovery Support } \\
\text { Operation }\end{array}$ & IDA & 2012 & 2012 & Closed & Economic Policy & - & 30.0 & \\
\hline \multirow{2}{*}{$\begin{array}{l}\text { Kyrgyz } \\
\text { Republic }\end{array}$} & P126034 & DPO1 & IDA & 2014 & 2015 & Closed & Economic Policy & - & 25.0 & \\
\hline & & & & & & & Total & - & 140.0 & - \\
\hline \multirow[t]{2}{*}{ Lebanon } & P149242 & $\begin{array}{l}\text { Emergency Nat'I Poverty } \\
\text { Targeting Proj }\end{array}$ & RETF & 2014 & 1900 & Active & Social Protection & - & - & 8.2 \\
\hline & & & & & & & Total & - & - & 8.2 \\
\hline \multirow[t]{2}{*}{ Nigeria } & P121455 & $\begin{array}{l}\text { NG-State Employment and } \\
\text { Expenditure }\end{array}$ & IDA & 2012 & 2018 & Active & Public Sector Governance & - & 200.0 & \\
\hline & & & & & & & Total & - & 200.0 & - \\
\hline Pakistan & P105075 & PK: PPAF III & IDA & 2009 & 2016 & Active & $\begin{array}{l}\text { Agriculture and Rural } \\
\text { Development }\end{array}$ & - & 250.0 & \\
\hline Pakistan & P103160 & PK: Social Safety Net & IDA & 2009 & 2016 & Active & Social Protection & - & 60.0 & \\
\hline Pakistan & P121394 & $\begin{array}{l}\text { PK: KP and FATA Emerg } \\
\text { Recovery Project }\end{array}$ & IDA & 2011 & 2015 & Closed & Social Protection & - & 250.0 & \\
\hline Pakistan & P125584 & $\begin{array}{l}\text { PK: KP Emergency Roads } \\
\text { Recovery Project }\end{array}$ & RETF & 2012 & 2015 & Closed & Transport & - & - & 8.0 \\
\hline Pakistan & P124268 & $\begin{array}{l}\text { PK: KP/FATA Economic } \\
\text { Revitalization }\end{array}$ & RETF & 2012 & 2016 & Active & $\begin{array}{l}\text { Financial and Private Sector } \\
\text { Development (I) }\end{array}$ & - & - & 20.0 \\
\hline Pakistan & P126426 & $\begin{array}{l}\text { PK: Revitalizing Health } \\
\text { Services in KP }\end{array}$ & RETF & 2012 & & Active & Health, Nutrition and Population & - & - & 16.0 \\
\hline Pakistan & P128096 & $\begin{array}{l}\text { PK:Promoting Girls Ed in } \\
\text { Balochistan }\end{array}$ & RETF & 2013 & 2015 & Closed & Education & - & - & 10.0 \\
\hline Pakistan & P126833 & $\begin{array}{l}\text { PK: FATA Rural Livelihoods \& } \\
\text { Infra }\end{array}$ & RETF & 2013 & 2016 & Active & $\begin{array}{l}\text { Agriculture and Rural } \\
\text { Development }\end{array}$ & - & - & 12.0 \\
\hline \multirow[t]{2}{*}{ Pakistan } & P130835 & $\begin{array}{l}\text { KP Southern Area Development } \\
\text { Project }\end{array}$ & RETF & 2013 & & Active & $\begin{array}{l}\text { Agriculture and Rural } \\
\text { Development }\end{array}$ & - & - & 18.0 \\
\hline & & & & & & & Total & - & 560.0 & 84.0 \\
\hline
\end{tabular}




\section{APPENDIX C}

\section{REFERENCE TABLES}

\begin{tabular}{|c|c|c|c|c|c|c|c|c|c|c|}
\hline Country & Proj ID & Project name & $\begin{array}{l}\text { Agreement } \\
\text { type }\end{array}$ & $\begin{array}{l}\text { Fiscal } \\
\text { year }\end{array}$ & $\begin{array}{l}\text { Closing } \\
\text { FY }\end{array}$ & $\begin{array}{l}\text { Project } \\
\text { status }\end{array}$ & Sector board & $\begin{array}{l}\text { IBRD } \\
\text { commit } \\
\text { amt }\end{array}$ & $\begin{array}{l}\text { IDA } \\
\text { commit } \\
\text { amt }\end{array}$ & Grant \\
\hline Philippines & P051386 & SZOPAD SOCIAL FUND & IBRD & 1998 & 2003 & Closed & Social Protection & 10.0 & - & \\
\hline Philippines & P058842 & $\begin{array}{l}\text { MINDANAO RURAL } \\
\text { DEVELOPMENT PROJECT }\end{array}$ & IBRD & 2000 & 2005 & Closed & $\begin{array}{l}\text { Agriculture and Rural } \\
\text { Development }\end{array}$ & 27.5 & - & \\
\hline Philippines & P073488 & PH_ARMM Social Fund & IBRD & 2003 & 2014 & Closed & $\begin{array}{l}\text { Agriculture and Rural } \\
\text { Development }\end{array}$ & 33.6 & - & \\
\hline Philippines & P095173 & $\begin{array}{l}\text { PH Mindanao Trust Fund- } \\
\text { Reconstr \& Dev }\end{array}$ & RETF & 2006 & 2016 & Active & Social Development & - & - & 50.0 \\
\hline Philippines & P084967 & $\begin{array}{l}\text { PH Mindanao Rural Dev. } \\
\text { Project-Phase } 2\end{array}$ & IBRD & 2007 & 2015 & Closed & $\begin{array}{l}\text { Agriculture and Rural } \\
\text { Development }\end{array}$ & 83.8 & - & \\
\hline \multirow[t]{2}{*}{ Philippines } & P127741 & PH National CDD Program & IBRD & 2014 & 2020 & Active & Social Development & 479.0 & - & \\
\hline & & & & & & & Total & 633.9 & - & 50.0 \\
\hline Sri Lanka & P086747 & $\begin{array}{l}\text { LK: Community Livelihoods in } \\
\text { Conflict Ar }\end{array}$ & IDA & 2004 & 2015 & Closed & $\begin{array}{l}\text { Agriculture and Rural } \\
\text { Development }\end{array}$ & - & 64.7 & \\
\hline Sri Lanka & P083932 & $\begin{array}{l}\text { LK: NE Housing Reconstruction } \\
\text { Program }\end{array}$ & IDA & 2005 & 2012 & Closed & Urban Development & - & 75.0 & \\
\hline Sri Lanka & P084580 & $\begin{array}{l}\text { LK: Education Sector } \\
\text { Development Project }\end{array}$ & IDA & 2006 & 2011 & Closed & Education & - & 60.0 & \\
\hline Sri Lanka & $\mathrm{P} 100390$ & LK: Puttalam Housing Project & IDA & 2007 & 2012 & Closed & Urban Development & - & 32.0 & \\
\hline \multirow[t]{2}{*}{ Sri Lanka } & P113036 & $\begin{array}{l}\text { LK: N\&E Local Services } \\
\text { Improvement }\end{array}$ & IDA & 2010 & 2017 & Active & Urban Development & - & 50.0 & \\
\hline & & & & & & & Total & - & 281.7 & - \\
\hline Uganda & P002952 & $\begin{array}{l}\text { UG-N Uganda Soc Action Fund } \\
\text { (FY03) }\end{array}$ & IDA & 2003 & 2009 & Closed & Social Protection & - & 100.0 & \\
\hline Uganda & P109216 & $\begin{array}{l}\text { UG-Emergency Demob \& } \\
\text { Reinteg. (FY08) }\end{array}$ & RETF & 2009 & 2011 & Closed & Social Development & - & & 8.3 \\
\hline \multirow[t]{2}{*}{ Uganda } & P111633 & $\begin{array}{l}\text { UG-SEC N Uganda SAF } \\
\text { (NUSAF2) (FY09) }\end{array}$ & IDA & 2009 & 2016 & Active & Social Protection & - & 100.0 & \\
\hline & & & & & & & Total & - & 200.0 & 8.3 \\
\hline
\end{tabular}

\section{Table C.2 List of ESW}




\begin{tabular}{|c|c|c|}
\hline Country & Project ID & Project Name \\
\hline Colombia & P094842 & Peace Programmatic III: Reparation and Reintegration Program, 2009 \\
\hline Colombia & & Adjusting the Labor Supply to Mitigate Violent Shocks: Evidence from Rural Colombia, 2011 \\
\hline Colombia & P095711 & Peace Programmatic I: Demobilization of Ex-Combats, 2008 \\
\hline Colombia & & Peace Programmatic II: Reparation for Victims of the Armed Conflict in Colombia, 2007 \\
\hline Colombia & & The Economic Foundation of Peace, 2003 \\
\hline Honduras & & Crime and Violence in Central America, a Development Challenge, 2011 \\
\hline Indonesia & & $\begin{array}{l}\text { Spending for development : making the most of Indonesia's new opportunities, Public Expenditure Review, } \\
2007\end{array}$ \\
\hline Indonesia & P121876 & Support for Developing Gender Engagement in Indonesia \\
\hline Indonesia & & Justice for the Poor \\
\hline Indonesia & & $\begin{array}{l}\text { Conflict and Dispute Resolution in Indonesia: Information from the } 2006 \text { Governance and Decentralization } \\
\text { Survey, } 2010\end{array}$ \\
\hline Indonesia & & Justice for the Poor \\
\hline Indonesia & & Support for Developing Gender Engagement in Indonesia, 2013 \\
\hline Indonesia & & Aceh Public Expenditure Analysis: Spending for Reconstruction and Poverty Reduction, 2007 \\
\hline Indonesia & & $\begin{array}{l}\text { Conflict and dispute resolution in Indonesia: information from the } 2006 \text { governance and decentralization } \\
\text { survey }\end{array}$ \\
\hline Indonesia & & $\begin{array}{l}\text { GAM Reintegration Needs Assessment: enhancing peace through community-level development } \\
\text { programming GAM reintegration needs assessment: enhancing peace through community-level } \\
\text { development programming }\end{array}$ \\
\hline Indonesia & & $\begin{array}{l}\text { Multi-stakeholder review of post-conflict programming in Aceh: identifying the foundations for sustainable } \\
\text { peace and development in Aceh }\end{array}$ \\
\hline Indonesia & & Preliminary Damage and Loss Assessment (2005) \\
\hline Indonesia & & Multi-Stakeholder Review of Post-Conflict Programming in Aceh (MSR) 2010 \\
\hline Jordan & & Economic and Social Impact Assessment \\
\hline Jordan & & Country Gender Assessment: Economic Participation, Agency and Access to Justice in Jordan, 2013 \\
\hline
\end{tabular}




\section{APPENDIX C}

\section{REFERENCE TABLES}

\begin{tabular}{|c|c|c|}
\hline Country & Project ID & Project Name \\
\hline Jordan & & The Economic Advancement of Women in Jordan: A Country Gender Assessment, 2005 \\
\hline Jordan & & Country Gender Assessment: Economic Participation, Agency and Access to Justice in Jordan \\
\hline Jordan & P109392 & Jordan: Measuring the Impact of National Policies and Strategies on Gender Equality \\
\hline Kyrgyzstan & P146775 & Kyrgyz Republic Conflict Filter \\
\hline Lebanon & & Economic and Social Impact Assessment \\
\hline Lebanon & & Gender-based differences among entrepreneurs, and workers in Lebanon, 2009 \\
\hline Nigeria & & Economic Report, 2013, Issue 1 \\
\hline Nigeria & & State Level Public Expenditure Management and Financial Accountability Review: A Synthesis Report, 2011 \\
\hline Pakistan & & Country Gender Assessment: Bridging the Gender Gap, Opportunities and Challenges, 2005 \\
\hline Pakistan & & Khyber Pakhtunkhwa Public Expenditure Review, 2013 \\
\hline Pakistan & P120179 & MDTF for Crisis Affected Areas of NWFP/FATA/Balochistan \\
\hline Pakistan & & Pakistan Country Gender Assessment: Bridging the Gender Gap, Opportunities and Challenges \\
\hline Philippines & & AARM Human Development Sector Study \\
\hline Philippines & & Addressing Gender in Conflict and Post-Conflict Situations in the Philippines \\
\hline Philippines & & Bangsamoro Development Plan, 2015 \\
\hline Philippines & & Philippines Human Development for Peace and Prosperity in ARMM, 2003 \\
\hline Philippines & & Human development for peace and prosperity in the Autonomous Region in Muslim Mindanao \\
\hline Philippines & & Joint Needs Assessment for Conflict-Affected Areas of Mindanao, 2005 \\
\hline Philippines & & Violent Conflicts and Displacement in Central Mindanao: Challenges for recovery and development, 2011 \\
\hline Philippines & & Facility for Advisory Support for Transition Capacities (FASTRAC) \\
\hline Philippines & & Gender and Peace-Building Experience in the Philippines \\
\hline Philippines & & Public Expenditure Review. Strengthening Public Finance for More Inclusive Growth, 2011 \\
\hline Sri Lanka & & Strengthening Social Inclusion (Part 1), 2006 \\
\hline Uganda & & Government's Poverty Eradication Action Plan \\
\hline
\end{tabular}




\begin{tabular}{lll}
\hline Country & Project ID & Project Name \\
\hline Uganda & Public Expenditure Review for Northern Uganda, 2007 \\
Uganda & Uganda Post-Conflict Land Policy and Administration Options: The Case of Northern Uganda, 2009 \\
Uganda & From Periphery to Center: A Strategic Country Gender Assessment/ SCGA, 2004 \\
Uganda & Post-conflict land policy and administration options: case of Northern Uganda \\
Uganda & P101771 & Northern Uganda Public Expenditure Review, 2007 \\
Uganda & & Repatriation, Rehabilitation, Resettlement and Reintegration of Reporters in Uganda \\
Global & World Development Report 2011: Conflict, Security, and Development \\
\hline
\end{tabular}

Table C.3 List of IFC Investments

\begin{tabular}{lllll}
\hline & & & & \\
Country & Project ID & Status & Business Category & $\begin{array}{l}\text { Approved. } \\
\text { Inv (\$ } \\
\text { million) }\end{array}$ \\
\hline Colombia & 27961 & Active & Infrastructure and Natural Resources & 19 \\
Colombia & 32481 & Active & Infrastructure and Natural Resources & 25 \\
Colombia & 28479 & Active & Infrastructure and Natural Resources & 34 \\
Honduras & 26394 & Active & Financial Institutions Group & 20 \\
\hline Honduras & 27250 & Active & Manufacturing, Agribusiness \& Services & 30 \\
\hline Indonesia & 26428 & Completed & Financial Institutions Group & 45 \\
\hline Nigeria & 24802 & Completed & Infrastructure and Natural Resources & 75 \\
\hline Nigeria & 25335 & Active & Manufacturing, Agribusiness \& Services & 10 \\
\hline Nigeria & 34450 & Active & Infrastructure and Natural Resources & 75 \\
\hline Pakistan & 24013 & Active & Infrancial Institutions Group & 5 \\
\hline Pakistan & 28010 & Active & Infrastructure and Natural Resources & 35 \\
\hline Pakistan & 26229 & Active & Financial Institutions Group & 50 \\
\hline Sri Lanka & 30613 & Active & Financial Institutions Group & 65 \\
\hline Sri Lanka & 28672 & Active & Financial Institutions Group & 3 \\
\hline Sri Lanka & 30421 & Active & & 11 \\
\hline
\end{tabular}




\begin{tabular}{lllll}
\hline & & & & \\
Approved. \\
Inv (\$ \\
Country & Project ID & Status & Business Category & 75 \\
\hline Sri Lanka & 31456 & Active & Financial Institutions Group & 25 \\
Sri Lanka & 31894 & Active & Manufacturing, Agribusiness \& Services & 34 \\
\hline Sri Lanka & 32392 & Active & Financial Institutions Group & 7 \\
Sri Lanka & 33889 & Active & Financial Institutions Group & 20 \\
\hline Sri Lanka & 34286 & Active & Financial Institutions Group & 7 \\
\hline
\end{tabular}

Table C.4 IFC Advisory Services

\begin{tabular}{|c|c|c|c|c|c|}
\hline Country & $\begin{array}{l}\text { Project } \\
\text { ID }\end{array}$ & Project Name & Status & Business Category & $\begin{array}{l}\text { Approved. } \\
\text { Inv (US, 000) }\end{array}$ \\
\hline Indonesia & 545704 & Aceh Investment Law & closed & IC & \\
\hline Indonesia & 550627 & Aceh World Hotel Link & closed & SBA & \\
\hline Indonesia & 552925 & Aceh \& Nias Mariculture Producer Livelihood Program (seaweed) & closed & SBA & \\
\hline Indonesia & 552987 & Aceh \& Nias Shrimp Producer Livelihoods Program & closed & SBA & \\
\hline Indonesia & 559345 & Aceh Public-Private Dialogue & closed & IC & \\
\hline $\begin{array}{l}\text { Kyrgyz } \\
\text { Republic }\end{array}$ & 561496 & $\begin{array}{l}\text { Kyrgyzstan Business Enabling Environment-inspections, permits, tax } \\
\text { administration }\end{array}$ & closed & IC & $3,637,790$ \\
\hline Lebanon & 553345 & (MFI roundtable) & closed & & \\
\hline Lebanon & 553488 & Technical Assistance to Rebuild the Financial Sector in Lebanon & closed & & 114,000 \\
\hline Pakistan & 598467 & Pakistan and Afghanistan CG Project & Active & SBA & 625,000 \\
\hline Philippines & 561416 & Chiquita Unifrutti & closed & SBA & $1,169,000$ \\
\hline Sri Lanka & 586787 & Sri Lanka Union Bank Access to Finance & Active & $\mathrm{A} 2 \mathrm{~F}$ & 201,784 \\
\hline Sri Lanka & 596707 & SME Banking SL & Active & $\mathrm{A} 2 \mathrm{~F}$ & 846,785 \\
\hline Sri Lanka & 597447 & Post-Conflict Integration & Active & SBA & $3,181,350$ \\
\hline Sri Lanka & 599638 & Sanasa Development Bank Limited & Active & $\mathrm{A} 2 \mathrm{~F}$ & 555,000 \\
\hline
\end{tabular}


Table C.5 MIGA Guarantees

\begin{tabular}{llll}
\hline Country & Project ID & Project Name & Year \\
\hline Honduras & 7617 & Energía Eólica de Honduras S.A & 2014 \\
Honduras & 11853 & Autopistas del Atlantico S.A. en C.V. & 2015 \\
\hline Honduras & 12720 & SunEdison PV Solar Power & 2015 \\
\hline Indonesia & 8113 & PT Weda Bay Nickel (Indonesia) & 2011 \\
\hline Indonesia & 8521 & PT Natrindo Telepon Seluler & 2011 \\
\hline Indonesia & 11862 & Rajamandala Hydropower Project & 2015 \\
\hline Jordan & 10391 & Jordan Bromine Company Limited & 2012 \\
\hline Jordan & 12716 & Adenium Jordan-1 & 2015 \\
\hline Jordan & 12664 & Jordan Solar One & 2015 \\
\hline Lebanon & 11576 & Butec Utility Services S.A.L. in Lebanon & 2014 \\
\hline Pakistan & 10762 & Bulleh Shah Packaging (Private) Limited in Pakistan & 2013 \\
\hline Pakistan & 6115 & Habib Metropolitan Bank Limited & 2012 \\
\hline Pakistan & 10003 & Star Hydro Power Ltd. & 2012 \\
Uganda & 9368 & Icam Chocolate Uganda Limited & 2011 \\
\hline
\end{tabular}




\section{Appendix D. Portfolio}

Portfolio selection. This evaluation identified the World Bank Group portfolio for review using five broad areas of intervention: (i) provision of services (infrastructure, education, health, etc.); (ii) jobs and private sector development; (iii) social inclusion and capacity building; (iv) security and justice; and (v) the convening power of the World Bank Group. In reviewing each country case, the evaluation assessed the relevance and efficacy of programs in each of these five areas when addressing a particular form of fragility or violence. The evaluation team then identified the portfolio to review through a "mapping exercise," where World Bank Group financial, analytical, and advisory instruments were classified according to (i) a particular FCV situation they were deployed in; and (ii) the five areas of intervention. This type of mapping was conducted for each country and then consolidated into an overall portfolio reviewed in this report. Identifying the portfolio for this evaluation was complicated by the fact that most of the FCV situations in these countries were confined to certain parts of their territory, whereas World Bank Group interventions and initiatives were often parts of broader national programs. World Bank Group instruments selected for this report include: projects that provided financing to address the needs of populations affected by conflict and violence in specific regions; nationwide projects with wider objectives and containing important components or elements relevant to conflict and violence issues; analytical work addressing specific issues of relevance to conflict and violence (diagnostics, political economy analyses, needs assessments, etc.) or with potentially catalytic effect over time. Full list of projects (loans and grants) and AAA is available in Appendix Table D.1.

Portfolio performance. The evaluation compared performance, as well as some other features of over 56 selected projects spanning 11 countries with the rest of the World Bank portfolio in these countries. The evaluation's focus on localized conflicts is reflected in the makeup of the portfolio: many of the projects were regional in scope (77 percent) and were conflict-specific - meaning the project explicitly addressed a driver or consequence of fragility in its design (67 percent). The content of the projects reflects World Bank thinking on how best to operate in a conflict environment. The CDD model was widely considered an appropriate tactic to establish presence in conflict areas, increase community involvement in programming, encourage community ownership of projects, and foster social cohesion, and 60 percent of projects embraced this approach. Almost 80 percent of all projects had capacity-building components. Close to 40 percent of projects underwent a level 1-2 restructuring. In terms of sectoral spread, the SURR GP was the leading originator (20 percent), followed by Education, Social Protection, and Labor, and Governance GPs (12-13 percent). 
Despite efforts to account for fragility in project design and implementation, they were rarely captured in results. Only 32 percent of programs recorded fragilityspecific outcomes; 26 percent had M\&E systems specifically designed to track issues of FCV. FCV-specific indicators varied widely within the selected sample and depended strongly on particular country and situation context, and included such metrics as the level of social cohesion within communities (Philippines, Uganda), reintegration of ex-combatants (Indonesia), public services in affected communities (Jordan), impact on the well-being of internally displaced population (Colombia), incidence of violent crime (Honduras), and others.

In terms of performance, in most cases, 8 out of 10 countries (the evaluation covers 11 countries, but performance information is collected for 10, excluding Nigeria, where there was only one recently launched relevant project in Niger Delta, SEEFOR) the FCV portfolio either outperformed or was on par with the rest of the portfolio in the same country (see Figure D.1). This positive difference in performance becomes even more pronounced if the countries are grouped by drivers of conflict and violence (Figure D.2). This finding is consistent with the similar conclusion of the 2014 IEG evaluation of FCS countries, where portfolio performance in low-income FCS was higher than in low-income non-FCS. The perceived risks to outcomes of Bank interventions in conflict-affected regions of MICs seem to be exaggerated, whereas the development achievements in these regions are very important as they are also related to peace, post-conflict rehabilitation, and strengthening resilience. This could also be an indicator of increased strategic focus within the World Bank to FCV situations in MICs and interventions to address them. It is also notable that both cases where the FCV portfolio was less successful (albeit not significantly) were IDA countries (Uganda and Honduras).

IFC: For 11 case study countries, the report identified 36 IFC projects relevant to FCV situations in non-FCS countries: 20 investment projects and 16 advisory service projects. Many of these IFC projects are still under implementation and their development outcomes have not been rated by either IFC or IEG. Only 10 projects ( 7 advisories and 3 investments) have been completed and rated by IEG for development outcomes and effectiveness. Six out of the 10 are advisory service projects in Aceh, Indonesia. Although the sample size is small, analysis of the advisory service portfolio in Indonesia indicates that IFC can be equally effective in more difficult circumstances of FCV. From 2008 to 2015, IEG assigned development effectiveness ratings to 13 projects in Indonesia. The success rate of IFC advisory service projects in Aceh is 50 percent, compared to 57 percent for the rest of advisory service projects in Indonesia. 
APPENDIC D

PORTFOLIO

Figure D.1. Average Performance Index by Country

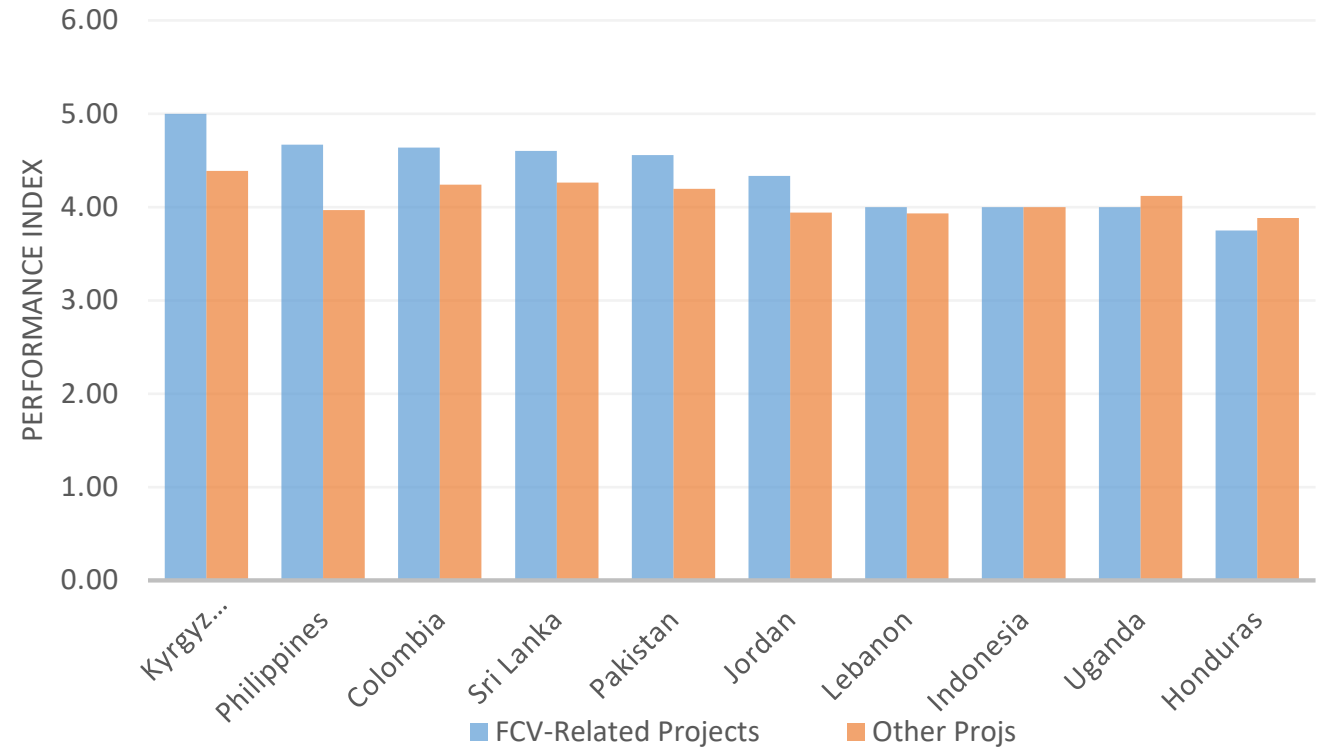

Notes: IEG/OPCS rating scale: Highly Satisfactory—6; Satisfactory-5; Moderately Satisfactory-4; Moderately Unsatisfactory-3; Unsatisfactory-2; Highly Unsatisfactory-1

\section{Figure D.2. Average Performance by Groups of Countries (typology of conflict drivers)}

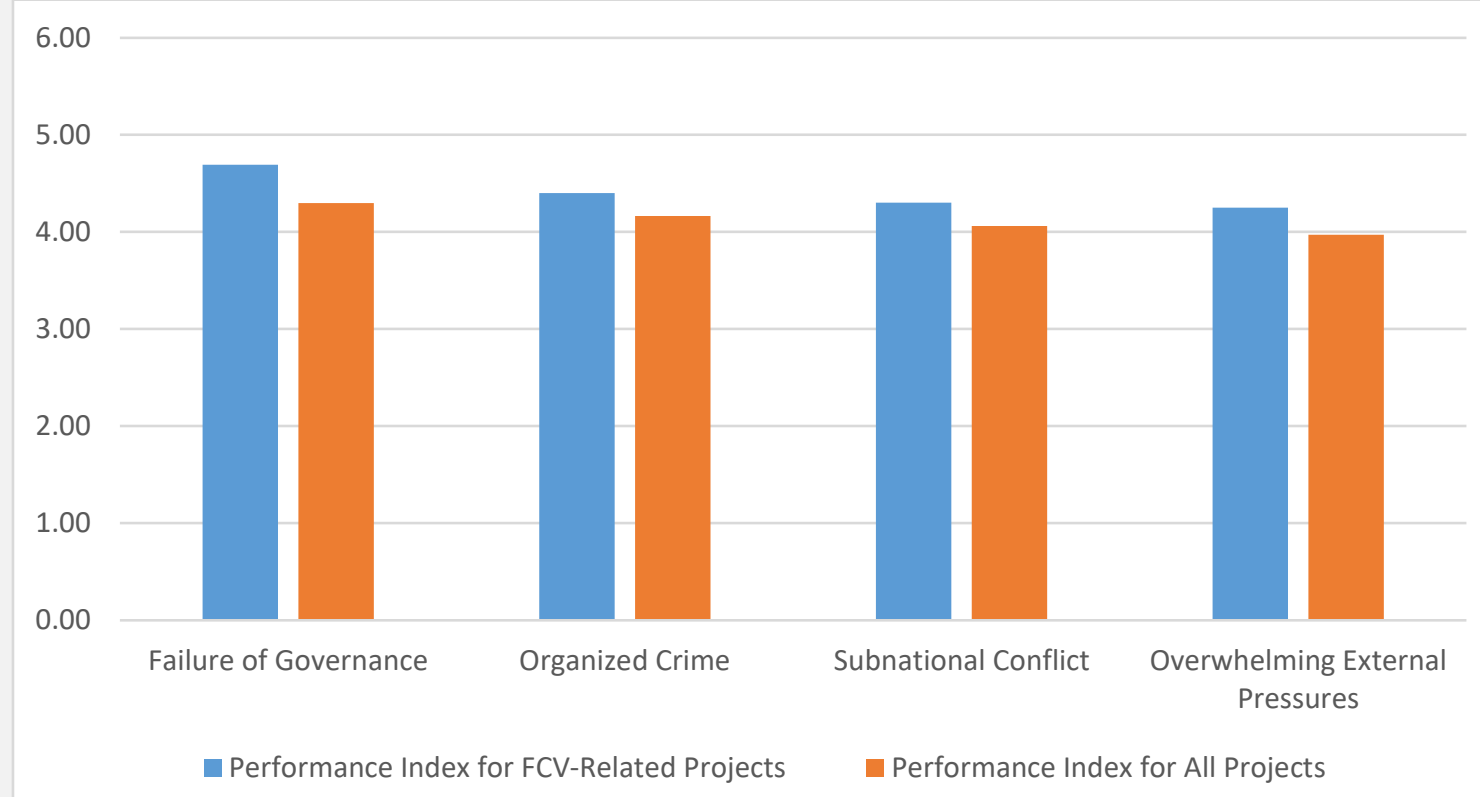

Notes: IEG/OPCS rating scale: Highly Satisfactory—6; Satisfactory—5; Moderately Satisfactory-4; Moderately Unsatisfactory-3; Unsatisfactory-2; Highly Unsatisfactory-1 
Table D.1. Sample Portfolio Mapping Matrix

\begin{tabular}{|c|c|c|c|c|}
\hline $\begin{array}{l}\text { Wrivers of Violence/Conflict } \\
\text { World Bank Grodx response } \\
\text { (by sectors) }\end{array}$ & $\begin{array}{l}\text { Subnational level } \\
\text { violence: } \\
\text { ethnic/religious } \\
\text { tensions, } \\
\text { secessionist } \\
\text { movements } \\
\end{array}$ & $\begin{array}{l}\text { Organized crime, gangs, } \\
\text { and drug trafficking }\end{array}$ & $\begin{array}{l}\text { Systemic failure of } \\
\text { governance and erosion } \\
\text { of state legitimacy }\end{array}$ & Overwhelming external pressures \\
\hline $\begin{array}{l}\text { Provision of public } \\
\text { services }\end{array}$ & $\begin{array}{l}\text { SZOPAD Social Fund- } \\
\text { Philippines } \\
\text { Mindanao Rural } \\
\text { Development Project I }\end{array}$ & $\begin{array}{l}\text { Rural Education- } \\
\text { Colombia } \\
\text { Peace and Development } \\
\text { Project I-Colombia }\end{array}$ & $\begin{array}{l}\text { Pakistan: Social Safety Net } \\
\text { Project }\end{array}$ & $\begin{array}{l}\text { Emergency National Poverty Targeting } \\
\text { Program-Lebanon } \\
\text { Emergency Services and Social } \\
\text { Resilience-Jordan }\end{array}$ \\
\hline $\begin{array}{l}\text { Jobs and private sector } \\
\text { development }\end{array}$ & $\begin{array}{l}\text { Aceh \& Nias Shrimp } \\
\text { Producer Livelihoods } \\
\text { Program } \\
\text { Northern Uganda Social } \\
\text { Action Fund }\end{array}$ & $\begin{array}{l}\text { Ficohsa-Honduras } \\
\text { Second Magdalena Medio } \\
\text { Regional Development } \\
\text { Project-Colombia }\end{array}$ & $\begin{array}{l}\text { Tameer Microfinance Bank } \\
(24013) \text {-Pakistan } \\
\text { State Employment and } \\
\text { Expenditure for Results } \\
\text { Project-Nigeria }\end{array}$ & $\begin{array}{l}\text { Middle East Micro Credit Company and } \\
\text { FINCA-Jordan }\end{array}$ \\
\hline $\begin{array}{l}\text { Social cohesion, local } \\
\text { empowerment and } \\
\text { capacity building }\end{array}$ & $\begin{array}{l}\text { Multi-Donor Facility for } \\
\text { Mindanao } \\
\text { Reconstruction and } \\
\text { Development } \\
\text { Northern Uganda Social } \\
\text { Action Fund }\end{array}$ & $\begin{array}{l}\text { Peace and Development } \\
\text { Project 1st Phase APL- } \\
\text { Colombia } \\
\text { Honduras Safer } \\
\text { Municipalities }\end{array}$ & $\begin{array}{l}\text { Second Poverty Alleviation } \\
\text { Fund Project Pakistan } \\
\text { State Employment and } \\
\text { Expenditure for Results } \\
\text { Project-Nigeria }\end{array}$ & $\begin{array}{l}\text { Emergency Services and Social } \\
\text { Resilience - Jordan }\end{array}$ \\
\hline $\begin{array}{l}\text { World Bank Group } \\
\text { convening role }\end{array}$ & $\begin{array}{l}\text { Multi Donor Facility_PH } \\
\text { Mindanao } \\
\text { Reconstruction \& } \\
\text { Development } \\
\text { MDF Aceh-Nias Rural } \\
\text { Access and Capacity } \\
\text { Building Project }\end{array}$ & $\begin{array}{l}\text { MDTF to support Colombia } \\
\text { Peace and Post-Conflict } \\
\text { Agenda }\end{array}$ & $\begin{array}{l}\text { Pakistan Post-Crisis Needs } \\
\text { Assessment }\end{array}$ & $\begin{array}{l}\text { Lebanon Economic and Social Impact } \\
\text { Assessment } \\
\text { Emergency Services and Social } \\
\text { Resilience - Jordan }\end{array}$ \\
\hline Security and justice & $\begin{array}{l}\text { Northern Uganda: Land } \\
\text { Policy and the Return to } \\
\text { Peace } \\
\text { Encouraging More } \\
\text { Resilient Communities in } \\
\text { Conflict-affected Areas } \\
\text { of the Philippines }\end{array}$ & $\begin{array}{l}\text { Protection of land and } \\
\text { Patrimony for IDPs- } \\
\text { Colombia } \\
\text { Crime and Violence in } \\
\text { Central America: A } \\
\text { Development Challenge }\end{array}$ & $\begin{array}{l}\text { Niger Delta Conflict } \\
\text { Analysis and Management } \\
\text { Program }\end{array}$ & \\
\hline
\end{tabular}




\section{Appendix E. People Met}

\section{COLOMBIA}

GOVERNMENT

Maria Angelica Bueno
Manuel Fernando Castro
Rita Combariza
Myriam Hernandez
Carlos Lemoine
Diego Fernando Maldonado

Hugo Navarro

Gina Ortiz

Gloria Matilde Ortiz

Ricardo Sabogal

Luis Daniel Santos

INTERNATIONAL ORGANIZATIONS

Karin Therese Andersson

Valerie Jordan

NGOS AND COMMUNITY ORGANIZATIONS

Leonel Narvaez

Paula Monroy

Francisco de Roux
Department for Social Prosperity

National Department of Planning

Former Director of FAMILIAS

Director of the Protection of Land and

Patrimony Project

Director of Centro Nacional de

Consultoria

National Department of Planning

Coordinator of Impact Evaluations, Peace and Development Projects

Presidential Agency for International Cooperation

Presidential Agency for International Cooperation

Director, Land Restitution Agency

Secretary of Social Development of

Cundinamarca

UNDP

European Union

Fundacion para la Reconciliacion

Fundacion para la Reconciliacion

Colombian Catholic Church 
WORLD BANK STAFF

Jairo Arboleda

Elena Correa

Martha Laverde

\section{HONDURAS}

Humberto López

Marcelo Fabre

Margarita Puerto Gomez
Consultant, former task team leader

Consultant, former task team leader

Former task team leader, Education Projects

Country Director for Central America, World Bank

Senior Social Development Specialist, World Bank

Social Development Specialist, World Bank

\section{JAPAN}

DeVElopment Partners

Komatsu Chicaru

JICA

Ochiai Naoyuki

Senior Advisor, JICA

Tomoko Shimada

Deputy Director, JICA

\section{INDONESIA (Jakarta)}

\section{GOVERNMENT}

Dr. Ir. Suprayoga Hadi, MSP

Mr. Munawar Liza

Development Partners

Simon Field

Muamar Vebry

Zulalzmi
Deputy Minister for Resources Development, Ministry for Development of Disadvantaged Regions

Former Mayor of Sabang City

Team Leader, Australian Aid

Programme Manager, EU

Deputy Country Director, GIZ 
APPENDIX E

People Met

INDONESIA (Aceh)

GOVERNMENT

Ir. Iskandar

Former Head of Aceh Reintegration

Agency

Ir. Netty Muharni

Head of Promotion Division,

Khaidir

BAPPEDA Aceh

Marthunis Muhammad

Head of Economic Section BAPPEDA

Aceh

Muhammad Taufik Abda

Former Head of local party, SIRA

Dr. Islahuddin

Commissioner-Bank Aceh

Rusli M Ali

Former Head of Provincial Coordinator Office, National Community

Development Program

Task Monitoring Team, Community

Yakob Isdahamy

Ranger Program

NGOS

Teuku Ardiansyah

Raihal Fairi

CSO KATAHATI

Zulfikar Muhammad

CSO KATAHATI

Hendra

CSO, Koalisi NGO HAM,

Roy Fahlevi

CSO, KONTRAS

Ahmad Salihin

CSO, Forum LSM Aceh

CSO, Forum LSM Aceh

\section{PHILIPPINES}

\section{GOVERNMENT OfFICIALS}

Usec. Luisito G. Montalbo

Executive Director, Office of the Presidential Adviser on the Peace Process 


\section{DeVElopment Partners}

Alma Evangelista

Cristina Santiago

Cyrel San Gabriel

Edoardo Manfredini

Emily Mercado

Gil R. Dy-Liaco

Morita Takahiro

Naarcisa M. Rivera

Patrick Safran

Private Sector

Edgar L. Bullecer

Engr. Edren M. Panti

Herminio B. Martin

John P. Perrine

Julio C. Teehankee, Phd

Maria Lourdes Pineda

NGO

Ever J. Adasolu

Francisco Lara Jr.

Jorge Golle

kki de la Rosa

Liezl Bugtay
Team Leader, Crisis Prevention and Recovery, UNDP

Senior Program Officer, JICA

Research and Knowledge Management Specialist ADB

Programme Manager, EU

EU

Development Assistance Specialist, USAID

Senior Representative, JICA

Senior Program Officer, Embassy of Canada

Principal Specialist (Fragile Situations), ADB

Director-External Relations, Unifrutti Group

Philippines

AVP-Corporate Environment, Health and Safety, Unifrutti Group Philippines

President and Chief Operations Officer, Unifrutti Group Philippines

Chairman, Unifrutti Group Philippines

Dean, College of Liberal Arts, DLSU

President, Rizal Microbank

Methodology Adviser, International Alert

Country Director, International Alert

ICT and Visibility Officer, International Alert

Deputy Country Manager, International Alert

Team Leader, International Alert 
APPENDIX E

PEOPLE Met

OTHER PARTNERS

Dr. Safrullah Dipatuan Chairman, Bangsamoro Development Agency

Ustadz Mohammad Shuaib Executive Director, Bangsamoro Development

Yacob

Agency

\section{WORLD BANK}

Roberto Tordecilla

Social Development Specialist

Mathew Stephens

Senior Social Development Specialist

Mayuko Shimakage

Consultant

Rene Manuel

Senior Procurement Specialist

\section{JORDAN}

\section{GOVERNMENT}

Abdulkarim M. Al-Khaldi

Ahid Ziydat

Ahmad G. Hawamdah

Ahmad Hmaidat

Bassem Awadallah

Fayez Trawneh

Feda Gharaibeh

Firyal Aqel

Hazem Nasser

Salih Kharabsheh

Sami Ahjak

Sami Toughoz

Ziad Fariz
Mayor, Zatari and Mansheya Municipality

(Project Director, ESSRP \& RLDP), Ministry of Municipal Affairs

Mayor, Mafraq Municipality

Head of Borrowing Division, Ministry of Finance

former Minister of Planning / Deputy Prime

Minister

Chief of Royal Court

Director of Humanitarian Unit, Ministry of

Planning and International Cooperation

Director of Development Coordination Unit, Ministry of Education

Minister of Water

Secretary General, Ministry of Planning and International Cooperation

Secretary Generals Assistant, Ministry of Finance Assistant Secretary General, Ministry of Finance Governor, Central Bank of Jordan 


\section{DONORS AND NGOS}

Ahmed Alkasir

Amy Schmidt

Byron Pakula

Ghimar Deeb

Gustavo Gonzalez

Jeffrey Tudor

Maria Iarrera

Mohammed Zahar

Nadia Al-Awamleh

Oliver Boudart

Tarja El Idrissi

Walid Abed Rabbo

Private Sector

Naser Darwish

Sandy Salkham

\section{WORLD BANK GROUP}

Ahmed Ali Attiga

Bilal Al-Sughayer

Eric Le Borgne

Sima Kanaan

Tania Meyer
Project Officer, DFATD (Canada)

Director of Program Development and Quality, Save the Children

Director, ACTED

Programme Specialist, Local Governance \& Municipal Development, UNDP

Sub-Regional Development Coordinator for the Syrian Crisis, UNDP

Head, DFID Office

Trade, Economic Affairs and PSD, EU

Head of Governance Program, USAID

Socio Economic Portfolio Analyst, UNDP Jordan

Focal Point for Aid Effectiveness, EU

Head of Section, Trade, Economic Affairs and PSD, EU

Senior Coordinator, UNDP

General Manager, VITAS (MEMCO is the microfinance department, which IFC supported)

Chief Financial Officer and Deputy General Manager, VITAS

Country Manager, IFC

Investment Officer, IFC

Lead Economist

Lead Social Development Specialist

Country Officer 


\section{LEBANON}

GOVERNMENT

Adel Chabab

Ahmad Al-Khaled

Bashir Osmat

Fadi Yarak

Farid el Khazen

Fouad Siniora

Hoda Kilany

Ibrahim Kanaan

Maher Baker

Marie Louise Abou

Jaoudeh

Mdme Nahla

Mireille Mouawad

Nabil Itani

Nabil Jisr

Nayla Mouawad

Randa Hamadeh

Sabine Corm

Sonia Khoury

Souad Al Masri

Wafaa Charafeddine

Walid Ammar

Yassine Jaber

\section{DONORS AND NGOS}

Amanda McLoughlin
NPTP Coordinator, MOSA

NPTP, MOSA

Advisor to Minister of Social Affairs (MOSA)

Director General, Ministry of Education \& Higher Education

Member of Parliament

former Prime Minister

Head of Cash Management Unit, Ministry of Finance

Member of Parliament and Chairman of the Budget and Finance Committee

Project Management Specialist, CHUDP

Project Manager, Prime Minister's Office

Head of Education, North Area (visit to Tarbieh el Haditha School, Abi Samra Area)

Head of Macro Fiscal Department, Ministry of Finance

Architect / Conservation Specialist, CHUDP

President, Council for Development and Reconstruction

Former Minister of Social Affairs

Head, PHC Department

Debt Directorate, Ministry of Finance

Project Manager, MEHE (visit to Tarbieh el Haditha School, Abi Samra Area)

School Principal (visit to Tarbieh el Haditha School, Abi Samra Area)

Funding Division Director, CDR

Director General, Ministry of Public Health

Member of Parliament and former Minister of Economy and Trade 
Charbel Habib

Heba Hage-Felder

Hester Somsen

Issa Sanogo

Liisa Maunula

Luca Renda

Lynne Miller

Mona Chemali Khalaf

Rebecca Carter

Ross Mountain,

\section{Private Sector}

Adel Satel

Carine Azkoul

Chahdan Jbeily

Khater Abi Habib

Marc Audi

Mireille Moufarrej

Nassib Ghobril

WORLD BANK GROUP

Eric Le Borgne

Ferid Belhaj

Haneen Sayed

Hassan Beides

Thomas Jacobs

Zeina El Khalil
Program Officer E-Cards, WFP

Head of Cooperation, Swiss Agency for Development and Cooperation

Ambassador of the Netherlands

Deputy Country Director, WFP

Minister-Counsellor, in her capacity as Chargé d'Affaires a.i.

Embassy of Finland

Country Director, UNDP

Deputy Representative for Operations, UNHCR

Economist and Independent Consultant on gender development issues

Lebanon Deputy Country Director, Danish Refugee Council

Deputy Special Coordinator, UN

General Manager-Group Chief Risk Officer, Bank Audi

Relationship Manager, International Banking Division, Fransabank

Group Chief Legal \& Compliance Officer, Bank Audi

Chairman \& General Manager of KAFALAT S.A.L

General Manager-Country Manager, Bank Audi

Head of Non-Banks Financial Institutions, International Division, Fransabank

Chief Economist, Head-Economic Research \& Analysis Dept., Byblos Bank

Lead Economist

Country Director

Program Leader

Program Leader

IFC Representative

Communications Officer 


\section{NPTP PROJECT BENEFICIARIES}

Azab Fayad \& Aycha

Assaad

Bassima Masri

\section{NIGERIA}

WORLD BANK GROUP

$\begin{array}{ll}\text { Anand Rajaram } & \text { Practice Leader } \\ \text { Deborah Isser } & \text { Senior Counsel } \\ \text { Doug Porter } & \text { Senior Judicial Specialist } \\ \text { Foluso Okunmadewa } & \text { Lead Specialist } \\ \text { George Larbi } & \text { Lead Public Sector Manager } \\ \text { Gloria Joseph-Raji } & \text { Economist } \\ \text { Indira Konjhodzic } & \text { Country Program Coordinator } \\ \text { Jens Kristensen } & \text { Lead Public Sector Specialist } \\ \text { John Litwack } & \text { Lead Country Economist } \\ \text { Joseph Akpokodje } & \text { Senior Environmental Institutions } \\ \text { Katherine Bain } & \text { Specialist } \\ \text { Khwima Nthara } & \text { Senior Public Sector Specialist } \\ \text { Onno Ruhl } & \text { Program Leader } \\ \text { Paula Rossiasco } & \text { Country Director } \\ \text { Volker Treichel } & \text { Social Development Specialist } \\ & \text { Program Leader }\end{array}$

\section{SRI LANKA}

Harsha Aturupane Lead Education Specialist

Seenithamby Manoharan Senior Rural Development Specialist

Shideh Hadian Senior Infrastructure Economist

Naresh Duraiswamy Senior Operations Officer 
Francoise Clottes

Andrea Merrick

UGANDA

GOVERNMENT

Candia Tom Aliti

Damien Kato

Dr. Aliro Tonny

Dr. Lukwago Asuman

Fred Twesiime

Juvenal Muhunwza

Keto Nyapendi Kayemba

Liz Nambuya

Maris Wanyera

Martin Odwedo

Mpoza Isaac David

Pius Bigirimana

Rebecca Amuge Otengo

Sakwa Masikya Mung'oma
Country Director

Country Officer
Assistant Commissioner Ministry of Health (GoU)

Director, Amnesty Commission

Coordinator, Office of the Prime Minister (GoU), NUSAF

Permanent Secretary, Ministry of Health (GoU)

Commissioner, DARC, Ministry of Finance

Planning and Economic Development

Commissioner, DARC, Ministry of Finance

Planning and Economic Development

Assistant Auditor General, Office of the Auditor General (GoU)

Assistant Director, Office of the Auditor General (GoU)

Commissioner, DARC, Ministry of Finance Planning and Economic Development

Permanent Secretary (ret.), Office of the Prime Minister (GoU), NUSAF

Commissioner Treasure Services, Ministry of Finance Planning and Economic Development

Permanent Secretary, Ministry of Gender, Labour and Social Development

Minister of State for Northern Uganda Rehabilitation, Office of the Prime Minister (GoU)

Field Operations Coordinator, Office of the Prime Minister (GoU), NUSAF 


$\begin{array}{ll}\text { Sanyu Jane Mpagi } & \begin{array}{l}\text { Director, Gender and Community } \\ \text { Development, Ministry of Gender, Labour and } \\ \text { Social Development } \\ \text { Coordinator Amnesty Commission-Gulu }\end{array} \\ \text { INTERNATIONAL PARTNERS } & \\ \text { Amb. Donal Cronin } & \text { Ambassador, Embassy of Ireland } \\ \text { Blaise Peccia-Galletto } & \text { Operations Adviser, Rural Development, European Union } \\ \text { Dr. Limlim Robert } & \text { Director, Office of the Prime Minister, NUSAF 2 } \\ \text { Nil Mueller } & \text { Director, Democracy, Rights \& Governance Office, USAID } \\ \text { Paul Asiimwe } & \text { Operation Officer, Climate Change, European Union } \\ \text { Thomas Easley } & \text { Counter LRA Advisor, USAID } \\ \text { Xavier Ejoyi } & \text { Project Management Specialist -Conflict, USAID }\end{array}$

WORLD BANK

$\begin{array}{ll}\text { Jim Adams } & \text { Former Country Director (Ret.) } \\ \text { Abderrahim Fraiji } & \text { Senior Operations Officer } \\ \text { Betty Bigombe } & \text { Senior Director, FCV CCSA } \\ \text { David Nielson } & \text { Lead Agriculture Services Specialist } \\ \text { Elisabeth Maier } & \text { TDRP } \\ \text { Emilie Rees Smith } & \text { Gender Specialist, UNICEF } \\ \text { Endashaw Gossa } & \text { Senior Social Protection Specialist } \\ \text { Jim McIntire } & \text { Former Country Director (Ret.) } \\ \text { Judy O'Connor } & \text { Former Country Director (Ret.) } \\ \text { Kees Kingman } & \text { Former task team leader } \\ \text { Mary Bitekerezo } & \text { Senior Social Development Specialist } \\ \text { Suleiman Namara } & \text { Task team leader, NUSAF } \\ \text { Victor Ocaya } & \text { Former task team leader } \\ \text { Willy Odwongo } & \text { Task team leader of Land Policy AAA }\end{array}$




\section{KYRGYZ REPUBLIC}

WORLD BANK
Alexander Kremer
Country Manager
Dinara Djoldosheva
Senior Country Officer

\section{WORLD BANK (Washington, DC, New York, and FCV Hub in Nairobi, Kenya)}

\begin{tabular}{|c|c|}
\hline Alys Willman & Senior Social Development Specialist \\
\hline Anne-Lise Klausen & Senior Operations Officer \\
\hline Aphichoke Kotikula & Senior Economist \\
\hline Bernar Harborne & Lead Social Development Specialist \\
\hline Clare Gardoll & International Affairs Officer \\
\hline Diana Jimena Arango & E T Consultant \\
\hline Ian Bannon (retired) & Sector Manager \\
\hline Juan Carlos Pereira, & Special Assistant to the Vice President, IFC \\
\hline Maria C. Correia & Lead Social Development Specialist \\
\hline Mary C.K. Bitekerezo & Senior Social Development Specialist \\
\hline Niels Harild & $\begin{array}{l}\text { Program Manager, Global Program on } \\
\text { Forced Displacement }\end{array}$ \\
\hline Paolo Verme & Senior Economist \\
\hline Radhika Srinivasan & Senior Social Scientist \\
\hline Reidun Otteroy & $\begin{array}{l}\text { UN-World Bank Fragility and Conflict } \\
\text { Partnership Trust Fund Coordinator }\end{array}$ \\
\hline Samia Ausaf & Consultant \\
\hline Samuel Chittik & Social Development Specialist \\
\hline Sara Nedolast & Senior Program Coordinator \\
\hline Shani Harris & Partnership Adviser \\
\hline Alexandre Marc & Chief Technical Specialist \\
\hline Catalina Quintero & Consultant \\
\hline
\end{tabular}




\section{UN AGENCIES}

JORDAN

Gustavo Gonzales

UNDP Sub-Regional Crisis Facility

KYRgyz RePUBLIC

Alexander Avanesov

UN Resident Representative

LEBANON

Issa Sanongo

WFP Deputy Country Director

Mette Nordstrand

Chief of Education, UNICEF

Simone Vis

Education Specialist, UNICEF

PHILIPPINES

Ruth Georgete

Programme Officer, International Labor Organization,

Simona Marinescu

Chief, Development Impact, Bureau for Policy and Programme Support, UNDP

UNDP

Titon Mitra

UNDP Country Manager, Philippines 